MAESTRÍA EN ECONOMÍA DE LA SALUD Y DE LOS SERVICIOS SOCIALES Y EN GESTIÓN DE ORGANIZACIONES DE SERVICIOS DE SALUD.

Facultad de Ciencias Económicas

Universidad Nacional de La Plata

\title{
ABORDAJE JURÍDICO ECONÓMICO DE LA REHABILITACIÓN DE LA SALUD BUCAL DE PACIENTES PSIQUIÁTRICOS EN PROCESO DE REINSERCIÓN SOCIAL.
}

Maestrando: Odontóloga Ana María Morasso

Directora de Tesis: Dra. Cecilia del Carmen Pozzo

La Plata, Marzo de 2011 


\section{AGRADECIMIENTOS}

Mi sincero agradecimiento a todas las personas que han contribuido a la concreción de este trabajo:

Al Licenciado Héctor Calvo, Director de la maestría, y a los docentes que la integraron por su entrega de conocimientos; al equipo del Programa de Acompañamiento para el Desarrollo de Tesis (PADT), y en especial al Dr. Raúl Mercer por sus consejos, su apoyo crítico y el seguimiento de este documento; mi infinito agradecimiento a la Dra Cecilia Pozzo, mi directora, por su dedicación y su compromiso en los momentos difíciles de este trabajo; al Director Provincial de Salud Mental, Dr. Aníbal Areco, por sus oportunas sugerencias y a la Licenciada Natalia Brunengo por su aporte de información; al Dr. Egidio Meliá, Director del hospital Neuropsiquiátrico Alejandro Korn y al Dr. Edgardo Maini, Jefe del Servicio de Odontología; a la Dra. Diana Uribarri, Directora de la Casa de Pre alta de la Provincia. de Buenos Aires por sus referencias y muestras de aliento; al Dr. Alfredo Kraut por brindarme su reconocida experiencia en el tema; a la Dra.en Psicología Angélica Zdunic por su aporte de conocimiento y las valiosas reflexiones y sugerencias; al Dr. Ricardo L. Macchi, mi maestro en Formación Metodológica y Estadística aplicada a la Salud; a la Licenciada en Economía, Lujan Pérez Meyer con quien verifiqué y discutí el análisis estadístico de los datos; al Contador Daniel Reija y al Licenciado en Administración Sergio Martín por su colaboración y a la constante preocupación e interés en el avance de la tesis del Licenciado en Economía Ricardo Cobanera; a las colaboradoras Marisa Carner y a la Licenciada en Administración Mariel Ortiz, con quien compartimos la promoción; a la Profesora Nelly Christmann por su asesoramiento así como la corrección y cuidado de la redacción final. Y, por último, a quien me indujo a iniciar esta Maestría, mi esposo, Doctor Aníbal Cobanera, cuya idoneidad y paciencia me ayudaron a encontrar y transitar el camino.

Finalmente, mi mayor respeto y consideración a los destinatarios del producto: las personas con padecimientos mentales. 


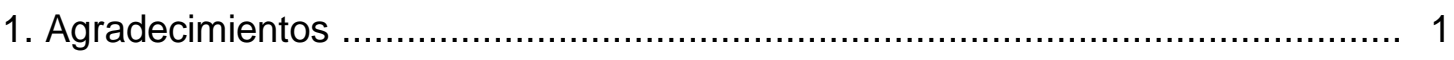

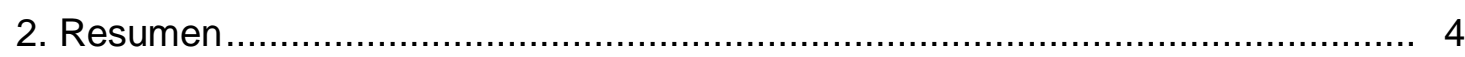

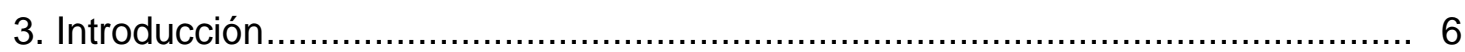

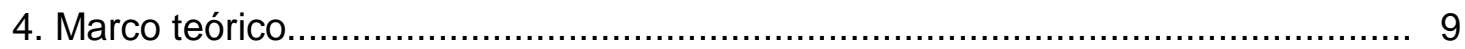

4.1 Salud-Enfermedad. Construcción histórica del significado................................. 10

4.2 Discapacidad, rehabilitación y desarrollo inclusivo ............................................ 15

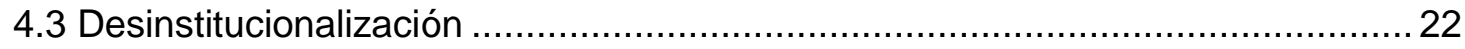

4.4 Programa de rehabilitación y externación asistida ........................................... 24

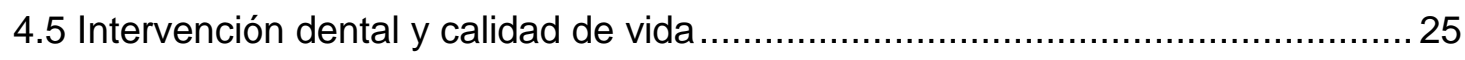

4.6 Depresión como factor de riesgo de la rehabilitación protética ........................... 26

4.7 Marco jurídico en la protección de las personas con alteraciones mentales ....... 28

4.8 Fundamento económico de la rehabilitación de la Salud Bucal .......................... 34

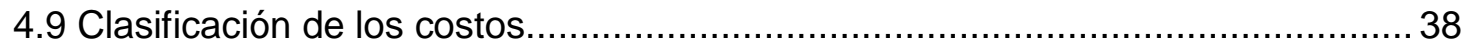

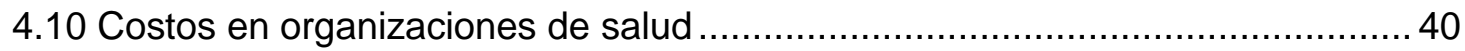

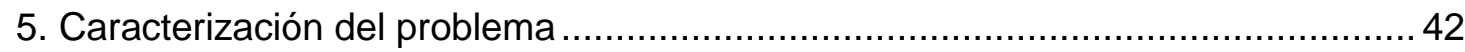

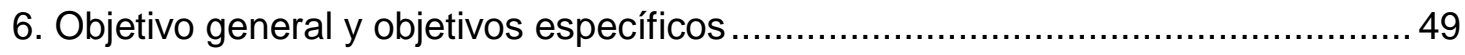

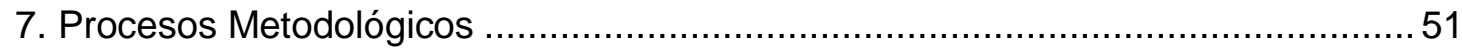

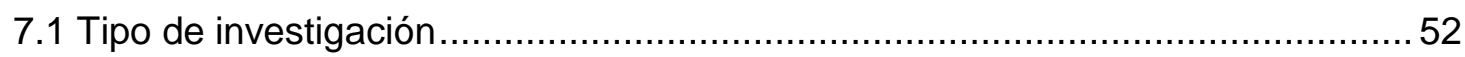

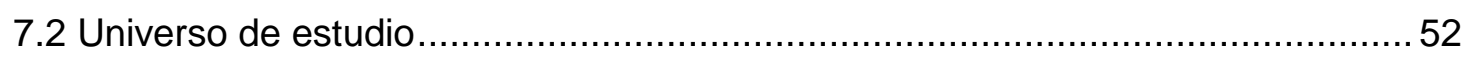

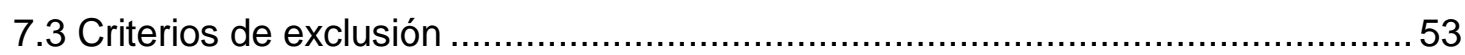

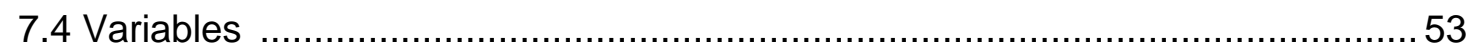

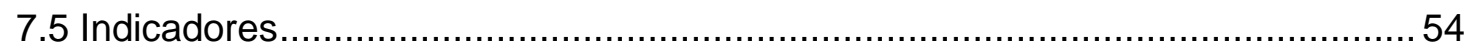

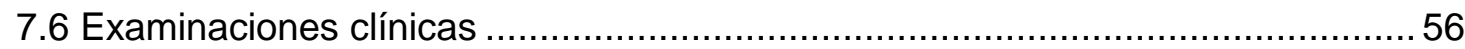

7.7 Análisis de la estructura de costos de la rehabilitación bucal.............................56

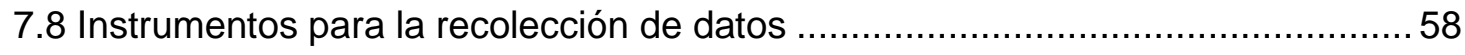

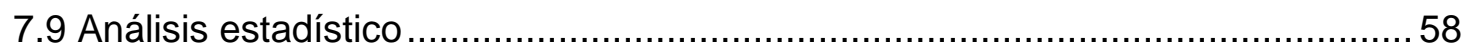

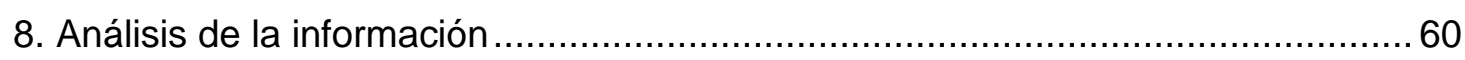

8.1 Fase diagnóstica: Situación de las instituciones neuropsiquiátricas ..................61

8.2 Fase diagnóstica: Situación de Salud bucal............................... 63

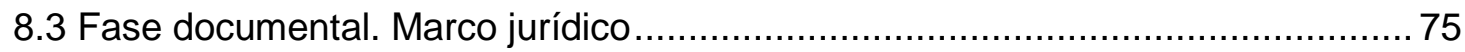

8.4 Documentos internacionales. Protección de la discapacidad............................... 75

8.5 Documentos internacionales. Protección de la discapacidad mental ................... 79

8.6 Derecho Argentino. Protección de la discapacidad mental ................................ 82

9. Análisis de la estructura de costos de la rehabilitación bucal................................87 
10. Conclusiones emergentes y desafíos pendientes.......

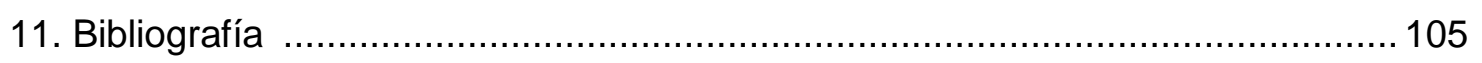

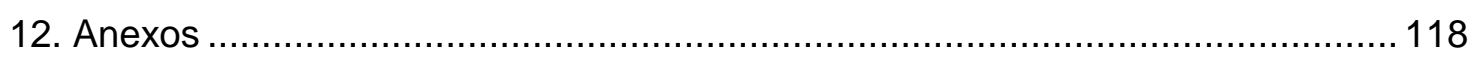




\section{RESUMEN}

Los trastornos mentales constituyen un problema sanitario en crecimiento siendo una de las cuatro prioridades sanitarias y representan el $22.2 \%$ de la carga global de enfermedad para América Latina y el Caribe.

El objetivo de este trabajo fue reconocer que la rehabilitación de la Salud Bucal, como componente esencial del derecho a la Salud, es una estrategia facilitadora de la inclusión social de adultos con problemas de Salud Mental.

El proyecto incluyó tres fases: a) diagnóstica de la situación de salud bucal, b) documental jurídica y c) análisis de la estructura de costos de la rehabilitación bucal propuesta.

La fase diagnóstica, de carácter aplicada, consistió en un estudio observacional descriptivo transversal. La muestra estudiada se integró con 385 adultos con un rango de edad de 20 - 65 años: 56 con alteraciones mentales en proceso de desinstitucionalización, (GD), 220 Institucionalizados (GI) y un grupo control de 109 adultos ambulatorios sin diagnóstico de alteraciones mentales (GC). Se consideró condición de emplazamiento que los 3 grupos fueran asistidos en el mismo servicio de odontología.

Se usó el indicador clínico directo (observación) CPOD (cariados, perdidos, obturados; unidad diente) que permiten cuantificar la morbimortalidad y la atención recibida, como consecuencia residual de la enfermedad bucal. En el grupo GD se evaluó la incapacidad de la funcionalidad dentaria mediante el baremo de Bertini que pondera la pieza dentaria perdida.

Se realizó análisis estadístico de los resultados: estimación de medidas de tendencia central y de dispersión y prueba de hipótesis para datos paramétricos y no paramétricos.

Los resultados permitieron describir una Salud bucal deficiente: en GI la pérdida dentaria fue $81,12 \%$; en GD $80 \%$. No se encontró diferencia significativa entre ambos La pérdida en el grupo control fue significativamente menor, alcanzando valores de $48.76 \%$.

Los resultados permitieron determinar, según el baremo aplicado, una debilitación permanente o pérdida de la función compatible con incapacidad de las funciones.

En la fase documental jurídica, de carácter observacional, se realizó una recopilación y análisis documental de la normativa internacional que protege jurídicamente la Discapacidad y específicamente la Discapacidad Mental (OEA, ONU, OPS/OMS), la protección por el Derecho Argentino (Constitución Nacional, normas internacionales con rango constitucional, leyes nacionales) y la ratificación de derechos y garantías constitucionales en la Constitución de la Provincia de Buenos Aires.

Los resultados del análisis permitieron describir un marco jurídico para la rehabilitación de la Salud Bucal que previene la judicialización del daño. 
Por último en el análisis de la estructura de costos se relevaron las necesidades de materia prima, mano de obra, costos directos fijos y costos indirectos para la rehabilitación de las piezas dentarias perdidas en base a prótesis removibles parciales y completas. Se estimó una producción según las necesidades relevadas a partir de la muestra estudiada y la posibilidad de reconversión de los procesos.

La información epidemiológica, jurídica y económica disponible a partir de los resultados de la muestra estudiada permite reconocer la factibilidad de incorporar la rehabilitación de la Salud Bucal - como componente del derecho a la Salud y como una estrategia facilitadora - a un plan integral para la inclusión social de adultos con problemas de Salud Mental. 


\section{INTRODUCCIÓN}


En nuestros días la situación de la salud- enfermedad- atención mental se ubica como un problema relevante para la salud pública y requiere ser abordada tanto en su especificidad como en forma integral, ya que es parte indisoluble del derecho a la salud y de los Derechos Humanos en general de todas las personas.

La epidemiología muestra que las enfermedades mentales son una de las cuatro prioridades sanitarias, junto con las enfermedades cardiovasculares, el cáncer y los accidentes de toda sociedad post - industrial así como en países jóvenes.

Los informes estadísticos indican que, aproximadamente, tenemos una probabilidad sobre dos de vivir un problema de salud mental a lo largo de nuestra vida. Hagnel señaló que, entre 10 y 60 años, la probabilidad es de 0.43 en los hombres y 0.73 en las mujeres. ${ }^{47}$

La Organización Mundial de la Salud (OMS) informó que el $25 \%$ de la población ${ }^{92}$ padece alguna forma de trastornos mentales o del comportamiento a lo largo de su vida y que una de cuatro familias tiene al menos uno de sus miembros con padecimientos mentales; porcentaje mucho mayor en países de bajos ingresos. A ello se sumaría el incremento del consumo de alcohol, la drogadependencia y el daño a la salud mental que suponen estados como la pobreza permanente, el desempleo o la discriminación social.

Sólo una quinta parte de esta población es tratada por profesionales de la salud mental. Por lo tanto, esta problemática no sólo abarca el campo de los problemas mentales, sino, también, gran parte de la actividad de los médicos generalistas. La realidad indica que la preocupación médica se centra en la enfermedad física, ignorando la repercusión negativa de las dimensiones psíquicas y relacionales.

Sin embargo esta cuantificación no basta para evaluar la gravedad del problema ya que con frecuencia estas personas, partiendo de una situación desventajosa, viven en condiciones deplorables debido a la existencia de barreras que obstaculizan la integración con el ámbito familiar y la participación plena en la comunidad, siendo entonces afectadas por serios problemas psicosociales.

La carga que representa a su entorno la persona con padecimientos mentales no es sólo emocional sino económica, con un impacto que además de negativo es prolongado.

Si se reconoce que la protección de esta población vulnerable es también una obligación del Estado, un primer problema a abordar es la visibilidad de la situación que permitiría poner el tema en un escenario de discusión para las políticas públicas pertinentes a las necesidades encontradas.

Un segundo problema es que los fenómenos mentales requieren una reflexión multidisciplinaria, con una real interdependencia de enfoques, los que hasta la fecha, aun con intentos aislados, suelen actuar sectorialmente desde diversos paradigmas científicos y distintos criterios asistenciales. 
En esa reflexión multidisciplinaria no está incluida la Salud Bucal y es hoy un desafío pendiente.

Este estudio aborda la inclusión del componente bucal de la salud en programas integrales para el proceso de transformación hacia la reinserción social.

Por lo tanto, reconocer que la rehabilitación de la Salud Bucal - como componente esencial del derecho a la Salud - es una estrategia facilitadora de la inclusión social de adultos con problemas de Salud Mental y el objetivo de este trabajo.

El proceso de realización incluyó en el marco teórico el abordaje del significado Saludenfermedad- atención mental, las alteraciones mentales como Discapacidad, el paradigma del desarrollo inclusivo desde la perspectiva de las personas con Discapacidad mental, la Desinstitucionalización, la protección jurídica y el fundamento económico de la rehabilitación de la Salud Bucal.

Se consideró como antecedentes de la problemática estudiada la información disponible a nivel nacional e internacional sobre la condición bucal y la normativa vigente al respecto.

La metodología del proyecto abarcó tres fases: una diagnóstica del estado de Salud Bucal, una documental jurídica que incluyó la ley Nacional de Salud Mental sancionada y promulgada en la etapa final de este proceso y por último un análisis de la estructura de costos de la propuesta.

El análisis estadístico de los resultados consideró la variabilidad individual y permitió inferir características generales a través de datos singulares o individuales de la muestra estudiada.

En las consideraciones finales $\boldsymbol{y}$ conclusión de este trabajo de tesis se aceptó la hipótesis de que la inclusión de la rehabilitación de la funcionalidad bucal, la reconversión de los procesos generaría valor a una lógica organizacional de un Programa Integral e Intersectorial para la Desinstitucionalización del adulto con alteraciones mentales en busca de la reinserción social. 


\section{MARCO TEÓRICO}




\section{Salud-Enfermedad Mental. Construcción histórica del significado.}

Los trastornos mentales constituyen un problema sanitario en crecimiento en el mundo y en la región de las Américas, siendo una de las cuatro prioridades sanitarias de toda sociedad post-industrial, junto con las enfermedades cardiovasculares, el cáncer y las lesiones provocadas por los accidentes.

En América Latina y el Caribe, para 1990 se le imputó a los trastornos psiquiátricos y a las enfermedades neurológicas el $8.8 \%$ de la carga total de enfermedad, estimada según los años de vida ajustados por discapacidad (AVAD). En el 2002 ascendieron a 22.2\%. ${ }^{27,50}$

Un informe de la Organización Mundial de la Salud ${ }^{92}$ señala que "los trastornos mentales y del comportamiento representan el $13 \%$ de la carga de morbilidad en el mundo; sin embargo el presupuesto para la salud mental de la mayoría de los países es inferior al $1 \%$ del gasto total en salud', por lo que la relación entre carga de morbilidad y gasto en salud es claramente desproporcionada ".

Las enfermedades mentales afectan en mayor grado a grupos poblacionales pertenecientes a estratos socioeconómicos más bajos, para los cuales los servicios son más escasos y sólo una minoría que requiere atención la recibe efectivamente, no obstante la magnitud del sufrimiento que los trastornos producen. Estos generan costos relacionados con el tratamiento a largo plazo y con la pérdida de productividad, retroalimentando así el circuito de la pobreza. ${ }^{138}$ Cabe agregar que las necesidades psicosociales son especialmente más altas en los grupos con mayor vulnerabilidad y dejan cicatrices en la vida de las víctimas. ${ }^{125}$

La situación resultante es una paradoja en la que coexisten por un lado, una abultada carga de problemas mentales y, por el otro, una respuesta insuficiente de los servicios de salud, que no sólo abarca la psiquiatría sino también gran parte de la actividad de los médicos generalistas, ya que las afecciones psiquiátricas constituyen, después de los procesos infecciosos corrientes, el segundo o tercer motivo de consulta. Otra forma de medir la insuficiente respuesta es por medio de la determinación del número de profesionales especialistas. En las Américas hay 2 psiquiatras por cada 100.000 habitantes, resultado significativamente menor que los que hay en Europa (9.8 por cada 100.000 habitantes). La comparación entre Europa y América es más favorable en relación a los profesionales psicólogos, ya que hay 3.1 y 2.8 por cada 100.000 habitantes, respectivamente. ${ }^{118,139}$

No existe una definición que especifique adecuadamente los límites del concepto "trastorno mental", término este que carece de una definición operacional consistente que englobe todas las posibilidades. El término trastorno mental implica una distinción entre trastornos "mentales" y "físicos" (anacronismo reduccionista del dualismo mente / cuerpo). 
Los conocimientos actuales ponen de manifiesto que hay mucho de físico en los trastornos mentales y mucho de mental en los trastornos físicos.

Cada trastorno mental es conceptualizado como un síndrome o un patrón comportamental o psicológico de significación clínica que aparece asociado a un malestar (ej. dolor) o a una discapacidad (deterioro de una o más áreas de funcionamiento) o a un riesgo significativamente aumentado de morir, sufrir dolor o pérdida de la libertad. Debe considerarse como la manifestación individual de una disfunción comportamental, psicológica o biológica. Ni el comportamiento desviado, ni los conflictos entre el individuo y la sociedad son trastornos mentales, a no ser que la desviación o conflicto sean síntomas de una disfunción. ${ }^{47}$

La Organización Panamericana de la Salud (OPS) define a la Salud Mental como "estado sujeto a fluctuaciones provenientes de factores biológicos y sociales, en que el individuo se encuentra en condiciones de conseguir una síntesis satisfactoria de sus tendencias instintivas potencialmente antagónicas, así como formar y mantener relaciones armoniosas con los demás y participar constructivamente en los cambios que puedan introducirse en su ámbito físico y social". 4

La consideración de persona enferma no sólo depende de alteraciones de su personalidad sino de las actitudes de la sociedad con relación a ese tipo de alteraciones. Este hecho demuestra la importancia de los valores sociales en la definición de salud o enfermedad mental. Generalmente, en todas las sociedades se diferencia a la persona que padece una alteración de su conducta de carácter crónico, de aquella que muestra dichas alteraciones en situaciones socialmente aceptadas y normativamente sancionadas, como pueden ser los ritos o los actos religiosos. El enfoque sociológico interpreta a la enfermedad como una entidad con alto grado de complejidad. El positivismo limita la enfermedad a un mal funcionamiento orgánico. El médico observa directamente 0 a través del diálogo 0 reconocimiento, y lo que él denomina enfermedad consiste en sensaciones subjetivas (síntomas) y en ciertos hallazgos (signos).

En agudo contraste, la posición cultural relativista considera la enfermedad sólo si es reconocida y definida por la cultura, las condiciones y adaptaciones al medio ambiente. La enfermedad es una construcción social; no existe sin que alguien la reconozca y defina. Y, por lo tanto, son los juicios de los seres humanos en relación con las condiciones que existen en el mundo natural los que la definen utilizando fenómenos biofisiológicos para etiquetar o categorizar una enfermedad 4

Desde el enfoque de la sociología, la construcción social de la enfermedad correspondiente a la anormalidad del comportamiento está sujeta a mayor ambigüedad e interpretación que otros problemas manifiestamente biológicos. 
Las distintas evaluaciones de los síntomas y procesos afectivos, cognitivos y del comportamiento utilizados para designar a una persona como sana o enferma varían según las representaciones sociales y paradigmas científicos dominantes en cada sociedad. Entonces, desde esta perspectiva, un mismo comportamiento puede ser evaluado de distinta forma según el contexto social y el período histórico en que emerge.

Siguiendo una descripción retrospectiva, en el siglo $\mathrm{XV}$, desde una concepción mágica se consideraba a la locura como una enfermedad del alma. La aproximación médica dominante hacia fines del siglo XVI explicaba los desórdenes mentales a partir de trastornos cerebrales por desequilibrios humorales.

En el siglo XVII se desarrollaron interpretaciones naturalistas de la enfermedad mental como la iatrofísica e iatroquímica. Durante el siglo XVIII, la enfermedad era considerada como un alejamiento voluntario de la razón que debía ser corregido con la internación y severas medidas disciplinarias: los muros del hospicio delimitaban la razón de la locura. Se extiende la idea de la peligrosidad, lo que justificaba el modelo de exclusión para cuidar el orden público.

Foucault argumenta la finalidad del aislamiento no como tratamiento, sino como medida para proteger la sociedad de aquellos que infringían las normas sociales ${ }^{32}$.

Explicaciones somáticas predominan en el siglo XIX; los desórdenes psicológicos son considerados como una disfunción cerebral. En la segunda mitad de ese siglo Kraepelin, máximo exponente "organicista", atribuyó la causa de la enfermedad a un mal funcionamiento del organismo y con su teoría innatista la herencia como causa de la enfermedad con fundamentos biológicos. En los citados ciclos temporales predominaron construcciones de la enfermedad mental desde modelos epidemiológicos monocausales dominantes para esa época.

A grandes rasgos, el siglo $\mathrm{XX}$ se caracterizó por la influencia del psicoanálisis, la expansión de la clasificación nosológica de las alteraciones mentales, el desarrollo de la neurología, la fisiología y la bioquímica -bases del desarrollo de la psiquiatría organicista, el auge de la psicofarmacología y, finalmente, el inicio de concepciones psicosociológicas de la enfermedad mental.

Álvaro J.L. distingue cuatro fases en el desarrollo socio-histórico de los diferentes criterios que definieron la salud-enfermedad mental: "la primera consideraba la enfermedad mental como posesión diabólica o inspiración divina". La segunda interpretaría a la enfermedad como desviación social; la tercera, como enfermedad física y, finalmente, la concepción basada en los diferentes modelos psicológicos y sociogenéticos. ${ }^{3}$

El autor citado sostiene que "los criterios principales para el diagnóstico son la existencia de sintomatología, el comportamiento social desajustado, la duración prolongada de los síntomas y que las categorías de diagnóstico son, además, mutuamente excluyentes. Sin 
embargo este tipo de detección de trastornos mentales ha sido objeto de críticas, ya que, establecen, en ocasiones, una realidad superpuesta a los problemas reales de las personas".

La razón moderna permite al hombre despojarse del dogmatismo de las condiciones religiosas, de las explicaciones metafísicas, para explicar los fenómenos a través de la evolución del conocimento y es así como, recién al finalizar el siglo $\mathrm{XX}$, los determinantes sociales se suman a la multicausalidad que explicaría la alteración.

Las concepciones actuales de la Salud Mental pueden ubicarse junto al origen de la Modernidad. A partir del nacimiento de la psiquiatría y la objetividad científica y la influencia del positivismo, la figura del médico aparece como la más efectiva en el fenómeno de la locura. Según Galende "el gran cambio en la práctica terapéutica se introduce por la medicalización de la relación de asistencia, pasándose de lo que era un encierro compulsivo y policial con convalidación de la Iglesia, a un tratamiento compulsivo de los enfermos". ${ }^{35} \mathrm{La}$ psiquiatría sustituye entonces los espacios de reclusión por los de curación y cuidado, sin que la función primaria se borre completamente.

Los expertos de países de distintas culturas y varios grados de desarrollo social han definido la salud mental de diferentes maneras. Estas abarcan el bienestar subjetivo, la percepción de la propia eficacia, la autonomía y las competencias personales, la dependencia intergeneracional y la autorrealización de las capacidades intelectuales y emocionales. ${ }^{92}$ Aunque desde una perspectiva transcultural es muy complejo llegar a una definición exhaustiva y universalmente válida, cabe admitir que el concepto de salud mental es más amplio que la mera ausencia de síntomas psíquicos.

En la actualidad, la enfermedad se relaciona con la pérdida del papel social, con la dependencia del otro y con la angustia. Pichón Rivière $E$. dice que el sujeto es sano en la medida que mantiene un interjuego dialéctico con el medio y no una relación rígida y estereotipada. ${ }^{134}$

La OMS define a la Salud Mental como "estado de bienestar en el cual el individuo es consciente de sus propias capacidades, puede afrontar tensiones normales de la vida, puede trabajar en forma productiva y fructífera y es capaz de hacer una contribución a su comunidad". ${ }^{140}$ La Clasificación Estadística de Enfermedades y Problemas relacionados con la Salud (CIE-10) define los trastornos mentales y del comportamiento como un conjunto nosológico donde los síntomas difieren sustancialmente, pero los trastornos se caracterizan por alguna combinación de alteraciones de los procesos del pensamiento, las emociones, el comportamiento y las relaciones interpersonales. 
La clasificación de los trastornos mentales tipifica los trastornos de las personas y no a las personas que los padecen. ${ }^{\text {29, } 113}$

La enfermedad mental no debería ser observada desde el dualismo cartesiano; por lo tanto, las dificultades de definición se deben a la imposibilidad de atribuirle un valor definitivo, invariable y universal. El abordaje, sobre todo en el campo del diagnóstico, presenta problemas metodológicos. En efecto: la salud mental, la salud física y el funcionamiento social son componentes esenciales de la vida humana estrechamente relacionados e interdependientes. ${ }^{16,119}$

El enfoque actual no la sitúa como un ente concreto sino conformado por conceptos ideales inmersos en el ámbito de la cultura y, por lo tanto, relativos a cada época y cada contexto social.

La salud mental de la población está influida por factores macrosociales y macroeconómicos con impacto en el sector salud. Las políticas gubernamentales tienen influencia sobre muchos de estos factores y pueden tener efectos tanto negativos como positivos sobre la salud mental. Así las personas más pobres, las desempleadas o con precariedad en las situaciones laborales condicionan un efecto negativo para la salud mental. La urbanización caótica y no planificada expuesta a adversidades ambientales y la carencia de vivienda adecuada trastocan los modelos tradicionales de vida familiar, aumentando la vulnerabilidad.

Las concepciones sobre la salud han variado a través de los tiempos, influidas por los contextos socio-políticos y científicos, y se asientan sobre presupuestos que las determinan. Algunas comparten idéntico supuesto científico en el marco de las ciencias físico- naturales y contribuyen a formar y expresar el paradigma biomédico; otros se encuadran en el marco de las ciencias sociales, constituyendo el paradigma social o alternativo. ${ }^{76}$

El modelo social como marco para la definición de Salud Mental es una estructura conceptual que contribuye a su definición desde la perspectiva socio-política y sirve de fundamento a la comprensión y explicación de la promoción de la Salud Mental. Desde esta perspectiva constituye un campo teórico-político en permanente construcción que supone el desarrollo de nuevos conceptos y modos de acción social, políticos, técnicos y administrativos en salud. Por lo tanto, el campo de la Salud Mental es complejo y transdisciplinario; admite la

\footnotetext{
${ }^{\mathrm{i}}$ Los códigos y los términos del Disorder System Mental DSM - IV son totalmente compatibles con los de la CIE-10, clasificación estadística internacional de enfermedades y problemas de salud, de la OMS, situación muy útil a la hora de aumentar la congruencia y reducir las diferencias poco significativas entre los términos de los dos sistemas. Los trastornos DSM - IV están agrupados en 16 clases de diagnósticos principales y una sección denominada "otros problemas que pueden ser objeto de atención clínica"
} 
comprensión de la subjetividad, la singularidad y la diferencia entre lo individual y lo colectivo, advirtiendo las interrelaciones saludables y perjudiciales de la vida social. ${ }^{36}$

Desde la perspectiva cualitativa, la Salud Mental es un proceso histórico y socialmente determinado de integración progresiva de elementos conflictivos, constitutivos del sujeto de la cultura y de los grupos. Este proceso es partícipe de los cambios que de manera activa transitan las personas y los grupos así como su entorno social. ${ }^{138}$

Desde la perspectiva etiológica, la Salud Mental está determinada y condicionada por procesos naturales, histórico- culturales, económico-sociales, jurídico-políticos, científicotécnicos y de organización de los servicios de salud, los cuales se dan interrelacionados y movilizados por relaciones de poder.

Desde la perspectiva política, la Salud Mental se entiende como una cuestión social, como un derecho humano inalienable ligado a los conceptos de ciudadanía, libertad, democracia y solidaridad y que requiere un sistema jurídico que la promueva, la ampare y la defienda de la discriminación, exclusión y violación de los derechos humanos.

Lorenzetti $\mathrm{R}^{73}$ afirma " que no hace muchos años la teoría social, política y el derecho es una transformación de la sociedad global, utópica, sin distinciones. Hoy las historias individuales que dan origen a decisiones judiciales en instancias superiores como la Corte Suprema, revelan las fisuras sociales en el campo de los Derechos Humanos en personas vulnerables" o con desigualdades en relación a las demás.

Desde la perspectiva científica epistemológica, la Salud Mental corresponde al entrecruzamiento de disciplinas y prácticas diversas vinculadas a múltiples campos del saber.

Las concepciones y prácticas fueron evolucionando respecto al tratamiento, pero no se observó cambios en la finalidad. En consecuencia, los diagnósticos psiquiátricos son etiquetas estigmatizadoras que reconvierten la categoría de hombre normal en enfermo mental y sometido a tratamiento, con la consiguiente pérdida en parte de su condición humana, la rotulación de peligroso y la separación del medio social. ${ }^{41}$

\section{Discapacidad, Rehabilitación y Desarrollo Inclusivo.}

Denominar específicamente a un ser humano implica ubicarlo en una clasificación y atribuirle un lugar de prestigio o menoscabo, una valoración. Es una forma de excluir al denominado, en este trabajo discapacitado, de todas las clases no incluidas en el nombre asignado, así como la posibilidad de generar actitudes hacia la persona nombrada.

Según un informe de las Naciones Unidas, más del 10\% de la población mundial sufre algún tipo de discapacidad (D). La dimensión demográfica y geográfica de la $D$ ejerce una 
influencia significativa en la sociedad y se considera que tiene repercusión sobre el $25 \%$ de la población total. ${ }^{121}$

La D no sólo afecta a la persona que la sufre sino, también a aquellos que la cuidan, a su entorno familiar y al desarrollo de la comunidad. En Argentina el $20.6 \%$ de los hogares albergan a una a persona con D. El $80 \%$ de las deficiencias tienen causas prevenibles y solo el $2 \%$ surgen de condiciones congénitas. ${ }^{79}$

Alrededor del $50 \%$ de las personas con D de la región tienen edad de trabajar y la mayoría están desempleados o excluidos del mercado laboral. Dados los altos niveles de pobreza y desempleo de la población general y la relación entre pobreza y $D$, la situación de este grupo poblacional es crítica. Cerca del $82 \%$ de los grupos con D en América Latina y el Caribe son pobres; entre el 80 y $90 \%$ están desempleados, y en Argentina alcanzan valores del $91 \%{ }^{126}$

Los resultados de estos estudios estadísticos dependen mucho de la definición de utilizada; sin embargo se incluyen en este proyecto como marcadores globales de la situación estudiada, ya que aún no existe a nivel local, regional o mundial una única definición de $\mathrm{D}$.

Estas cifras muestran la dimensión del problema poniendo de manifiesto su alcance universal y el fuerte y generalizado impacto del fenómeno sobre la sociedad en su conjunto.

Entre los discapacitados y el resto de la comunidad se generan complejas relaciones: la mirada de la gente está centrada en la carencia, dependencia, aislamiento y se desvalorizan sus capacidades y potencialidades. Los obstáculos sociales y laborales, entre otros, estimulan la discriminación al generar inferioridad, y dificultar la resocialización: se produce como consecuencia una carencia de los derechos fundamentales. Esta exclusión legal y social es mayor en el caso de los discapacitados mentales, desigualdad agravada respecto a los pacientes institucionalizados contra su voluntad, sobre todo cuando resultan cronificados (Ob. Cit)

De allí que la OMS en 1980 estableciera criterios para denominar y definir las distintas condiciones de discapacidad, distinguiendo entre deficiencia, incapacidad y minusvalía, términos incorporados en el Programa de Acción Mundial para los impedidos (ONU 1982) ${ }^{\text {ii. }}{ }^{111}$

Según los criterios de clasificación de la OMS, deficiencia es una pérdida o anormalidad permanente o transitoria -psicológica, fisiológica o anatómica- de la estructura o función. Incapacidad es cualquier restricción o impedimento del funcionamiento de una actividad, por deficiencia en la forma o dentro del ámbito considerado normal para el ser humano. $Y$ minusvalidez es una incapacidad que constituye una desventaja para una persona dada, en

\footnotetext{
ii Actualmente "personas con Discapacidades" de conformidad con estándares internacionales.
} 
cuanto limita o impide el cumplimiento de una función normal para esa persona, considerando su edad, sexo y factores sociales y culturales ${ }^{91}$

Una investigación sociológica realizada por Pantano $\mathrm{L}^{122}$ analiza la clasificación internacional de deficiencias, discapacidades y minusvalías. La autora define a la enfermedad como la exteriorización de un hecho patológico que afecta el comportamiento del individuo quien objetiva la experiencia adoptando una serie de pautas según lo que cree que se espera de él por el hecho de estar enfermo. Estas experiencias representan discapacidades. Dicha situación pone al individuo en desventaja respecto a sus pares; constituye así la minusvalía.

Estos tres últimos "acontecimientos" que la autora denomina exteriorización, objetivación y socialización vienen a completar el modelo tradicional de enfermedad y se grafica de la siguiente forma:

Siguiendo las clasificaciones internacionales, Pantano propone definir Deficiencia, en la experiencia sanitaria, como toda pérdida o anormalidad de una estructura o función psicológica, fisiológica o anatómica. Discapacidad, en la experiencia de la salud, como toda restricción o ausencia (debida a una deficiencia) de la capacidad de realizar una actividad en la forma o dentro del margen que se considera normal para un ser humano.

Por último define Minusvalía, en la experiencia de salud, como una situación desventajosa para el individuo, consecuencia de una deficiencia o de una discapacidad que limita o impide el desempeño de un rol que le es normal para su edad, sexo y condición socio cultural.

Las diferentes clasificaciones internacionales fueron asumidas por la Asamblea General de las Naciones Unidas en el Programa de Acción Mundial para los Impedidos, cuyos enunciados constituyen un instrumento normativo y de acción para ser aplicados por los Estados con la intención de respetar una norma de derecho internacional. ${ }^{111}$

La Declaración de los derechos de los impedidos insta a "prevenir la incapacidad física y mental, ayudar a los impedidos a desarrollar sus actividades, así como fomentar en la medida de lo posible la vida social normal".

La Convención Interamericana para la eliminación de todas las formas de Discriminación contra las personas con Discapacidad ${ }^{83}$ en 1999 (aprobada por ley 25280, julio de 2000) define el significado del vocablo discapacidad como" deficiencia física, mental o sensorial ya sea de naturaleza permanente o temporal que limita la capacidad de ejercer una o mas actividades esenciales de la vida diaria que puede ser causada o agravada por el entorno económico y social".

Una visión más amplia califica a la D como producto social, condicionado por la relación existente entre la diferencia individual y el entorno sociopolítico, económico y cultural en el cual habita y se desarrolla (o deja de hacerlo).Otra relación a considerar es $D$ y 
funcionamiento humano. Los niveles de funcionamiento varían enormemente dentro de una población, ya sea en relación con las capacidades físicas, intelectuales, habilidades sensoriales o como resultado del impacto de la salud mental.

Desde este nuevo paradigma, la $\mathrm{D}$ es inherente a la sociedad que discapacita. Cuando las personas de diferente nivel de funcionamiento se enfrentan a obstáculos que les impiden o limitan el acceso a los servicios de salud, educativos, empleo, servicios públicos y al entorno físico y arquitectónico, se genera una condición de discapacidad. Por lo tanto la D es una interacción entre el funcionamiento humano y un ambiente que no toma en cuenta los diferentes niveles de funcionamiento. ${ }^{10}$

Por lo tanto definir quien tiene una $D$ o no, no depende sólo de las características personales de los individuos sino de cómo la sociedad donde viven organiza su entorno. La ecuación explicativa del impacto del ambiente en la relación entre $D$ y limitación funcional indica:

Discapacidad $=$ limitación funcional $\mathrm{x}$ ambiente ${ }^{(12)}$

Si se da un valor cero a un ambiente que no ofrece barreras, independientemente del peso atribuido a la $D$, el resultado valorado de la $D$ es el siguiente:

\section{Limitación Funcional $1 \times$ ambiente $0=0$ Discapacidad \\ Limitación Funcional $5 \times$ ambiente $0=0$ Discapacidad}

Si las dificultades ambientales adquieren valores 1 o más, se producen incrementos en el impacto funcional de la $\mathrm{D}$ en la vida de una persona:

\section{Limitación Funcional $1 \mathrm{x}$ ambiente $1=1$ Discapacidad \\ Limitación Funcional $5 \mathrm{x}$ ambiente $5=25$ Discapacidad}

La 54. ${ }^{a}$ Asamblea Mundial de la Salud (2001) aprobó la nueva Clasificación Internacional del Funcionamiento (CIF), de la $D$ y de la Salud cuyo objetivo es "brindar un lenguaje unificado y estandarizado y un marco conceptual para la descripción de la salud y de los estados relacionados con la salud..." 90

La CIF se basa en la integración del modelo médico y social, con la finalidad de incluir las diferentes dimensiones de la salud: biológica, individual y social. Los cambios conceptuales que se introducen con la CIF incluyen:

- "Funcionamiento" como un término genérico que abarca funciones corporales, estructuras corporales, actividades y participación. Indica los aspectos positivos de la 
interacción de un individuo (con una condición de salud) y los factores contextuales (ambientales y personales).

- "Discapacidad" como un término genérico, que incluye deficiencias en las funciones corporales y en las estructuras corporales, limitaciones en la actividad (capacidad) y restricciones en la participación (desempleo). Indica los aspectos negativos de la interacción entre un individuo (con una condición de salud) y sus factores contextuales (ambiente y personales).

En este marco, la $D$ es una variable que resulta de la interacción entre una variable que tiene que ver con la funcionalidad de la persona y otra variable que tiene que ver con el ambiente y la organización social, siempre relacionado a una condición de salud.

Se denominan "funciones corporales" a las funciones fisiológicas de los sistemas corporales, en este estudio sistema bucal. "Estructura corporal", a las partes anatómicas como los órganos -aquí dientes, lengua, labios y carrillos-. Se entiende como "deficiencia" a un problema en las funciones o estructuras corporales tales como una desviación significativa de la norma, generalmente respecto al estado biomédico del cuerpo y sus funciones o una pérdida de dichas funciones o estructura -pérdida parcial o total de la integridad dentaria-. ${ }^{120}$

La cavidad bucal es un complejo sistema órgano-funcional, en el que actúan como componentes: los huesos maxilares, la articulación temporomaxilar ATM (subsistema articular);los músculos masticatorios maseteros y temporales, de la mímica y suprahioideos, fuentes de movimientos y receptores de estímulos; los nervios (subsistema neuromuscular); y el subsistema dentario, constituido no solamente por piezas dentarias, sino por el conjunto que conforman la base esquelética y la unión con el proceso alveolar a través del ligamento periodontal, la mucosa orolabial, elementos primordiales en la transmisión de la fuerza durante la masticación.

Este sistema constituye una unidad funcional que necesita de todos sus componentes para poder ser activo y efectivo en sus funciones masticatoria, estética y fonética:

- Función masticatoria: es el conjunto de movimientos biomecánicos que integran dientes, maxilares, ATM, músculos masticatorios, lengua y tejidos blandos bucales, y que tienen como misión preparar mecánicamente el alimento para ser deglutido y digerido. La función del grupo dentario incisivo es seccionar, la de los caninos es desgarrar y la de los premolares y molares, triturar. El individuo con una oclusión normal presenta un esquema masticatorio regulado y coordinado con amplitud de movimientos y una forma de trituración de los alimentos determinada. Este esquema oclusal tiene cierto grado de tolerancia y, ante ciertas variaciones, encuentra un nuevo equilibrio neuromuscular; pero si las variaciones son medias o extremas, se rompe el equilibrio y aparecen movimientos masticatorios parafuncionales lesivos para todos los integrantes del sistema. 
- Función estética: el subsistema dentario conforma el sostén de los tejidos blandos de la cara; su ausencia origina alteraciones de la expresión y de la fisonomía, dando aspecto de senectud, afectando la armonía, belleza y /o estimación de la persona. El grupo dentario anterior tiene máxima importancia en la vida de relación, a punto de constituir un elemento de prestigio. De él depende en gran parte el factor simpatía.

Una corriente jurisprudencial entiende que el menoscabo estético es una lesión a las condiciones estéticas de la víctima, es decir a su integridad personal y que esa situación genera "a) un daño derivado de la simple violación del derecho subjetivo de mantener intangible la base somática de su integridad, b) daño material derivado de la frustración de los beneficios económicos y sociales esperados y c) daño moral relacionado con los sufrimientos que pueda producir en la víctima." 135

- Función fonética: las piezas dentarias colaboran en la articulación de las palabras. En los estudios de los sonidos articulados hay letras que se pronuncian apoyando la lengua contra los incisivos superiores, por lo tanto en el supuesto de inexistencia, se produciría un sonido sibilante interfiriendo la comunicación humana.

La OMS determina que el derecho a gozar del más alto nivel posible de salud no solo comprende el derecho a la promoción, prevención y curación, sino también acceso a la rehabilitación.

La rehabilitación es el proceso continuo y coordinado, tendiente a obtener la restauración máxima de la persona con $\mathrm{D}$ en los aspectos funcionales, físico, psíquico, educacional, social, profesional y ocupacional, con el fin de reintegrarla como miembro productivo a la comunidad, así como promover las medidas para prevenir la D. ${ }^{112}$

La rehabilitación como proceso puede abarcar medidas para proveer o restablecer funciones o para compensar la pérdida (dentaria) o falta de una función o de una limitación funcional (estética, fonética y masticatoria) y engloba medidas y actividades desde la rehabilitación básica y general hasta las específicas como, en este proyecto, la rehabilitación del componente bucal de la salud.

- "Actividad" es la realización de una tarea o acción por una persona. Representa la perspectiva de un individuo respecto al funcionamiento.

- "Participación" es la implicación de una persona en una situación vital. Representa la perspectiva de la sociedad respecto al funcionamiento.

La desventajas de las personas "discapacitadas" o con capacidades mentales distintas de las consideradas "normales" - seguidas de desigualdades - derivan de vallas físicas (aspecto corporal) y sociales que impiden o dificultan su reinserción en la comunidad. De allí que resulte comprensible estimular su rehabilitación para la integración social plena. 
Los modelos de desarrollo procuran el bienestar de la comunidad global, pero los aplicados excluyen de los beneficios del desarrollo a diversos grupos comúnmente reconocidos en situación de vulnerabilidad, como las personas con problemas mentales.

Para abordar el paradigma del Desarrollo Inclusivo desde la perspectiva de las personas con $D$, es necesario interrelacionar con el concepto de inclusión otros dos asociados con la D: la diversidad humana y el diseño universal.

Por diseño universal se entiende el diseño y construcción de productos (en este proyecto prótesis dentales) que puedan ser utilizadas por las personas como medio seguro y que en la medida de lo posible no ofrezcan adaptaciones particulares y sean accesibles.

Este enfoque valora, sin exclusiones, la contribución de cada ser humano al proceso de desarrollo, promoviendo la diferencia, transformando la diversidad en una ventaja, un valor, una oportunidad y un derecho.

Lorenzetti, al reflexionar sobre igualdad de oportunidades, afirma que la igualdad es una relación comparativa. "La regla de justicia es que debe tratarse a los iguales en forma igual y a los desiguales de modo desigual. Ningún principio ni garantía es absoluto y el legislador puede establecer categorías, grupos o clasificaciones que supongan un trato diferente a las personas. Se adecuan a esta regla todas aquellas normas generales que adjudican las mismas consecuencias jurídicas a quienes cumplen con los mismos requisitos". ${ }^{73}$

Se entiende por Desarrollo Inclusivo la formulación y puesta en práctica de políticas, planes, programas, proyectos y acciones para el desarrollo socioeconómico y humano que se orientan, garantizan y hacen posible la igualdad de oportunidades y el disfrute y goce de los derechos para todas las personas, independientemente de su status social, género, condición física o mental y raza ${ }^{12}$.

Es necesario redimensionar la $\mathrm{D}$ como parte de la diversidad y no como una condición objeto de subestimación, discriminación, marginación y exclusión, condición dominante en los contextos socioculturales actuales, organizados alrededor de ideales estrechos de normalidad y funcionalidad.

Por lo tanto, toda actividad que promueva el desarrollo inclusivo aprovecha y potencia los derechos y capacidades de cada una de las dimensiones del ser humano en su diversidad y especificidad, promoviendo la garantía de la igualdad de oportunidades y de la equidad.

Tomando como punto de partida la relación entre $D$ (en este estudio, la pérdida de la estructura y funcionalidad de la salud bucal en personas con problemas de salud mental) y la producción, un escenario donde se aplique el desarrollo inclusivo generaría las condiciones para que las personas desarrollen sus capacidades según su condición y se incorporen al proceso productivo, habiendo hecho previamente cambios en su imagen y funcionalidad, para erradicar cualquier forma de discriminación y exclusión. 
Para ello se ponen en consideración procesos de diseño universal (rehabilitación de las piezas dentarias perdidas), los cuales constituyen una de las actividades generadoras de valor en la lógica organizacional de un modelo multidisciplinario para la reinserción social.

\section{Desinstitucionalización.}

La desinstitucionalización en salud mental es el producto de un proceso que promueve una profunda reforma del modelo hegemónico manicomial de las instituciones totales.

Este producto se comporta como un proceso complejo y, aun sin considerar las posturas teóricas que se asumen ante la reforma psiquiátrica, no se trata de desarticular por decreto los grandes hospicios, sino de ir creando formas alternativas de asistencia a personas internadas, buscando las condiciones para la reinserción social.

La asistencia psiquiátrica convencional no ha conseguido alcanzar los objetivos compatibles para la reinserción social de las personas con padecimientos mentales y el hospital psiquiátrico, como única modalidad asistencial, obstruye el logro de tales objetivos, surgiendo la necesidad de una revisión crítica de su papel hegemónico y centralizador como prestador de servicios.

La crítica al hospital psiquiátrico fue enunciada desde cuatro ejes: ético jurídico, que cuestiona la violación de los derechos humanos; clínico, que señala el papel patogénico y "cronificante" de la enfermedad mental; institucional, que denuncia el carácter cerrado de la institución con relaciones de sumisión imperantes; sanitarista, que pone de manifiesto la concentración y asignación de recursos humanos y financieros en detrimento de servicios descentralizados y ambulatrios. ${ }^{117}$

La desmanicomialización o desinstitucionalización psiquiátrica es una preocupación de ciertos especialistas de la salud mental, la bioética y el derecho. La reestructuración no es un proceso sencillo por el entrecruzamiento disciplinario sobre las representaciones de la salud mental y la enfermedad mental. Por lo tanto, este proceso exige un debate social con discusión acerca del derecho a la salud mental y con la búsqueda de financiamiento que cumplimente este derecho.

Se trata de un cambio total de paradigma por el cual un patrón curativo de atención, de base manicomial, evoluciona a un modelo integral de base epidemiológica y orientación comunitaria.

Si esa deshospitalización ocurre sin una existencia digna y cuidados y tratamientos adecuados para ellos y sus familias, propios de la reinserción, las consecuencias para el paciente, su entorno y la comunidad son graves. 
Morgado y Abello de Lima señalan como consecuencias graves de una deshospitalización apresurada, desamparo, alta rotatividad (revolving door system) y problemas con la comunidad, con la policía y la justicia. ${ }^{81}$

A través de su evolución histórica, la teoría de la enfermedad mental encuentra en la actualidad un conflicto conceptual, porque muchas veces se categoriza y trata como enfermedad mental a pacientes con enfermedades cerebrales o con problemas económicos, existenciales o políticos que no requieren terapias medicalizantes sino alternativas económicas, existenciales, morales y políticas.

A partir de estos principios y de los conocimientos científicos disponibles, no se puede determinar que las personas con afecciones mentales sean más peligrosas que las denominadas sanas y que, si se dispone de alternativas terapéuticas en la comunidad, los pacientes pueden ser mejor asistidos fuera de las instituciones psiquiátricas. ${ }^{37}$

En la década del '60, el psiquiatra italiano Franco Basaglia comienza a hablar de "desinstitucionalización" de los enfermos mentales, desarrollando prácticas basadas en el principio de comunidades terapéuticas. ${ }^{11}$

En Argentina también en la misma década, Goldemberg M., inicia una experiencia en Lanús (Buenos Aires), seguida en los años 80 por Cohen H., en la Provincia de Río Negro, legitimada por la ley provincial 2440. Y posteriormente, nuevas experiencias se iniciaron en las provincias de San Luis, Santa Fe y Mendoza.

Otras han surgido desde las propias instituciones psiquiátricas como en el hospital Estévez en el año 1999, con el Programa de Rehabilitación y externación asistida ${ }^{78}$ (PREA), o en el Alejandro Korn en Melchor Romero con la apertura de casas de prealta y centros comunitarios.

Estas experiencias persiguen la integración de estas personas para que puedan formar parte de la comunidad, ser uno más y no necesariamente quedar excluidos.

Esta apertura de la institucionalización implica variadas situaciones de conflictos y resistencias, ya que todavía hay mucho prejuicio; una representación de la locura, la discapacidad muy asociada al aislamiento y al encierro. Muchas veces la sociedad se conmueve por lo que pasa en las instituciones totales, pero a la hora de trabajar para la integración, la incertidumbre y el miedo circundan el ambiente del "loco" a pesar de que desde lo discursivo el mensaje sea otro.

El proceso de transformación hacia la desinstitucionalización implica un cambio en la estructura de toda la sociedad (económico y social) que incluye la familia, la cual desde el modelo productivista, cuando está organizada eficientemente (trabajan madre y padre), es uno de los anillos del sistema de opresión social. ${ }^{52}$

Erving Goffman, desde la perspectiva sociológica introduce la idea de pérdida y mortificaciones y la idea de estigma, ${ }^{40}$ y afirma que,"como cualquier grupo de personas, 
aquellas con problemas mentales forman una vida propia que, mirada de cerca, se hace significativa, razonable y normal, y que un buen modo de aprender algo sobre cualquiera de esos mundos consiste en someterse personalmente en compañía de sus miembros a la rutina diaria de las menudas contingencias a que ellos mismos están sujetos". ${ }^{39}$

\section{Programa de rehabilitación y externación asistida. PREA. (Res. No 001832 Ministerio} de Salud. Provincia de Buenos Aires)

Los fundamentos del programa consideran:

- Que el hospital psiquiátrico aísla al enfermo de su medio generando mayor discapacidad social, consume importantes recurso destinados a la Salud Mental y no permite alcanzar los objetivos compatibles con la atención comunitaria, creando condiciones con alta probabilidad de incumplimiento de los derechos humanos y civiles de la persona considerada enferma (Declaración de Caracas).

- Que existen importantes antecedentes de acciones de rehabilitación que han logrado revertir la exclusión social, desarrollando alternativas para evitar las internaciones prolongadas que no obedezcan a las estrictas razones clínicas.

- Que en los grandes hospitales psiquiátricos de la provincia de Buenos Aires se observa un deterioro propio del largo período de internación, que tiende a la cronificación de los pacientes, a la exclusión de su entorno familiar, a la pérdida de las condiciones laborales, al deterioro afectivo, cognitivo, descenso de la autoestima y del autovalimiento ( Morasso y col. ${ }^{80}$ describen en una institución neuropsiquiátrica de la Provincia de Buenos Aires un tiempo de internación expresado en valores promedio (desviación estándar) de 13.49 (10.56) años (mayor en mujeres 16.69(10.89) que en varones 10.18(9.20) $P<0.05$. Las prácticas de rehabilitación son escasas y la cronicidad de la patología no es determinante de la necesidad de internación.

- Que los megahospitales son observados críticamente por la gestión del Ministerio de Salud y sus resultados distan de ser satisfactorios en base a los recursos involucrados en el proceso de recuperación de los pacientes, como consecuencia de una asignación ineficaz e ineficiente.

- Que los trabajadores de la salud resultan ser víctimas de esta situación, padeciendo las consecuencias de ser soporte de un sistema custodial de disciplinamiento y medicalización.

- Que existen acciones "no manicomiales" y que múltiples prácticas (planificadas y no planificadas) funcionan como alternativas cotidianas y que podrían ser ampliadas.

- Que los relevamientos realizados en hospitales psiquiátricos presentan la siguiente distribución de población: 
a) pacientes en situación de crisis que necesitan internación de corto plazo.

b) pacientes geronto-psiquiátricos con alteraciones orgánicas con escasas perspectivas de egreso, para los cuales el hospital no es la alternativa pertinente a la especificidad de su patología.

c) pacientes con psicosis con internaciones de mediano y largo plazo, que contituyen un alto porcentaje de la población hospitalaria. (Morasso y col. ${ }^{80}$ relevaron que el $65.25 \%$ de la muestra estudiada pertenecía a este grupo). Este grupo padece problemas de deterioro propios de la institucionalización, los crónicos de la enfermedad con pérdida de habilidades y capacidad, sumado al abandono socio-familiar por la imposibilidad de que la familia lo tome a su cargo o por la contraindicación al respecto. El 20al 25\% de los internados en condición de alta se encuentran en esta situación.

Estos fundamentos indican la necesidad de:

- Una revisión crítica del papel del hospital psiquiátrico en la prestación de servicios.

- Una reestructuración de la atención psiquiátrica ligada a la atención primaria de la salud y a la capacitación de recursos humanos en salud mental, procurando modelos alternativos que permitan la promoción de la reinserción social.

Destinatarios:

Pacientes con internaciones de mediano y largo plazo que no padezcan inhabilidades extremas que impidan su autovalimiento básico o impliquen factores de riesgo conductuales.

\section{Propósito:}

El programa se propone la externación y reinserción social en el marco de la comunidad a través de la promoción, organización e instalación de dispositivos alternativos de atención y redes sociales que interrelacionen a pacientes, familiares y trabajadores de la salud que operen como soporte de este proceso.

Este programa promueve la aceptación social de las diferencias, la revalorización del lugar de los vínculos. Desde la mirada del paradigma del desarrollo inclusivo la resignificación y transformación en un trabajo intersectorial para promover la convivencia igualitaria en la comunidad de personas con distinto grado de perturbación o discapacidad.

Se toma como eje una concepción de salud-enfermedad como proceso dinámico y permanente de abordaje de conflictos, en este caso derivados de alguna discapacidad. Se propone por lo tanto que los pacientes con diverso grado de inhabilidad sean abordados a partir de un trabajo de rehabilitación singular diferente del modelo tradicional.

\section{Intervención Dental y Calidad de Vida}

Las cualidades atractivas faciales han cimentado las actitudes afectivas y acciones sociales y son importantes situaciones de empleo. 
Los informes de cirujanos generales sobre Salud Bucal revelaron desigualdades en algunos grupos poblacionales clasificados por edad, sexo, ingresos, etnias y razas $(U S$ Department of Health and Human Services, 2000). ${ }^{71}$

Sin embargo la Salud Bucal y la Salud Bucal relacionada con la calidad de vida (OHRQoL) de aquellos marginados por desempleos prolongados son desconocidas.

La nutrición comprometida, la higiene, la accesibilidad a la atención en esta población subasistida probablemente resulte en aumento de la cantidad y extensión de la caries dental, pérdida dentaria y enfermedad periodontal, afectando consecuentemente la salud sistémica, la calidad de vida y la productividad económica.

El Departamento de Servicios Humanos de San Francisco (SFDHS) ofrece el programa de Servicio de Asistencia al personal empleado (PAES), como asistencia temporaria a familias necesitadas, para adultos en condición de empleo, solteros e indigentes.

Este programa se inició en 1999 como una colaboración entre SFDHS y Salud Pública y es el único programa en su género en Estados Unidos. El propósito del programa dental es eliminar los severos problemas dentales que plantean una barrera de empleo y autosuficiencia.

Un estudio llevado a cabo por Hyde S. y col $^{44}$ evaluó los efectos de tratamientos rehabilitadores sobre la calidad de vida en empleados del programa PAES. Las conclusiones del mismo indicaron que la mejoría de la Oral health-related quality of life (OHRQoL) y las consecuencias en el empleo encontradas por los participantes que completaron los tratamientos dentales del programa indican beneficios para algunos de los receptores, y que la enfermedad bucal plantea una significativa barrera para el empleo y autoservicios, como así también la salud en general y la salud mental.

\section{Depresión como factor de riesgo en rehabilitación protética.}

Es necesario ubicar el concepto de salud dentro de un marco general, para poder estudiar y analizar la relación existente entre los factores de riesgo y los estados de salud enfermedad.

Investigadores y analistas deberán tener en cuenta todos estos factores para el logro del propósito fundamental, la preservación de la salud.

El enfoque reduccionista de salud-enfermedad debe ser complementado desde una perspectiva más amplia con un enfoque psicobiológico - social del hombre, es decir tener en cuenta que este atraviesa una vida de complejas transacciones internas y externas.

Cuando la enfermedad dental se manifiesta con una consecuencia residual - pérdida de la pieza dental, alteración articular, estética, fonética y funcional -, la prevención terciaria (Levell H.R. y Clark E. G.) ${ }^{54}$ consiste en evitar la discapacidad total, una vez que se hayan estabilizado las modificaciones anátomo-fisiológicas. 
Así en un "continuo de prevención", la aplicación de métodos de intervención - en el caso estudiado, la rehabilitación protética en grupos especiales (adultos psiquiátricos en proceso de desinstitucionalización) -, implicaría la medición del impacto del cambio de la condición bucal percibida en la calidad de vida, para el monitoreo y ajuste de la desviación del método de intervención.

La rehabilitación estética y funcional de los individuos es, en esencia, el fondo de la prostodoncia como disciplina; el impacto del cambio será sensiblemente diferente según como la persona se sienta o perciba el déficit o esa consecuencia residual, como es la pérdida dentaria. ${ }^{130}$

Sin la comprensión de los factores de riesgo como la depresión, variable interviniente en esta población diana y del enfoque psicobiológico-social, la recuperación que se pueda lograr por una prótesis puede ser mal interpretada y puede no justificarse. ${ }^{48}$

La depresión es identificada por la World Health Organization (WHO) como cuarta en el ranking, contribuidora de carga global de enfermedad. Proyecciones realizadas para el 2020 la ubican como causa mundial de discapacidad y muerte prematura, seguida en segundo término por la enfermedad isquémica cardíaca. ${ }^{137}$

La depresión co-ocurre con otras enfermedades como las cardiovasculares, traumatismos, diabetes, cáncer y trastornos del estado de ánimo.

Si bien hay un incremento del conocimiento que la depresión afecta la condición bucal y los resultados del tratamiento especialmente en personas mayores, una de las más importantes intervenciones como la provisión de prótesis no ha sido cabalmente estudiada con relación a la depresión.

Esto es quizá sorprendente porque las rehabilitaciones protéticas en general están dirigidas al mejoramiento de la percepción de la Salud Bucal, más que ha cambiar las duras consecuencias residuales relacionadas con la enfermedad.

Una asociación entre depresión y beneficios percibidos por tratamientos protésicos podría tener mayores implicaciones para la evaluación y demanda de tratamiento. Cuando la depresión está presente, el potencial para la eficacia del tratamiento con prótesis recién instaladas puede no ser apreciada por el individuo, y una salud deteriorada referida a la necesidad de rehabilitación protética podría ser una estimación equivocada; o el tratamiento puede no ser demandado, cuando éste podría, en realidad, ayudar a mejorar la calidad de vida para la integración social.

John y col. ${ }^{48}$ en Alemania estudiaron la asociación entre depresión e insatisfacción en adultos mayores. Los resultados indicaron que la depresión influencia la percepción de la salud y en particular de la salud percibida, caracterizada por las mediciones OHRQoL.

Los autores encontraron una significativa asociación entre depresión e insatisfacción por prótesis en adultos mayores, contribuyendo a la existencia de un caudal de datos acerca de la 
influencia de la depresión sobre una variedad de resultados psicológicos y psicosociales en tratamientos médico-odontológicos.

Inversamente, estimaciones equivocadas de deterioros de salud (protéticos) pueden ser usadas y el tratamiento puede no ser demandado, cuando este sería provechoso.

Siendo el objetivo de esta investigación reconocer a la rehabilitación protética como parte de la estrategia de recuperación de la salud y de la inclusión social, será pertinente, desde la investigación, controlar el efecto de esta variable en la fase del diseño y del análisis estadístico y, desde la aplicación clínica, programar un enfoque multidisciplinario interdependiente, con iguales paradigmas científicos y criterios asistenciales acordes al logro de la desinstitucionalización para la reinserción social plena.

\section{Marco jurídico en la protección de las personas con trastornos mentales.}

Con el desarrollo del ámbito jurídico, los ciudadanos adquieren conciencia de que, en tanto personas, son acreedores de derechos intangibles y sus crecientes demandas van transformando las distintas formas del discurso jurídico.

La enorme dimensión y el alcance universal del problema de la discapacidad, incluyendo la mental, se manifiestan en un fuerte impacto en la vida social.

En el terreno de las ciencias biomédicas se plantean problemas humanos límites relacionados con el bien salud que afectan las categorías jurídicas elaboradas por la moderna dogmática del derecho y mueven al reajuste o revisión.

Las respuestas tradicionales del derecho apuntaron a la positivación, a la protección constitucional, o a la regulación específica perdiendo operatividad. En el marco de transformaciones culturales, la integración con otras ciencias, la inclusión de la normativa de derechos fundamentales pierde sentido sin un consenso social informado, cuya perspectiva y valores tienen que acompañar al legislador infraconstitucional, ya que la ley ordinaria expresa el contenido del precepto constitucional integrándolo, completándolo y dándole sentido operativo ${ }^{51}$.

Documentos de alcance internacional procuraron jurídicamente el respeto por la dignidad y el valor de la vida humana y el mejoramiento de sus condiciones, doctrina que fue incorporándose a la normativa de los diferentes países. ${ }^{13}$

La evolución fundamentó la ideología de estos derechos surgidos en diferentes momentos históricos, marcando cambios que intentan enfrentar nuevas problemáticas de considerables grupos humanos. Estos derechos personalísimos constituyen una categoría de derechos esenciales que pertenecen a la persona por su sola condición humana 
Esta abundancia de normas jurídicas deontológicas y éticas - protectoras de los derechos humanos básicos y libertades fundamentales de las personas con discapacidad mental - no se refleja en la práctica, pues tales derechos, por lo general, carecen de protección y fiscalización adecuadas. Aparece así una contradicción entre los derechos que surgen de los ordenamientos jurídicos vigentes y la realidad concreta: el paciente, sobre todo el institucionalizado, se convierte de hecho en un individuo "sin derechos", en un no sujeto. ${ }^{52}$

En referencia a la situación de las personas con alteraciones de la salud mental, la ausencia de producción jurídica está vinculada a una calificación: personas que tienen problemas mentales, problemas toxicológicos, de conducta, estableciendo una frontera compleja, problemática.

Esa evolución histórica tuvo un impacto sobre el lenguaje, con un impulso inicial, pero donde se señala un primer problema en el campo de las personas con afectaciones mentales. Este lenguaje tiene una contra cara que es la exclusión dada por el umbral de designación, ya que cuando decimos "loco" estamos frente a un proceso de descalificación que, además, posee un fuerte potencial que vuelve invisible al problema, lo asocia con el encierro y la desaparición del mundo social.

El segundo problema a enunciar es lo que se puede llamar por su carácter fase analítica de todos los derechos específicos, explicados y desarrollados en las sentencias. En este campo se encuentra el derecho a recibir o negarse y un derecho a negarse a esos tratamientos.

La libertad humana integra hoy lo que se denomina el ámbito de la individualidad personal en el que se toman las decisiones basadas en la autonomía y este es el ámbito protegido como núcleo duro de la individualidad personal, tanto en el derecho constitucional como en el derecho público y el derecho privado.

Una decisión lleva implícita una elección y por lo tanto necesita para ella información; este derecho es muy relevante, ya que esta información es calificada en el caso de las personas que tienen dificultades de discernimiento. Por lo tanto el derecho a la información aplicado a la salud se refiere a la problemática que existe entre profanos y expertos, que es un desnivel cognoscitivo del nivel de conocimiento, aquí acentuado y agravado por la falta de discernimiento.

Esta situación también es analizada por la economía como una falla del mercado de la salud, asimetría de la información, en una situación donde las decisiones de demanda de atención de una persona denominada principal - en este estudio personas con padecimientos mentales y necesidades de rehabilitación de la funcionalidad dentaria - son tomadas por un agente (odontólogo). Esta relación de agencia tiene ante estas personas con características particulares de vulnerabilidad señaladas ut supra un alto riesgo de judicialización. 
No es sólo información sino consejo calificado, asistencia; y no sólo consejo en un solo acto sino permanente y continuo el que debe recibir una persona que está en esta situación.

Los derechos de los pacientes son derivaciones de derechos civiles, debiendo advertir las condiciones de debilidad jurídica de las personas con minusvalías físicas o psíquicas, requiriendo una tutela aún más diferenciada de idénticos derechos para las personas con problemas mentales.

Históricamente existió cierta desidia en parte de la comunidad jurídica para el abordaje de la temática de los pacientes con afecciones mentales, especialmente la población pobre. El derecho cae bajo la influencia de los principios sociales y la mitología que rodea a la enfermedad mental.

Tal indiferencia acrecienta la fragilidad y esta endeblez jurídica se amplifica en tanto que estas personas con D mental, que resultan judicializadas, quedan atrapadas por cierto conflicto entre el Derecho y la Psiquiatría, conflicto que elude los principios bioéticos que debieran generar equilibrio en estos campos profesionales. El desacuerdo entre la racionalidad jurídica y las razones psiquiátricas conduce a la equivocada instrumentación de principios, entre ellos la inimputabilidad, la culpabilidad, la incapacitación, la responsabilidad derivada de internaciones arbitrarias y el daño derivado de tales decisiones (en este estudio daño bucal).

La dicotomía planteada -tratamiento o libertad- es falsa y la resolución no se logra con privilegiar algunos bienes jurídicos como la seguridad o libertad, tratamiento o autonomía.

El ejercicio del derecho a la libertad, la autodeterminación y los demás derechos fundamentales se promueven sólo mediante un tratamiento adecuado, ya sea en un marco institucional (ante situaciones de emergencia y como última instancia) o a través de mecanismos alternativos (nuevos modelos de atención comunitaria o servicios de salud mental en hospitales generales).

La histórica formulación de los derechos de los pacientes se ha transformado en derecho nacional a partir de la reforma constitucional de 1994. La vigencia de las normas y/o tratados internacionales -que adquieren jerarquía constitucional- permite afirmar que ahora todos tienen derecho a la vida, a la integridad psicofísica, a la libertad, a la protección de la salud y a la dignidad. Los Principios de Salud Mental ${ }^{110}$ (ONU 1991) respaldados por normas constitucionales y ordinarias confirman la vigencia de los llamados "derechos específicos de los pacientes mentales".

El sistema jurídico se integra en este campo con las normas codificadas -civiles, penales y de procedimiento, entre otras- y con las leyes especiales o estatutos. Para que la filosofía de Derechos Humanos se convierta en derecho positivo es necesario no sólo que una norma jurídica con rango constitucional o de ley los reconozca y derive de ello la posibilidad de atribuirse el derecho fundamental como derecho positivo, sino que las infracciones a esa 
norma faculten a los titulares para acudir a los tribunales y solicitar su protección o restablecimiento mediante acciones procesales, en nuestra Constitución: el amparo, habeas data y habeas corpus, especialmente ante la jurisdicción ordinaria. ${ }^{28}$

Constitución, derechos fundamentales y proceso constituyen y deben ser tres pilares que unidos por el ordenamiento jurídico sostienen el Estado de Derecho.

El reconocimiento de rango constitucional de los Derechos Humanos en nuestro país marca un hito histórico en el proceso de la protección jurisdiccional, requiriendo el acompañamiento de garantías y promoción que aseguren su libre ejercicio y substanciación. No es sencillo operar y aplicar las normas fundamentales. Aquellas normas que por su redacción no puedan considerarse operativas deberán ser tenidas en cuenta sólo como programáticas.

Bidart Campos afirma que "Bien que no nos ha encandilado el optimismo lingüístico que atribuye operatividad a todas las normas declarativas de derechos, porque por si solo el enunciado de operatividad no es capaz de resolver la totalidad compleja de problemas que analizamos en torno de normas operativas y programáticas, si creemos bueno y útil que, además de la calidad ya recomendada de las formulaciones gramaticales, el lenguaje normativo permita inferir -e interpretar- que toda norma declarativa de derechos tiene naturaleza operativa mientras no haya indicio cierto de que es programática y de que necesita reglamentación infraconstitucional". ${ }^{12}$

La vida es un acontecimiento natural, nos viene dado por el hecho del comienzo y el bien protegido por la norma es supremo, porque de él dependen todos los demás bienes ${ }^{18}$. El derecho fundamental a la atención de la salud (entendiendo por atención una variada gama de servicios como protección ambiental, prevención y promoción de la salud, tratamiento y rehabilitación), principio constitucional fundante, explícitamente tutelado es una extensión del derecho a la vida y a la integridad psicofísica ${ }^{127}$

La atención de la salud como bien jurídico es diferente de casi todos los demás bienes y servicios y por ello debe basarse en la existencia de una obligación -un derecho- que asegure el acceso de todas las personas a un sistema de servicios de salud. No es por lo tanto un derecho "de" sino un derecho "a"; es decir un derecho prestacional, que da lugar a una acción exigible al Estado y conlleva un gasto social, dependiente de los recursos que se quieran involucrar como voluntad política del momento. ${ }^{129}$

El derecho a las prestaciones de salud se ha tratado como si fuera un derecho subjetivo absoluto, lo que no parece posible en nuestro ordenamiento jurídico.

El presupuesto básico,"las prestaciones de salud constituyen un recurso escaso", podría ser puesto en duda si la sociedad decidiera asignar todos los recursos a la salud. Sin embargo esto no sucede, ya que la sociedad tiene que satisfacer también otros bienes igualmente escasos e importantes como la vivienda, el trabajo, la educación o la justicia 
Por esa razón la norma constitucional reconoce el derecho a la salud y, como la demanda es cualitativa y cuantitativamente cambiante, encomienda al legislador (con el supuesto previo del conocimiento de las necesidades y recursos financieros) la implementación efectiva de ese recurso: el goce del derecho es indirecto, condicionado por el legislador.

La discontinuidad y el cortoplacismo de muchos programas de salud, así como los automatismos de los sistemas burocratizados, atentan contra la formulación de una demanda orgánica y revelan que los expertos no tienen, por lo general, ni ofertas ni demandas explícitas ni priorizadas.

El conocimiento de la dinámica sanitaria -de las necesidades, de los recursos para su financiamiento- constituiría un insumo útil para aumentar el grado de racionalidad, eficacia y eficiencia de las intervenciones públicas a largo plazo.

Si admitimos la escasez de los recursos, hay un problema de adjudicación y de precisar qué tipo de contenido tiene la pretensión.

Esta situación tiene su reflejo jurídico en la clasificación del derecho a las prestaciones de salud. En tal sentido, como integrante de la esfera íntima del individuo es de goce directo y, en virtud de ello, el titular tiene una pretensión positiva, que sustenta una acción procesal y es posible considerarla como un derecho subjetivo absoluto.

Por otra parte, la razón de la ausencia de operatividad hace que se traten de derechos relacionales, en virtud de los cuales para concedérselos al titular hay que quitarle algo a otro, ya que afectan cuestiones presupuestarias o mecanismos complejos de interacción. Es por ello que requieren de un paso previo, que es el proceso legislativo para su instrumentación.

Es así que en estos casos no hay un derecho a una prestación de lo que se derive un goce directo, sino que el sujeto activo tiene un derecho de pretensión procedimental dirigida a la protección. ${ }^{74}$

Este es el caso del derecho de las prestaciones de salud en los que, estando consagrados en la norma constitucional, se deja librado al legislador infraconstitucional el establecimiento del grado de satisfacción de ese derecho. En razón de que este puede establecer parámetros de satisfacción excesivamente bajos, que de hecho importan una denegación del derecho, habrá que determinar si la facultad de legislar en estos casos es ilimitada o se desenvuelve dentro de algunos límites de control constitucional.

La protección jurídica fortalece a quienes son acreedores de derechos intangibles y que se asegure su cumplimiento. La dependencia del paciente psiquiátrico crea una situación de vulnerabilidad e incapacidad para comprender racional y objetivamente sus situaciones de carencia que, en esta población especial, desprotegida por añadidura respecto del profesional experto dotado de poder fáctico, es agravada. ${ }^{52}$

En los juicios por responsabilidad de los profesionales, la situación de desventaja procesal del paciente y la escasez de medios probatorios del actuar de aquellos, más la ausencia de 
colaboración de los demandados, determinan que cierta jurisprudencia y doctrina se pregunten si no correspondería al deudor de la práctica probar su diligencia o si no fuera justo aligerar la carga de prueba de la relación de causalidad "adecuada" entre conducta negligente y resultado dañoso, o, considerar por presunción "lo que es más probable" tal relación de causalidad. ${ }^{26}$

Ante tal desigualdad, nuevos personajes y mecanismos de protección -antes ignorados por los ordenamientos jurídicos y ahora sujetos de derecho- se enfrentan al derecho tradicional referido a las personas abstractas. Sin embargo, estos grupos vulnerables y diferenciados siguen discriminados y relegados del sistema legal. Los operadores jurídicos eluden estos colectivos por lo que aún nos debemos la transformación del modelo asistencial y su consecuente normativa jurídica.

La OMS fundamenta el problema de la $D$ como una responsabilidad social compartida y no individual e incluye la necesidad de promocionar y proteger los Derechos humanos de las personas con $D$ que frecuentemente encuentran obstáculos con relación al goce de estos derechos y libertades fundamentales. ${ }^{116}$

Los Derechos Humanos constituyen la base jurídica y el mínimo ético irrenunciable sobre las cuales asientan las sociedades democráticas. ${ }^{17}$. Estos desarrollos favorecen el diálogo fructífero entre bioética y derecho, reconociendo en la filosofía de los Derechos Humanos una especie de hilo conductor, que remite a la dignidad personal como cristalización histórica de la conciencia ética de la sociedad. Desde la óptica de los Derechos Humanos y los principios bioéticos, el reconocimiento de la salud es una precondición o valor instrumental necesario para la posible realización de otros valores y el ejercicio de otros derechos de raigambre constitucional. ${ }^{45}$ Cierto grado de salud física y mental es necesario para poder ejercer los derechos y libertades fundamentales y, de esta forma, participar en la vida social y económica de un Estado.

Sin embargo, la aplicación de los instrumentos de Derechos Humanos en el contexto de la salud es todavía muy limitada; por ello es importante incorporar en las políticas, planes, legislaciones y prácticas vinculadas a los grupos vulnerables la normativa internacional existente en la materia y las disposiciones jurídicas que fortalecen y protegen los derechos humanos de las personas con $D$ mentales, puesto que en ellas reside el resguardo de la dignidad de estas personas.

Hoy se trabaja en "la teoría de la implementación" para que no solo constituyan declaraciones sino normas jurídicas, que no deberían ser conceptos indeterminados o de carácter internacional, sino que deberían entrar en los ordenamientos nacionales y ser normas jurídicas determinadas. Es decir; deberían ser derechos precisos, cuyos titulares podrían ejercerse con acciones y deberes para las autoridades. 
Pero hoy se plantea algo más que el ingreso del movimiento de Derechos Humanos a los ordenamientos nacionales. La norma jurídica no puede ser vista como una emanación legislativa con término final en la promulgación o legislación o con el dictado de una sentencia. Existe en un importante número de casos de exposición del problema por el legislador, pero despreocupación por la resolución de los conflictos reales que provocan estas declaraciones. ${ }^{75}$

\section{Fundamento económico de la Rehabilitación de la Salud Bucal en pacientes con trastornos mentales.}

La esencia de la economía es reconocer la realidad de la escasez y estudiar la forma en que los individuos efectúan las elecciones y decisiones para que con esos recursos escasos disponibles puedan satisfacer las necesidades individuales y colectivas de la sociedad. ${ }^{128} \mathrm{EI}$ sistema económico, cualquiera sea su tradición política y cultural, debe decidir qué producir, cuánto de cada bien, cómo asignar los recursos y cómo distribuirlos entre sus miembros. Esa producción depende de los recursos y de la tecnología disponible en una organización.

La aplicación de los principios de la economía al sector salud pretende adecuar sus instrumentos y modelos de análisis a la producción de bienes y servicios de salud que, si bien comparten características con otras actividades del campo económico, tiene connotaciones que le son propias.

Los problemas económicos que aparecen en la provisión de servicios de salud pueden explicarse como ajustes a la existencia de incertidumbre tanto a la incidencia como a la eficacia de su tratamiento.

Los cuidados odontológicos agregados a los cuidados médicos, son uno entre los muchos factores que influyen en la salud. En los niveles de población con renta baja, como la población diana de referencia, hay otros bienes como la nutrición, las condiciones de vivienda, de trabajo que tienen un efecto significativo sobre la salud.

La conceptualización bio-económica del proceso salud enfermedad reconoce modelos de causalidad multifactoriales con determinantes sociales; que la salud es un valor económico escaso; que los cuidados y sus consecuencias necesitan ser medidos y que la salud futura así como sus niveles funcionales necesitan poder estimarse y ser usados para evaluar la carga de la enfermedad o, colectivamente, el impacto de las medidas adoptadas.

En salud cuando se habla de demanda se habla de necesidades, considerando la que cada uno o su grupo familiar o su entorno social pueda percibir, más lo que los profesionales de la salud recomiendan y lo que la población de referencia necesita en términos de cuidados 
de salud según el patrón epidemiológico dominante. Este último debería formar parte de los estudios de demanda para el análisis prospectivo de la misma.

La adquisición de servicios de salud es compleja y particular, ya que por las características tecnológicas intrínsecas parece incuestionable la asunción de riesgos en todas las modalidades de servicios de salud, incluidos los odontológicos, siendo la enfermedad un fenómeno incierto e impredecible.

Al existir incertidumbre, la información o conocimiento se convierte en un bien que tiene un costo de trasmisión y uno de producción,; por lo tanto, dados estos costos, esta información se concentrará en los que puedan beneficiarse en mayor medida con su posesión y así lo que se compra a la mayoría de los profesionales de la salud es información bajo la forma de cuidados especializados, en este trabajo atención odontológica para adultos con alteraciones mentales.

Desde el enfoque de la economía normativa, este bien adquirido no satisface los supuestos necesarios de comerciabilidad, ni de optimalidad siguiendo la hipótesis paretiana. Son éstas precondiciones para garantizar la equivalencia entre equilibrio competitivo y situaciones óptimas. ${ }^{6}$

Para estudiar sus múltiples relaciones y diversidad de intereses, el enfoque teórico trata el concepto de relación de agencia, donde una persona denominada principal delega en otra denominada agente un determinado poder de decisión. Se planteán problemas significativos si los objetivos y, por lo tanto, las funciones de utilidad de ambos son diferentes y si, además, existe asimetría en la distribución de la información. ${ }^{38}$

Siempre hay desigualdad de información entre productor y comprador de un bien en lo referente a los métodos de producción; la diferencia de información a la que se ha hecho referencia es en cuanto a las consecuencias de los cuidados o sea la funcionalidad (utilidad) del producto.

La condición de vulnerabilidad y dependencia del paciente psiquiátrico determina una fuerte asimetría en sus relaciones con el sistema de salud, la familia y el sistema judicial.

La demanda de servicios integrales de salud está asociada y con una alta probabilidad a amenazar la integridad personal. En adultos con alteraciones de su salud mental hay, además, deterioros de su plenitud física y una posibilidad substancial de pérdida o reducción de su capacidad laboral, determinando no solo un riesgo sino un riesgo costoso, aparte del costo intrínseco de los servicios de salud.

Cuando se trata de estimar la demanda para grupos específicos, el conocimiento de los problemas de salud debería formar parte del estudio para el análisis prospectivo de la misma, la proposición de objetivos y metas para modificar la situación y la medición del impacto de las medidas adoptadas. 
El conocimiento de los costos de una organización es una valiosa herramienta de gestión para mejorar el proceso de asignación de los recursos, la toma de decisiones y el control de la gestión.

La información necesaria en una empresa para la adopción de decisiones se obtiene, entre otros, de los sistemas y subsistemas que integran la contabilidad general, de costos y de los informes de producción.

La contabilidad general es el medio más idóneo para recoger, clasificar y resumir los acontecimientos que diariamente se producen en la vida de una empresa. La contabilidad traduce en información toda aquella que sea susceptible de ser expresada en unidades monetarias. El estudio de las decisiones exige presentar al intérprete nuevas configuraciones de costos capaces de proporcionar la información precisa y objetiva que la situación requiere.

La contabilidad de costos es una rama de la contabilidad general que sintetiza y registra los costos de unidades de análisis previamente definidas, con el fin de que puedan medirse, controlarse e interpretarse los resultados de cada una de ellas a través de la obtención de costos unitarios y totales, en progresivos grados de análisis.

Sus principales propósitos son contribuir al control de las operaciones y facilitar la toma de decisiones posibilitando la elección de la alternativa más apta con miras a maximizar utilidades o minimizar los costos.

La contabilidad de costos es esencialmente analítica, pero también hace síntesis. Es analítica en cuanto toma las distintas partidas que le suministra la contabilidad financiera o las provenientes de su propio sistema de retroalimentación; y, paulatinamente, en diversos registros, las clasifica y desmenuza por objeto, tipo de costo, grado de variabilidad y función a la que van destinadas, para hacerlas converger finalmente en registros recolectores de costos que, en primera síntesis, informan respecto del costo unitario y total de cada producto.

La función de producción, siguiendo la teoría económica, puede ser definida como la relación técnica entre la cantidad obtenida de un producto y las cantidades aplicadas de distintos factores:

$$
\begin{aligned}
& P=(F 1, F 2, F 3 \ldots F n) \\
& P=\text { cantidad de producto a obtener. } \\
& F=\text { cantidad aplicada de distintos factores. }
\end{aligned}
$$

Tal producción aplica factores para la obtención de resultados y también existe en ella una relación técnica entre cantidad obtenida (actividad desarrollada) y cantidad aplicada de esos factores (personas, equipos, descartables, pruebas diagnósticas). La gestión de recursos persigue producir al menor costo (eficiencia) proporcionando un producto eficaz y efectivo. 
El costo es una variable dependiente que surge como resultado de las tareas y acciones realizadas para la producción de un bien y servicio.

Los conceptos contable y económico de costos pueden armonizar, si se piensa que la contabilidad, al registrar, clasificar y analizar sus distintos componentes, opera con un modelo que tiene por finalidad valuar inventarios, obtener resultados más exactos y controlar y planear operaciones, así como suministrar toda información cuantitativa para las distintas configuraciones de costos que interesan a la empresa de salud en su actividad multipropósito.

Desde el punto de vista contable el concepto de costo se refiere exclusivamente a la suma de valores cuantificables en dinero, que representan consumo de los factores de producción realmente incurridos o efectivamente desembolsados en la gestión de la producción de un servicio o un bien determinado.

Terzoli R. considera al costo de producción como un fenómeno que reviste características económicas, técnicas y financieras y sostiene que "Económicamente considerado, el costo de producción que se origina en el consumo de los factores, bienes económicos, por efecto del proceso de fabricación, no es más que el consumo de utilidades económicas de dichos factores y el insumo de dichas utilidades en el producto terminado. Técnicamente considerado, el costo de producción representa el consumo de factores productivos utilizados en el proceso de fabricación y la incorporación de estos mismos en los productos en proceso y terminados. Financieramente considerado el costo de producción es la expresión monetaria del consumo de factores invertidos en el proceso de fabricación”. ${ }^{30}$

Bottaro define al costo de producción como "La expresión cuantitativa del consumo de factores productivos, ya adquiridos, que han sido insumidos en el proceso elaborado". ${ }^{30}$

Por lo tanto son costos activables los consumos que se operan en el proceso productivo que respondan razonablemente a las exigencias técnicas del mismo proceso. Aquellos costos que no responden a dicha característica deben ser considerados quebrantos del período.

Lawrence lo define como "La suma de todos los desembolsos o gastos efectuados en la adquisición de elementos que ocurren en la producción y venta." ${ }^{30}$. La diferencia entre estos dos grupos generales de costos radica en la distinta función en que se originan y su tratamiento contable. Los primeros o costos de producción se incorporan al producto formando su valor de inventario; los segundos no se activan, sino que, como costos de comercialización, figuran en la cuenta resultados.

Estas definiciones permiten deducir que para configurar el costo de producción de un bien deben darse dos características determinantes: a) que en el proceso de producción se opere el consumo razonable y racional de los factores de la producción, y b) que necesariamente y como consecuencia del proceso se produzca la incorporación directa e 
indirecta del mismo en el producto elaborado. Por consumo razonable y racional quiere significar aquel que responde a condiciones técnicas normales de operación.

Los principales insumos utilizados por cualquier empresa industrial para producir uno o más artículos son los siguientes: materiales, salarios, contribuciones sociales, suministros, depreciación de bienes de uso, fuerza motriz, luz, calefacción, seguros entre otros. Existe aceptación general cuando se aplica un sistema de costeo corriente en el sentido de que todos los costos del área fábrica, en el momento de ser consumidos para obtener el producto y como tales, sirven para valuar los inventarios. ${ }^{72}$

La administración o gerencia de los recursos ha adquirido importancia superlativa, debido a la necesidad de lograr un uso eficiente de los recursos escasos disponibles para solventar las demandas de la población.

\section{Clasificación de los costos.}

Clasificar los costos es agruparlos sistemáticamente en base a criterios, de manera de reunir en grupos o categorías a los que poseen ciertas características comunes representativas de las distintas configuraciones y diferenciadas de los agrupados en otras categorías.

En la contabilidad financiera se consideran los costos (gastos en la acepción corriente) en su aspecto objetivo o funcional, exponiéndolos de manera tal que permitan formular la información que, según los criterios generalmente aceptados, es capaz de suministrar.

La contabilidad de costos, que es analítica por naturaleza, recolecta, agrupa y analiza los datos relativos al costo, interpretándolos, proyectándolos posteriormente de acuerdo con los requerimientos de la información que se desea obtener, como única manera de conocer en detalle y en conjunto lo que ocurre en el interior de la explotación. Su función es proporcionar información para costear productos, para el planeamiento y control y para la toma de decisiones.

Para la determinación de los costos y para que la información para la toma de decisiones aportada sea pertinente es preciso analizar los elementos que lo componen.

Se considera oportuno hacer una distinción semántica para clasificar conceptos de uso específico y unificar criterios terminológicos entre costos, gastos y desembolsos.

Desembolso es toda salida de dinero por cualquier concepto. Generalmente se lo toma como sinónimo de "gasto", pero conceptualmente y desde el punto de vista financiero, es el medio por el cual se atiende a éstos, ya sea por la salida de efectivo o la creación de un pasivo. 
Gasto es el hecho económico que ocasiona los desembolsos. Su realización es necesaria para atender la adquisición de bienes o servicios como por ejemplo la materia prima, la obtención de la nómina de personal, contrato de seguros, etc. que son considerados gastos y de acuerdo con la acepción de desembolso pueden ser sufragadas en efectivo o contrayendo una deuda (generando un pasivo).

Costo es el consumo de bienes económicos, factores de la producción ya adquiridos (gastos) que se opera en el proceso productivo o distributivo. Cuando se adquieren bienes de uso, materias primas, cuando se contratan seguros, se incurren en gastos de la organización, se pagan gastos por adelantado entre otros, todos ellos no son en sí mismo costos, sino que son gastos activables que se convertirán en costos con posterioridad, gradualmente, al utilizarse o consumirse la materia prima en el proceso productivo, al depreciar las maquinarias (aquí equipos y tecnología física) y cargar la cuota parte correspondiente a la producción, cuando se amortizan los cargos diferidos o cuando se aplican los gastos anticipados al proceso.

Se considerará costo de producción inventariable cuando el consumo de un gasto de capital o a un gasto correlativo a ingresos sea insumido por el producto ya que en caso contrario se estará en presencia de un consumo del período cancelable por ganancias y pérdidas.

Los elementos estructurales que componen el costo de fabricación son, entonces, materias primas, mano de obra constituyendo el costo primo y costos comunes de fabricación, según criterio de directos o indirectos. ${ }^{70}$

Estos criterios dependerán de la unidad de acumulación (unidad de costeo) que se adopte para su acumulación: producto (lote de producción, línea de productos), departamento (centro de costos), proceso o actividad.

La gama de posibilidades de relación de un costo con una unidad de costeo se reduce a tres: directo, indirecto o ajeno.

Son costos directos aquellos que, en forma lógica y práctica, pueden ser asignados en su totalidad a una unidad de costeo, identificándose el material consumido con el producto en que se emplea. ${ }^{72}$ Son costos indirectos o costos comunes aquellos que sólo pueden identificarse parcialmente con una unidad de costeo, o sea, se encuentra relacionada con la unidad de acumulación considerada, pero también lo están con otras. En estos casos, la determinación cuantitativa del costo identificable con cada una de las unidades requiere un proceso de prorrateo, previa elección de una base para éste, no estableciéndose identificación entre los materiales consumidos y el producto.

Son costos ajenos aquellos que no guardan ninguna relación identificable con una determinada unidad de costeo. Cada unidad de acumulación concentra costos directos e 
indirectos, pero no incluye necesariamente en forma total o parcial todos los costos incurridos por la organización, ya que pueden existir costos no relacionados con la unidad relevada. ${ }^{72}$

El elemento distintivo o caracterizante de la condición de directo o indirecto de la materia prima gira en torno a la posibilidad de identificación o no entre el mismo y los productos en fabricación. En consecuencia, será directo el material que se identifica y se emplea en la fabricación de un solo producto o lote de productos semejantes que integran una orden específica de producción y será indirecto en beneficio de más de un producto o lote integrante de distintas órdenes de fabricación. La asignación entre ellas se hará mediante bases de aplicación que indiquen el grado en que dicho material ha beneficiado a cada uno de los productos o lotes.

En conclusión, antes de calificar a un costo como directo o indirecto será necesario identificar la unidad de acumulación de costos a la que está referida la distinción.

La mano de obra representa el factor humano interviniente en la producción y está formada por salarios y demás prestaciones devengadas por todo el personal interviniente en el proceso de producción. También se clasifica como directa e indirecta; pero la primera forma parte del segundo elemento del costo de producción, ya que la indirecta integra lo que se denomina costos comunes de fabricación.

Los costos comunes o costos indirectos de fabricación constituyen el tercer elemento estructural del costo de producción, formado por un conjunto de partidas que son aplicables a un período y que no corresponden a los elementos integrantes del costo primo. Estos costos no pueden identificarse con ninguna orden específica, ya que benefician al conjunto de la producción.

\section{Costos en organizaciones de salud.}

En la producción de un determinado servicio de salud se utilizan una serie de elementos que tienen un costo. La contabilidad de costos aplicada a los servicios de salud consiste en establecer cuánto cuesta cada uno de ellos con el fin de determinar el costo total del servicio involucrado.

Prácticamente cada organización de servicios de salud requiere un propio sistema o, al menos, un ajuste general, pues las características operativas, administrativas, societarias y de equipamiento difieren notablemente unas de otras.

El hospital, siendo una empresa de servicios, elabora un gran número de productos (consultas, egreso hospitalario, horas médico u odontólogo) como resultado de su actividad en cuanto a la realización de prácticas profesionales tales como servicios al paciente, incluyendo servicios de salud bucal en aquellos que tuvieran servicios de atención odontológica. 
La función de producción hospitalaria es un proceso basado en la obtención de un producto final, incremento del nivel de salud y bienestar de las personas, como consecuencia de la práctica de servicios de salud sobre un sustrato constituido por el paciente.

Esta relación entre sustrato (complejidad de la enfermedad) y estructura hospitalaria es la que da origen a los múltiples productos finales.

El primer nivel del proceso se refiere a la configuración de los recursos de las organizaciones o estructura hospitalaria conformada por una serie de imputs (tecnología, personal, equipamiento, unidades dentales etc.) que pueden actuar potencialmente sobre los pacientes.

El segundo nivel del proceso corresponde a la utilización que el paciente hace de los recursos como consecuencia de su relación con el dispositivo asistencial. Es lo que se denomina producción primaria o técnica de productos intermedios (análisis, diagnóstico por imágenes, extracción y prótesis dentaria).

El tercer nivel o de producción secundaria tiene como resultado el producto final hospitalario que es aumentar el nivel de salud del sustrato.

Por lo tanto, la configuración del producto final es consecuencia del agregado y combinación de características propias del paciente, su enfermedad y la evolución de la misma, las cuales, junto con la acción gestora del proceso clínico por parte del profesional de la salud, han determinado el tipo y cantidad de bienes y servicios (productos intermedios) que el paciente ha de recibir.

La evaluación financiera aplicada a los servicios de salud integra el proceso financiero con los otros componentes de la gestión como la comparación del presupuesto de gastos con las erogaciones efectuadas y el nivel de producción alcanzado y la determinación de variaciones. Permite la identificación de errores u omisiones y constituye una guía para la toma de decisiones, operar medidas correctivas y ajustar fases del proceso. ${ }^{55}$ 


\section{CARACTERIZACIÓN DEL PROBLEMA}


La falta de rehabilitación de la Salud Bucal es una de las actividades que impacta negativamente en la lógica organizacional generadora de valor para la desinstitucionalización en la búsqueda de la reinserción social.

La población con problemas mentales es uno de los actores sociales más desvalidos, a los que por su condición se la priva de los derechos reconocidos a todos los seres humanos. En grupos sociales de bajos ingresos esta situación es mucho más compleja, tendiendo con ello a la cronificación al encaminarla a un modelo asilar, donde permanecen recluidos o simplemente detenidos en el tiempo y a veces de por vida ${ }^{37}$ El paciente "hospitalizado" tiene problemas de reconexión con el afuera y pérdida de roles en virtud de la barrera que los separa del ambiente externo.

Paradójicamente, frente a la situación de pauperización que afecta a las instituciones en nuestro país, existiría en esta población una revalorización de las camas del hospital psiquiátrico: muchos pacientes o su familia rechazan la externación, aunque estén en condiciones de recibir el alta médica, ante una situación más hostil que encontrarían en su propio medio.

La realidad transforma a la familia en un estímulo negativo para la nueva inclusión. Cuando sus miembros ingresan al mercado productivo y la familia está organizada eficientemente se torna en uno de los anillos de opresión del sistema social que expulsa a la persona con alteraciones mentales.

El objeto de estudio para el análisis y la comprensión de la temática es la protección jurídica y el fundamento económico de la inclusión de alternativas para el abordaje corporal desde el componente bucal de la salud, en la búsqueda de la desarticulación sintomática hacia el logro de la desinstitucionalización.

La salud como derecho se ha convertido en un tópico social que de tanto reivindicarlo se ha ido vaciando de contenido. Este aspecto expone la contradicción entre la prédica normativa de los derechos humanos, la obligación de proveer el acceso a la salud impuesta a los gobiernos y la realidad que no logra traducirla en acciones concretas; excluye así una franja de la población de los servicios relativos al cuidado de la salud.

Si bien la salud como derecho tiene rango constitucional, la Constitución Argentina de 1853 omite la consideración de la salud. La Convención de 1957 incorporó en el artículo 14 bis una referencia a la Seguridad Social y en la reforma de 1994 solo se hace referencia en el artículo 14 bis y en el 42 en el marco del consumidor. ${ }^{24}$

La salud en sí misma no puede ser garantizada por ningún Estado, asociación o individuo. Sin embargo, la Constitución debería referirse al tema, garantizando el "derecho al acceso equitativo al sistema de salud", al considerar a la salud no como una cuestión individual sino con dimensión social; por lo tanto debería ser un objeto de ocupación responsable del Estado. ${ }^{49}$ 
El derecho fundamental a la atención de la salud (entendiendo por atención una variada gama de servicios como protección ambiental, prevención y promoción de la salud, tratamiento y rehabilitación), principio constitucional fundante, explícitamente tutelado es una extensión del derecho a la vida y a la integridad psicofisica. ${ }^{127}$

La atención de la salud como bien jurídico es diferente de casi todos los demás bienes y servicios y por ello debe basarse en la existencia de una obligación -un derecho- que asegure el acceso de todas las personas a un sistema de servicios de salud. No es por lo tanto un derecho "de" sino un derecho "a", es decir un derecho prestacional, que da lugar a una prestación exigible al Estado y conlleva un gasto social, dependiente de los recursos que se quieran involucrar como voluntad política del momento. ${ }^{129}$

La protección jurídica fortalece a quienes son acreedores de derechos intangibles y de asegurar su cumplimiento. La dependencia del paciente crea una situación de vulnerabilidad e incapacidad para comprender racional y objetivamente sus situaciones de carencia, que en esta población especial -profana por añadidura respecto del profesional experto dotado de poder fáctico- es agravada.

Esta conceptualización es señalada desde la economía como una falla del mercado de la salud, donde el profesional o agente es quien debe tomar las decisiones (iniciar la demanda) en nombre del principal, en una situación de asimetría de la información que muchas veces no inicia sino induce la demanda de atención en un marco de soberanía del consumidor vulnerada o inexistente,

Ante tal desigualdad, nuevos personajes y mecanismos de protección, antes ignorados por los ordenamientos jurídicos y ahora sujetos de derecho, se enfrentan al derecho tradicional referido a las personas abstractas. Sin embargo, estos grupos vulnerables y diferenciados siguen discriminados y relegados del sistema legal. Los operadores jurídicos eluden estos colectivos por lo que aún nos debemos la transformación del modelo asistencial y legal.

En años recientes, en la mayoría de los países industrializados se han incrementado los estudios para valorar la prevalencia de enfermedades dentales y de necesidad de tratamiento en la población en general. En contraposición, se dispone de poca información sobre la condición dental de adultos con enfermedades mentales y del comportamiento y la correspondiente necesidad de tratamiento de estos grupos especiales, en particular un área de la comunidad de gran importancia y que es todavía considerada negligentemente.

Ciertamente el interjuego de factores de riesgo como la edad, incapacidades intelectuales o motoras, falta de higiene bucal, anomalías en la función muscular, así como medicación psicofarmacológica, en pacientes psiquiátricos pueden contribuir a un estado de Salud Bucal pobre. 
Los resultados del estudio de Hede B. $(1995)^{42}$ sobre pacientes institucionalizados en Dinamarca determinaron valores para el indicador Cariados, Perdidos, Obturados, unidad Superficie dentaria (CPOS) (media aritmética y desviación estándar) de 70.5 (41.1) e indicaron que las variables enfermedad mental y tratamiento psiquiátrico influyen sobre la Salud Bucal. El 55\% de las superficies dentarias resultaron cariadas vs. $33 \%$ de las de la población general sin trastornos psiquiátricos.

Pregliasco y col. $(2001)^{123}$ en Italia estudiaron una población de adultos con retraso mental, con un promedio de institucionalización de 28.4 años, y donde el $21.46 \%$ de la muestra eran desdentados totales.

Vigild y col (1993) ${ }^{133}$ clasificó a la población estudiada según la necesidad protética:

Distribución de la Población Estudiada con referencia a los tipos de composición dentaria

Tipos dentarios

Desdentado total maxilar sup. e infer.

Desdentado total max. sup. solamente

Desdentado total max. inf. solamente

Desdentados sin prótesis

Dentados sin prótesis

Dentado max. inf., total max. sup.

Dentado parcial max.inf. y total max. sup.

Dentado parcial max. sup. e inferior

Dentado parc. maxilar sup. solamente

Dentado parcial max. inferior solamente

TOTAL
$\%$

42

9

0

11

21

7

3

1

4

0

98
407

Los resultados de la cohorte de pacientes psiquiátricos institucionalizados estudiados por Angelillo y col. ${ }^{5}$ (1995) en Italia indicaron una alta prevalencia de caries, necesidad de tratamiento y pobre higiene bucal.

La cohorte estudiada por Gabre y col. ${ }^{34}$ (1984-1994) mostró que, al iniciar el seguimiento, el número medio de piezas remanentes fue 20.7 y al finalizar 17, determinando una diferencia altamente significativa $(P<0.0001)$ en los resultados entre los dos puntos de prevalencia. El promedio de incidencia de morbilidad del período fue 3.72 piezas dentarias perdidas.

Del total de pacientes que integraron el estudio de Hernández S.F. ${ }^{43}$ (2002) el 88.82\% presentaron caries, siendo mayor la prevalencia de las mujeres $(55,4 \%)$ que en los varones (44.6\%). 
El estudio de Velazco y col. (1999) ${ }^{132}$ en España, en pacientes psiquiátricos hospitalizados, determinó que el $13.5 \%$ de la población eran desdentados totales con un promedio de 24.9 piezas CPOD.

Rekha y col. (2002) ${ }^{124}$ en la India compararon un grupo de 326 pacientes psiquiátricos con un grupo contol de 156 personas consideradas normales. El 75,5\% de los pacientes del primer grupo exibió experiencias de caries significativamente más alta comparadas con $66 \%$ del grupo control.

Manish Kumar (2006) ${ }^{53}$ atribuye que los valores de caries encontrados en la población estudiada, podrían ser debidos a la concentración de fluoruro del agua de bebida de la ciudad de Dangere, 1.5- 2.2PPM, según un mapeo químico de calidad de agua, llevada acabo en el año 2001 por Bapuj (Instituto de ingeniería y Centro de Tecnología de Dangere)

Más de los dos tercios de la población (67.85\%) está libre de caries. Los valores medios de dientes cariados es 0.6. La prevalencia de pérdida dentaria es de $18.9 \%$, y el $29.9 \%$ requiere extracción, coincidiendo con los resultados de Vigild (1993), que tampoco encuentra registros de piezas obturadas.

Gabre P. y col. (1997) ${ }^{33}$ evaluaron en Suecia 132 pacientes psiquiátricos con un rango etáreo 21-40 años y, aun con valores Cariados, Perdidos, Obturados, unidad Diente (CPOD) significativamente más bajos a los enumerados, encontraron en el componente perdidos la mayor carga de la enfermedad.

Al Hisayat y col. (2006) $)^{1}$ evaluaron en pacientes psiquiátricos la prevalencia, distribución y factores asociados a la atrición o desgaste dentario. Se describió que el $65 \%$ de la población se encontraba desempleada, el 28.7 \% eran fumadores y que el $53.9 \%$ tuvieron desórdenes psicológicos con una duración de 1 a 8 años y el $29.4 \%$ durante más de 8 años. El número de piezas perdidas fue $6.8 \pm 5.9$. La prevalencia de desgaste con más de grado 3 fue de 90.9 \% - la más alta prevalencia fue encontrada en el rango 26-35 años.

Los pacientes con depresión y ansiedad revelaron los más altos grados de desgaste, sugiriendo que la enfermedad en sí, o la medicación recibida podrían influenciar los valores de desgaste dentario.

Los estudios epidemiológicos disponibles sobre el nivel de Salud Bucal y Necesidad de Tratamiento de este grupo de pacientes muestran alta prevalencia de caries y necesidad de tratamiento. iii

Durante recientes décadas ha ido creciendo el interés en cuantificar las consecuencias que afectan la función, el confort y la capacidad para realizar las actividades diarias. La

\footnotetext{
iii El anexo № 1 Situación de Salud Bucal en Pacientes Psiquiátricos Institucionalizados resume los datos relevados por los diferentes autores.
} 
valoración de la disfunción, incomodidad o inhabilidad referida colectivamente como impacto social producirá beneficios futuros indudables.

En primer término, las valoraciones de las prioridades pueden ser mejoradas. Las mediciones del impacto social individuales o de grupos específicos, como nuestro mercado meta (adultos psiquiátricos), podrán ser usados con datos clínicos para la formulación de programas a fin de resolver la mayor parte de las condiciones disfuncionales.

La interpretación de los procesos patológicos es fundamental para su prevención y el manejo clínico. Los conocimientos sistemáticos acerca de las consecuencias de la enfermedad constituyen un valor adicional en la persecución de los objetivos.

En segundo término, estas valoraciones pueden mejorar la interpretación de la Salud Bucal y sus consecuencias relacionadas con el comportamiento del o los individuos. Percepciones individuales del impacto han sido identificadas como un motivo para la prevención y la generación de comportamientos en búsqueda de cuidados. La identificación de esas percepciones ofrece una oportunidad de promover comportamientos apropiados más efectivamente.

Un tercer beneficio es atraer la atención de la importancia de las enfermedades orales y sus consecuencias como parte de la salud general.

La verdadera significación del impacto social de las enfermedades bucales se percibe cuando se comienzan a analizar los informes de las pérdidas de días de escolaridad o de trabajo, por esa causa.

Una variación de los diferentes métodos de valoración ubica a los desórdenes funcionales y sus consecuencias sociales en resultados de verdadera jerarquía.

Un estudio llevado a cabo en una institución neuropsiquiátrica de la Pcia. de Buenos Aires permitió establecer la situación de Salud Bucal de adultos institucionalizados con trastornos mentales y del comportamiento. ${ }^{80}$ La muestra se integró con 207 pacientes institucionalizados (I) con una edad promedio de 48.97 (10.94) años, rango 20-65 y un tiempo de internación que registró un valor media aritmética de 13.49 (10.56) años. Un grupo de 102 pacientes ambulatorios, sin diagnóstico de trastornos mentales fue considerado como grupo control (C).

Para describir la situación clínica se usó el indicador CPOS, que cuantifica la cantidad de superficies cariadas, perdidas y obturadas. Los resultados revelaron una media (desviación estándar) CPO para I de 89.54 (41.91) y para C de 52.32 (32.46) encontrándose diferencia significativa entre ambos grupos $\mathrm{P}<0.05$.

La presente investigación reconoce en este estudio un antecedente, ya que encuentra el mayor problema clínico en el estado de desdentamiento de esta población psiquiátrica, por otro lado coincidente, en cuanto a la carga de la enfermedad, con los resultados relevados por los autores citados. 
Así, en un "continuo de prevención", la rehabilitación de las piezas perdidas evitaría la discapacidad total y sus consecuencias residuales.

La rehabilitación bucal de adultos psiquiátricos en proceso de desinstitucionalización haría suponer que determinadas preocupaciones por la autoimagen, el verse bien, brindar un aspecto agradable a los demás, sean indicadores del desarrollo de conductas impulsoras de cambios destinados a lograrlo y por lo tanto mejoraría la calidad de vida. Este proceso tiene como objetivo mejorar la vida de relación para que los pacientes comiencen una etapa de reaprendizaje de destrezas, reconocimiento del ámbito del trabajo y capacidades perdidas durante los años de institucionalización.

Con esta investigación se pretende conocer la situación de Salud Bucal de adultos con alteraciones mentales, identificar nuevos enfoques legales y prácticas jurisprudenciales, que constituyan el marco jurídico apto para velar por los derechos humanos y el resguardo de estos grupos vulnerables, así como proporcionar los fundamentos económicos para la inclusión de la rehabilitación bucal a un programa integral de rehabilitación para la externación como estrategia facilitadora de la inserción psicosocial, siendo la socialización de la existencia una vía para la recuperación de la salud. 


\section{PROPÓSITO Y OBJETIVOS ESPECÍFICOS}

OBJETIVO GENERAL. 
Reconocer que la rehabilitación de la Salud Bucal como componente esencial del derecho a la Salud, es una estrategia facilitadora de la inclusión social de adultos con problemas de Salud Mental.

\section{OBJETIVOS ESPECÍFICOS.}

Describir la situación de Salud Bucal de la población objetivo.

Planificar la integración del componente bucal de la salud al modelo asistencial para el logro de un abordaje integral de la salud.

Incorporar el análisis de la estructura de costos a un proyecto de rehabilitación de la Salud Bucal para adultos con problemas de salud Mental en proceso de reinserción social. 


\section{PROCESOS METODOLÓGICOS}




\section{Tipo de investigación}

El proyecto incluyó tres fases:

a) diagnóstica: consistente en la determinación de la situación del estado bucal (estudio observacional descriptivo transversal).

b) documental jurídica (estudio observacional descriptivo): recopilación y selección y ordenamiento de información secundaria para la determinación del marco jurídico.

c) análisis de la estructura de costos de la rehabilitación bucal.

\section{Universo de estudio}

a) Diagnóstica:

\section{a.1) Situación de las instituciones neuropsiquiátricas.}

Se relevó y describió la ubicación, tipo, cantidad de usuarios y costo persona año de hospitales neuropsiquiátricos, y de instituciones sede de los programas de externación en la Provincia de Buenos Aires, en base a información secundaria otenida mediante entrevistas semiestructuradas a informantes clave.

\section{a.2) Situación de salud bucal.}

La población diana estuvo integrada por pacientes neuropsiquiátricos de la Provincia de Buenos Aires.

El universo de estudio estuvo integrado por:

a) grupo en proceso de Desinstitucionalización (GD), bajo programa de Externación y Rehabilitación Asistida ${ }^{78}$ para la integración social; constituido por adultos psiquiátricos con internaciones de mediano y largo plazo - que no padecieran inhabilidades extremas que les impidieran su autovalimiento básico o implicaran factores de riesgo conductuales - ingresados a un programa de rehabilitación y externación asistida dependiente del hospital neuropsiquiátrico Alejandro Korn de la Provincia de Buenos Aires.

b) grupo Institucionalizado (GI) compuesto por adultos con trastornos mentales internados en el hospital neuropsiquiátrico Alejandro Korn.

c) grupo control (GC) conformado por adultos ambulatorios sin diagnóstico de trastornos mentales, concurrentes al servicio de odontología que posee dicho hospital.

Se consideró condición de emplazamiento que los tres grupos fueran asistidos en el mismo servicio de odontología. 
Para describir la situación basal del componente bucal de la salud, como reconocimiento previo se seleccionó una muestra aleatoria mediante muestreo sistemático y, para la integración, se usaron los registros institucionales.

Para los adultos de los grupos GD y Gl se transcribieron de las historias clínicas los diagnósticos de los trastornos mentales y se categorizaron siguiendo los criterios DSM IV.

b) Documental jurídica.

Documentos internacionales para la protección jurídica de Derechos Humanos, discapacidad y discapacidad mental: plexo legal (artículos de leyes sancionadas) y jurisprudencial (sentencias en segunda instancia) a nivel nacional y provincial.

\section{Criterios de exclusión}

a)

- Pacientes que excedan la edad de la población económicamente activa. (PEA)

- Pacientes que en el momento del estudio estuvieran fuera del alcance del programa de externación.

- Pacientes con alteraciones de la función motora de orden general tipificadas como graves.

- Pacientes que, por las características, síntomas y trastornos asociados de la patología psiquiátrica, el criterio médico considera un riesgo la utilización de prótesis.

- Pacientes que padecieran, conjuntamente con la patología psiquiátrica, otras enfermedades de carácter general en estadío terminal.

b)

- Decretos nacionales

- Resoluciones ministeriales

\section{Variables}

Para la descripción del perfil epidemiológico basal se aislaron variables cualitativas como sexo, edad, patología psiquiátrica, cuya evolución no se vio afectada por las otras variables estudiadas; se las consideró, por lo tanto, variables independientes.

Las variables que por la interacción con las anteriores permiten cuantificar la relación estudiada fueron consideradas como dependientes: salud-enfermedad bucal como dato de morbilidad (en sus dos dimensiones: lesiones de caries $C$ y en estados que el observador considera como incurable o extracción indicada Ei.; atención (tratamiento realizado: 
resolución por extracción $\mathrm{P}^{\mathrm{i} v} \mathrm{o}$ por obturación de la pieza dentaria $\mathrm{O}$, e incapacidad masticatoria, estética y fonética.

\section{Indicadores}

Se usaron indicadores sociodemográficos para describir la situación del universo de estudio (información secundaria), tales como cantidad de población, necesidades básicas insatisfechas, cobertura de Obra Social.

Para enumerar la pérdida de la pieza dentaria como consecuencia residual de la enfermedad bucal se usaron indicadores clínicos directos (observación) que permitieron cuantificar los datos de morbi-mortalidad y de atención estudiados.

Para establecer la prevalencia del fenómeno analizado, evaluar su extensión y tratamiento se utilizó el indicador CPOD.

Las abreviaturas indican:

C: lesiones de caries

Ei: lesiones de caries incurables (o caries con extracción indicada a criterio del observador).

Se consideraron dos dimensiones de la variable enfermedad (caries) por tener evolución y costos de resolución diferentes.

$\mathrm{P}$ : pérdida dentaria.

O: obturación (caries tratadas y rehabilitadas).

Este indicador es considerado pertinente y sensible para la medición de la magnitud de las variables estudiadas, ya que expresa numéricamente el valor de C (cariados), Ei (extracción indicada), P (perdidos) y O (obturados) en la unidad establecida:

- $\quad \mathrm{D}=$ diente: pondera como unidad de análisis el diente en su totalidad indicando el número de dientes CPO por individuo.

iv La abreviatura P puede abarcar a piezas perdidas por avulsión dentaria. 


\section{Descripción comparativa de los códigos de caries usados en el estudio}

La caries dental se describió y registró en base a una modificación de los códigos WHO (World Health Organization 1979), no considerando el código WHO1.

\section{Código Estudio}

C0: Sup. Intactas

Caries de esmalte sin pérdida de sustancia detectable clinicamente

\section{C1: No usado}

C2: Caries de esmalte con pérdida de sustancia detectable

C3: Caries dentinaria

C4: Cavidades profundas con compromiso pulpar

\section{Códigos WHO}

WHO 1: Caries iniciales sin detección clínica de pérdida de sustancia (Incluye código $\mathrm{CO}$ )

WHO 2: Caries de esmalte con pérdida de sustancia detectable WHO 3: Caries dentinaria WHO 4: Cavidades profundas con compromiso pulpar

Para cuantificar la situación de incapacidad de la funcionalidad del subsistema dentario se usó como indicador el baremo de Bertini $^{77}$ que norma el grado de incapacidad para patologías y/o secuelas por pérdida de la función masticatoria, estética y fonética:

\begin{tabular}{|llcccccccc|}
\hline Función & I.c & I.I & C & 1Pm & $2 \mathrm{Pm}$ & $1 \mathrm{M}$ & $2 \mathrm{M}$ & $3 \mathrm{M}$ \\
\hline Masticatoria & 1 & 1 & 2 & 3 & 4 & 6 & 6 & 2 \\
Estética & $\begin{array}{l}\text { Superior } \\
\text { Inferior }\end{array}$ & 8 & 7 & 7 & 3 & 1.5 & 1 & 0.5 & - \\
& 6 & 5 & 5 & 3 & 1.5 & 1 & 0.5 & - \\
Fonética & $\begin{array}{l}\text { Superior } \\
\text { Inferior }\end{array}$ & 8 & 7 & 7 & 3 & 1.5 & 1 & 0.5 & - \\
& 6 & 5 & 5 & 3 & 1.5 & 1 & 0.5 & - \\
\hline
\end{tabular}

Referencias:

$\begin{array}{llll}\text { I.c Incisivo central } & \text { I.I Incisivo lateral } & \text { C Canino } \\ \text { Pm } & \text { Premolar } & \text { M Molar }\left(1^{\circ}, 2^{\circ} \text { y } 3^{\circ}\right)\end{array}$
Valores expresados en porcentuales. 
Se ponderó la pieza dentaria perdida, excluyendo de la valoración la disminución provocada por cualquier pérdida de sustancia o por restauración de la misma.

Con la pérdida de una pieza dentaria no se pierde solamente la funcionalidad de la misma, sino que, por migración de las vecinas, extrusión de las antagonistas, disminución de la dimensión vertical, se altera la armonía oclusal, se rompe el equilibrio y se anula fisiológicamente la función dentaria. Para la función masticatoria se sumó a la valoración la que corresponde al antagonista perdido ya que también pierde su funcionalidad, por lo tanto el valor se halla duplicado.

\section{Examinaciones clínicas}

Las examinaciones clínicas fueron realizadas, para los tres grupos, por un solo observador con espejo descartable y luz natural.

\section{c) Análisis de la estructura de costos de la rehabilitación bucal.}

\section{Unidad de análisis:}

Se procedió a relevar las necesidades de materia prima, mano de obra, costos directos fijos, costos indirectos (carga fabril) y la producción para la reposición de piezas dentarias perdidas (rehabilitación) en base a prótesis removibles. La valorización de los costos se efectuó en base a valores nominales o corrientes.

\section{Materia prima:}

La valorización del costo de la materia prima se realizó en base a valores corrientes, promedio de la consulta realizada a 3 proveedores de la ciudad de La Plata al 30/ 11/ 2010.

La tipificación y cantidad de insumos, así como los tiempos operatorios (costos variables) siguieron las normas de trabajo del Programa Nacional de Garantía de Calidad de la Atención Odontológica de la Confederación Odontológica de la República Argentina ${ }^{20}$ (CORA, marzo 1995). Se analizó la estructura de costos de los códigos 04.02.01, prótesis removible y código 04.02.14 prótesis completa.

La valuación de la aparatología protética se realizó en base a los valores nominales promedio de la consulta realizada a 3 laboratorios de prótesis, auxiliares de la odontología, uno de uso frecuente por los profesionales de la Institución y los restantes sin relación con 
los mismos, en la misma zona geográfica que el primero, ya que la organización no cuenta con servicios propios de producción y, por lo tanto, terceriza su realización.

\section{Mano de obra:}

Se tomó como base de cálculo la cantidad de personal por categoría y horas de trabajo efectivas aplicadas a la tecnología de operación.

La estimación se realizó en base a 1 odontólogo grado $B$, clase 33, con régimen horario de 36 horas semanales (odontólogo de planta y 1 odontólogo residente de segundo año, segundo nivel, casado.

La mano de obra para el odontólogo de planta permanente se valuó según los valores monetarios de escala salarial del Decreto Ley 10471/ Julio 2010 de la provincia de Buenos Aires, vigentes al momento del estudio (Valor Base \$ 921.36). Anexo № 2.

Para el residente se usó los de la Resolución 426-17/2/92 del Ministerio de Salud de la Provincia de Buenos Aires, también en vigencia. (Valor Base \$1433.26). Anexo № 3.

Se consideró como personal auxiliar o de apoyo al personal profesional una asistente dental y una recepcionista de 36 horas semanales. La valuación de este personal se hizo en base a los valores monetarios de la escala salarial del Decreto Ley 10430/ Julio 2010 de la provincia de Buenos Aires, vigentes y correspondientes a la categoría 24, módulo 3818 más las bonificaciones que señala la escala para dicha categoría. Anexo № 4 .

Se incorporó el costo del total de mano/de obra directo, la incidencia del sueldo anual complementario, licencias pagas, cargas sociales a cargo del empleador, ART.

Las licencias se estimaron en base a lo dispuesto por el Decreto Ley 10430 (Pcia Bs. As) en el artículo (ART.) 37; y para la licencia anual ordinaria según el ART. 39 se consideraron 21 días para la categoría odontólogo de planta y 14 días para el residente.

Se excluyeron del cálculo las licencias comprendidas en el ART.43 (maternidad, paternidad y alimentación y cuidado del hijo), en el 47 (adopción) y en el 49 (enfermedades prolongadas o accidentes de trabajo).

\section{Costos directos fijos.}

Se consideró la amortización de 1 unidad dental, 1 compresor 5.5HP,500I,T/B, en línea, baja/baja y 2 turbinas super torque (período de amortización 10, 5 y 3 años respectivamente a partir de la fecha de la inversión de los activos). Se usaron valores nominales de precios estándar de mercado, promedio de 3 consultas realizadas. 
Costos indirectos (carga fabril).

Se tomaron valores del $100 \%$ de los costos variables y semivariables.

\section{Producción.}

Para la etapa inicial del proyecto se consideró la cantidad de demanda determinada por el tamaño de la muestra estudiada. Para poder estimar la máxima incidencia esperada, considerando la cronicidad de la patología, el promedio alto del tiempo de internación y el número bajo de pacientes en condiciones de egreso institucional para integrar un programa de externación para la reinserción social - se realizaron entrevistas a informantes clave para valorar cantidad de población anual (máxima incidencia esperada) que ingresa al programa de externación.

\section{Instrumentos para la recolección de datos}

Los datos de la información secundaria relevada mediante entrevistas semiestructuradas a informantes clave fueron inscriptos en planillas ad hoc.

Los datos que describen la situación basal del componente bucal de la salud obtenidos por observación directa fueron inscriptos en una ficha odontológica individual, instrumento estandarizado con un odontograma.

Este diagrama, que representa a las piezas dentarias, permitió el registro (sobre la base de símbolos predeterminados) de toda la patología prevalente, así como la resolución terapéutica realizada con anterioridad al momento de la observación, con precisión de la pieza dentaria y de cada una de las cinco superficies que la componen. (Anexo № 6 )

\section{Análisis estadístico}

Las observaciones fueron presentadas para el tratamiento biométrico y estadístico como datos de enumeración en escala ordinal.

Se estimaron, como dato de tendencia central, la media aritmética y mediana y de dispersión la desviación estándar y rango. 
Se analizó la distribución de los valores CPOD y de los datos de la funcionalidad masticatoria y estética/fonética mediante análisis gráficos Box Plot y análisis numéricos Simetría-kurtosis, prueba Shapiro Wilks y Shapiro Francia.

Se usaron como prueba de hipótesis t de Student, ANOVA, Chi cuadrado y análisis de regresión de las variables. Se usó el coeficiente de correlación $r$ de Pearson. Como alternativa no paramétrica, las de Man Witney, Kruskall Wallis y el coeficiente no paramétrico de Spearman. 


\section{ANÁLISIS DE LA INFORMACIÓN}




\section{a) Fase diagnóstica.}

\section{a.1) Situación de las instituciones neuropsiquiátricas.}

La Provincia de Buenos Aires está integrada por 124 municipios que el Ministerio de Salud divide en 12 regiones sanitarias. Se describe a continuación la capacidad instalada, valores presupuestarios y costos estimados por persona para la atención de las alteraciones de salud mental:

\section{$\underline{\text { Hospitales Interzonales; }}$}

Región sanitaria IV

Hospital Interzonal "José a. Estévez". Garibaldi 1661. Temperley. Lomas de Zamora.

Para mujeres: 1004 camas.

Presupuesto anual 2011 (Pesos, valor nominal) 53127300.

Costo estimado persona/año: 52915.64, persona/mes 4409.64

Región sanitaria VII

Hospital Interzonal Especializado Neuropsiquiátrico Colonia "Domingo Cabred".Avda Dr. Cabred S/N Open Door. Lujan

Para varones: 1008 camas.

Presupuesto anual 2011 (Pesos, valor nominal) 59497200.

Costo estimado persona/año: 59025, persona/mes 4918.75 .

\section{Región sanitaria XI}

Hospital Interzonal de Agudos y Crónicos "Dr. Alejandro Korn" Calle 520 e/ 173 y 178 S/N Melchor Romero. La Plata.

Hospital general: 168 camas

Hospital Neuropsiquiátrico: varones y mujeres: 957 camas.

Presupuesto anual 2011 (Pesos, valor nominal) 130295300.

Costo estimado persona/año: 68074.87 , persona/mes 5672.90

Los valores fueron estimados considerando que se destina el $50 \%$ del valor del presupuesto anual (65147650) para las camas psiquiátricas, según informe.

Fuente: Ministerio de Salud. Pcia de Buenos Aires. 


\section{Hospitales subzonales:}

Región sanitaria VIII

Hospital Subzonal Especializado Neuropsiquiátrico "Dr. Domingo Taraborelli". Calle 49 № 1868. Necochea.

Varones y mujeres: 80 camas.

Presupuesto anual 2011 (Pesos, valor nominal) 10222300.

Costo estimado persona/año: 127778.75, persona/mes 10648.23.

La provincia cuenta con 4 hospitales especializados en Discapacidad mental, llamados Especializados, nombre que sustituye a la anterior denominación de psicopedagógicos:

Región sanitaria XI

Hospital Subzonal Especializado "Ramos Mejía" Calle 143 e/521 y522. La Granja. La Plata.

Para varones: 80 camas.

Hospital Local Especializado "A "San Lucas. Calle 52 e/ 191 y 197 S/N Lisandro Olmos. La Plata.

Niños y niñas: 40 camas.

Hospital Subzonal Especializado "Dr José Ingenieros" Calle 161 y 514. Melchor Romero. La Plata.

Varones: 80 camas.

Hospital Subzonal Especializado "Dr, Dardo Rocha". María Auxiliadora S/N Uribelarrea. Cañuelas

Para Varones: 97 camas.

Son hospitales que atienden Retraso mental con escaso giro cama por las características de la población atendida.

\section{Proceso de Desinstitucionalización:}

Hay dos modelos de tratamiento en externación de pacientes:

- Curaduría Provincial

- Programas dependientes de los hospitales con internación

Hospital José A. Estévez: Programa PREA

Hospital Alejandro Korn:

Casa de Pre- Alta (calle 56 e/ 9 y 10 La Plata). 
Cantidad de usuarios: 69

Centro Franco Basaglia. (calle 49 e/ 17 y 18 La Plata)

Cantidad de usuarios: 44

Centro Pichon Rivière. (calle 37e/ 6 y 7 La Plata)

Cantidad de usuarios: 93

Hay una lista de espera de más de 300 usuarios quienes, estando en condiciones de lograr un nivel de autonomía para su externación, carecen de recursos financieros para alquiler de vivienda.

\section{Indicadores Socio Demográficos}

Región sanitaria XI:

Población total (al 12/ 2010) 1172240

Población NBI (\% al 12/2008).

Población sin cobertura de obra Social(al 12/2004)... 432272

Población sin cobertura de obra Social(\%al 12/2004) 42

Fuente: Ministerio de Salud. Pcia de Buenos Aires.

Dirección Provincial de Estadística.

\section{a.2) Situación del componente bucal de la salud en adultos con alteraciones mentales en proceso de desinstitucionalización.}

La muestra estudiada se integró con 385 adultos: 56 con alteraciones mentales en proceso de desinstitucionalización (GD), 220 institucionalizados (Gl) y 109 adultos ambulatorios sin diagnóstico de trastornos mentales, considerado como grupo control (GC), con una edad expresada en valores media aritmética (SD) de 48.02 (9.02) para GD; rango 28-65; 49.65 (10.90) para Gl; rango 20-65 y 40.92 (10.45), rango 24 - 65 para GC.

Las características de la muestra se observan en la tabla I. No se encontró diferencia significativa $\mathrm{P}>0.05$ entre sexos en los grupos estudiados. 
Tabla I

CARACTERÍSTICAS DE LA MUESTRA. 2010.

\begin{tabular}{|c|c|cc|ccc|c|cc|}
\hline & \multicolumn{3}{|c|}{ PRE - DES } & \multicolumn{3}{c|}{ INSTITUC. } & \multicolumn{3}{c|}{ CONTROL } \\
\hline & \multicolumn{3}{|c|}{ EDAD } & \multicolumn{3}{c|}{ EDAD } & \multicolumn{3}{c|}{ EDAD } \\
\hline & $\mathrm{n}$ & $\bar{X}$ & S.D. & $\mathrm{n}$ & $\bar{X}$ & S.D. & $\mathrm{n}$ & $\bar{X}$ & S.D \\
\hline VARONES & 28 & 46.25 & 9.31 & 111 & 49.32 & 12.13 & 50 & 40.72 & 10.84 \\
\hline MUJERES & 28 & 49.78 & 8.52 & 109 & 50.07 & 9.52 & 59 & 40.58 & 10.19 \\
\hline TOTAL & 56 & 48.02 & 9.02 & 220 & 49.65 & 10.90 & 109 & 40,65 & 10.45 \\
\hline
\end{tabular}

$P>0.05$ entre sexos / grupos

Tiempo de internación $\bar{X} 13.86$ S.D. 10.76 años

Tiempo de predesinst. $X \quad 3.02$ S.D. 2.90 años

El análisis gráfico de los valores CPOD indica una distribución normal de los datos, con un valor mediana de 18 (rango 5-32). Los resultados del análisis de normalidad mediante métodos numéricos son: Shapiro Wilk P 0.8744, Shapiro Francia P 0.9177 y Asimetría Kurtosis $\mathrm{P}$ 0.8188, no son significativos $\mathrm{P}>0.05$ como lo muestra el gráfico I. 
Gráfico I

CPOD Predesinstitucionalizados

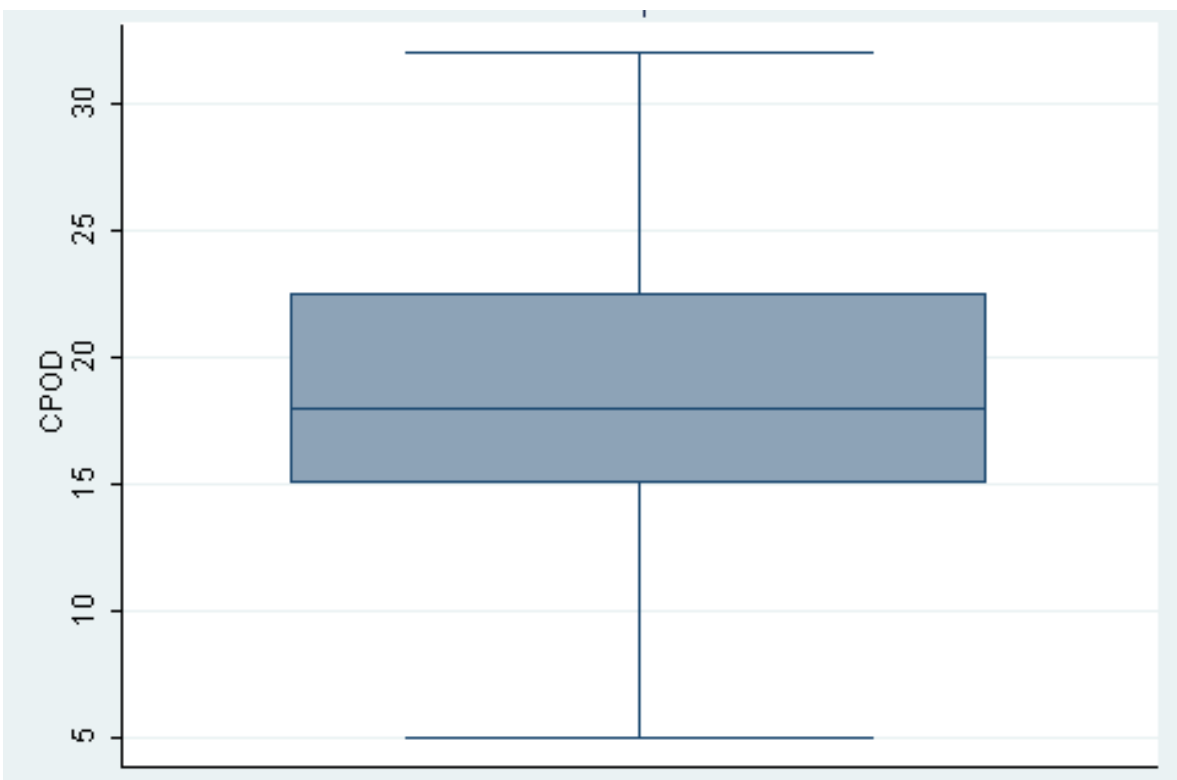

Shapiro-Wilk: 0.8744

Shapiro-Francia: 0.9177

Skewness/Kurtosis:0.8188

Gráfico II

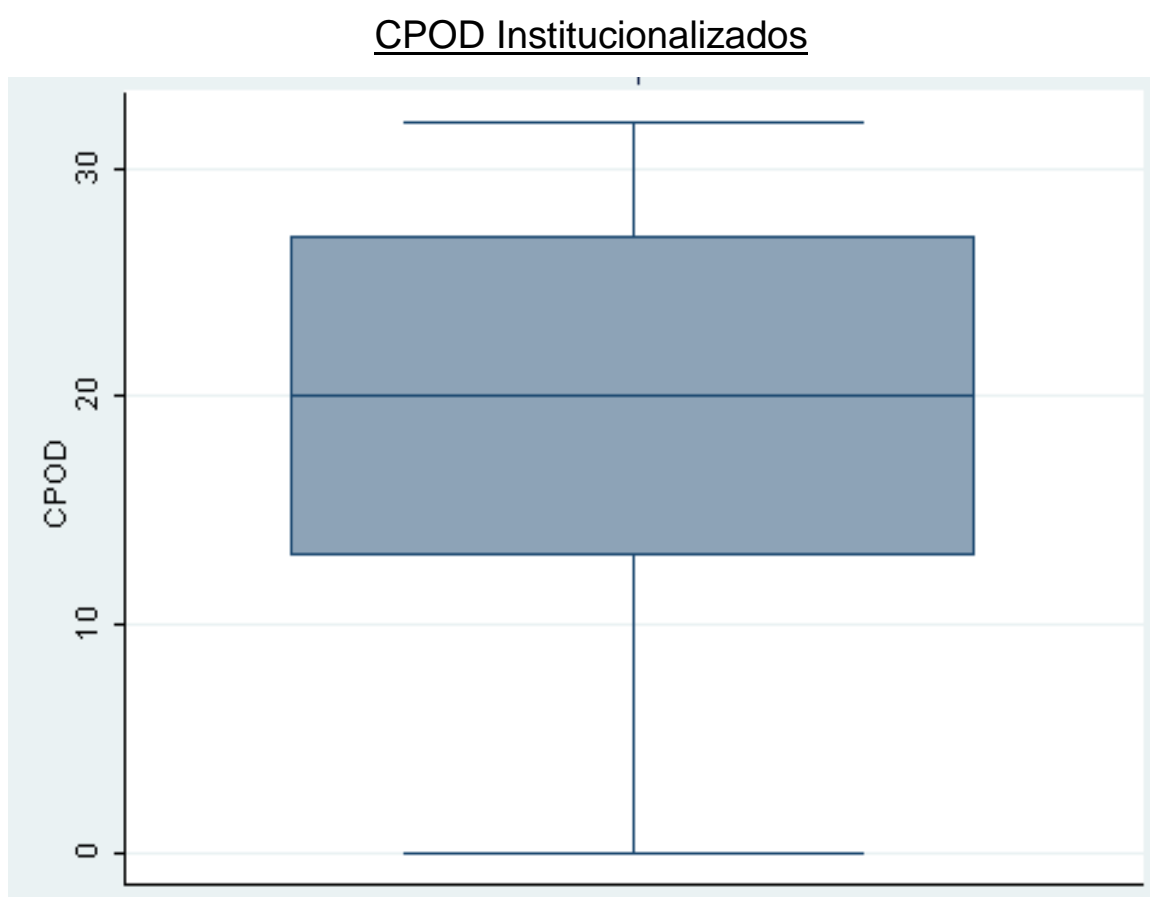

${ }^{*}$ Shapiro-Wilk: 0.00436

*Shapiro-Francia: 0.01198

*Skewness/Kurtosis: 0.0000 
${ }^{*} \mathrm{P}<0.05$

El gráfico II muestra una distribución no gausiana de los valores CPOD para los adultos Institucionalizados, con valor mediana 20 (rango 2-32).

Los resultados del análisis de normalidad mediante los métodos numéricos son Shapiro Wilk P 0,0043, Shapiro Francia P 0.01198 y Asimetría- Kurtosis $P 0.0000 P<0.05$ :

El gráfico III muestra una distribución no gausiana para los valores CPOD del grupo considerado control:

Gráfico III

CPOD CONTROL

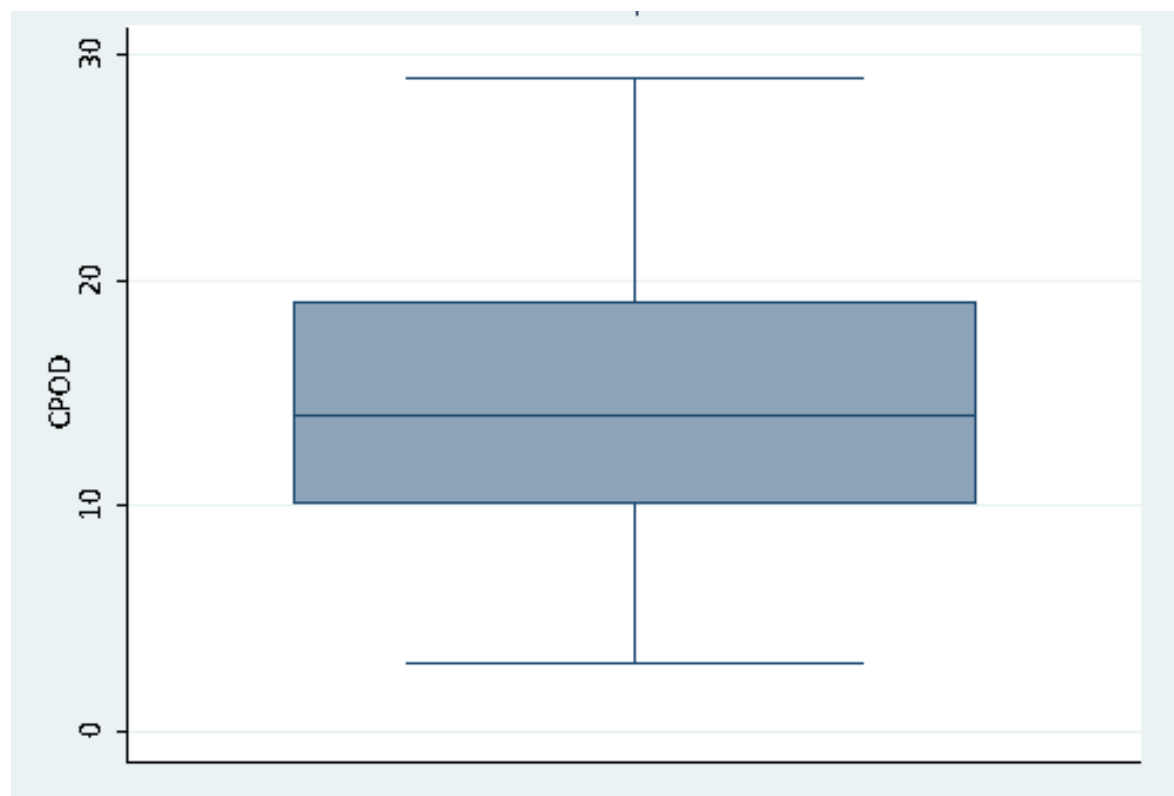

Shapiro - Wilk: $0.4559 \quad$ Skewness/Kurtosis: $0.1940 \quad$ Shapiro Francia: 0.7785

Se enumeró la consecuencia residual de la enfermedad bucal usando el indicador CPO unidad diente (CPOD) determinando para el grupo Predesinstitucionalizado un valor media aritmética (SD), de 18.75 (6.19) dientes afectados. 


\section{Tabla II}

SALUD BUCAL (CPOD) EXPRESADA COMO VALOR PROMEDIO (SD) POR SEXO EN PACIENTES PSIQUIÁTRICOS PREDESINSTITUCIONALIZADOS. 2010

\begin{tabular}{|c|c|c|c|c|c|c|c|}
\hline \multirow{2}{*}{ SEXO } & \multirow{2}{*}{$\mathbf{n}$} & \multirow{2}{*}{ C } & \multirow{2}{*}{ Ei* } & \multirow{2}{*}{ E } & & \multicolumn{2}{|c|}{ CPOD } \\
\hline & & & & & 0 & $\overline{\bar{x}}$ & $\overline{S D}$ \\
\hline FEM. & 28 & 0.96 & 0.32 & 17.53 & 1.11 & 19.93 & 6.56 \\
\hline MASC & 28 & 1.78 & 1.57 & 12.46 & 1.75 & 17.57 & 5.69 \\
\hline TOTAL & 56 & 1.37 & 0.95 & 15 & 1.43 & 18.75 & 6.19 \\
\hline
\end{tabular}

$\begin{array}{ll}\text { * Extracción indicada } & P \\ 0.1565\end{array}$

\section{Tabla III}

SALUD BUCAL (CPOD) EXPRESADA COMO VALOR PROMEDIO (SD) POR SEXO EN PACIENTES PSIQUIÁTRICOS INSTITUCIONALIZADOS. 2010.

\begin{tabular}{|c|c|c|c|c|c|c|c|}
\hline \multirow{2}{*}{ SEXO } & \multirow{2}{*}{ n } & \multirow{2}{*}{ C } & \multirow{2}{*}{ Ei* } & \multirow{2}{*}{$\mathbf{E}$} & & \multicolumn{2}{|c|}{ CPOD } \\
\hline & & & & & $U$ & $\overline{\mathbf{X}}$ & SD \\
\hline FEM. & 109 & 1.14 & 1.43 & 17.10 & 0.70 & 20.37 & 7.42 \\
\hline MASC. & 111 & 1.36 & 2.55 & 14.83 & 0.24 & 18.98 & 8.95 \\
\hline TOTAL & 220 & 1.25 & 1.99 & 15.95 & 0.46 & 19.67 & 8.24 \\
\hline
\end{tabular}

* Extracción indicada

P 0.8934 
La muestra de pacientes Institucionalizados mostró un valor media aritmética de 19.67 dientes afectados y una dispersión de 8.24. Se encontraron valores mayores para mujeres respecto a los varones, pero la diferencia no fue significativa $\mathrm{P} 0.8934$ como se observa en la tabla II.

Tampoco se encontró diferencia significativa en el análisis de los valores del indicador $\mathrm{CPO}$, usado en el estudio para medir la consecuencia residual de la enfermedad bucal entre los pacientes Institucionalizados y los que están en proceso de Desinstitucionalización $\mathrm{P}$ 0.7818 .

La correlación entre las variables edad y CPOD es $r 0.4423 \mathrm{P}<0.006$ (significatividad 5\%). El coeficiente de determinación para las variables edad, sexo y patologías psiquiátricas, incluidas en el análisis de regresión es 0.2343 para la cantidad de dientes cariados (C), perdidos (P) y obturados (O) P 0.194 quedando $76.57 \%$ de la carga de la enfermedad, medida por el indicador CPOD determinadas por variables no incluidas entre las estudiadas.

Los resultados de los test no paramétricos Man Whitney y Kruskall Wallis tampoco mostraron diferencias significativas $\mathrm{P} 0.1187$ y $\mathrm{P} 0.1195$ respectivamente.

Se analizó mediante ANOVA los valores CPOD según la categorización del diagnóstico médico existente en las historias clínicas, siguiendo criterios DSM IV. Para los adultos en proceso de Desinstitucionalización (GD), las diferencias de las varianzas entre los valores CPOD de las categorías analizadas no fueron significativas:

SALUD BUCAL (CPOD) EXPRESADO COMO VALOR PROMEDIO (SD) POR SEXO EN PACIENTES PREDESINSTITUCIONALIZADOS SEGÚN DIAGNÓSTICO DE ALTERACIÓN MENTAL 2010

\begin{tabular}{|c|c|r|c|c|c|}
\hline \multirow{2}{*}{ Patología } & \multirow{2}{*}{ Frecuencia } & \multicolumn{2}{|c|}{ CPOD } & \multicolumn{2}{c|}{ CÓDIGO } \\
\cline { 3 - 6 } & & Media & S.D. & DSM IV & CIE 10 \\
\hline Esquizofrenia & 42 & 19.78 & 5.88 & 5 & F20 \\
\hline Retraso Mental & 10 & 15.8 & 6.97 & 1 & F70-F79 \\
\hline Uso alcohol & 4 & 15.25 & 4.99 & 4 & F10-F19 \\
\hline Total & 56 & 18.75 & 6.19 & & \\
\hline P 0.093 & & &
\end{tabular}

Para el grupo de pacientes Institucionalizados tampoco se encontró diferencia significativa en los valores CPOD según las alteraciones estudiadas, como lo muestran los siguientes resultados: 


\section{SALUD BUCAL (CPOD) EXPRESADO COMO VALOR PROMEDIO (SD) POR SEXO EN PACIENTES INSTITUCIONALIZADOS SEGÚN DIAGNÓSTICO DE ALTERACIÓN MENTAL 2010}

\begin{tabular}{|c|c|c|c|c|c|}
\hline \multirow{2}{*}{ Patología } & \multirow{2}{*}{ Frecuencia } & \multicolumn{2}{|c|}{ CPOD } & \multicolumn{2}{c|}{ CÓDIGO } \\
\cline { 3 - 6 } & & Media & S.D. & DSM IV & CIE 10 \\
\hline Esquizofrenia & 96 & 20.98 & 7.93 & 5 & F20 \\
\hline Retraso Mental & 73 & 18.31 & 7.84 & 1 & F70-F79 \\
\hline Psicosis & 35 & 19.2 & 9.83 & 5 & F29 \\
\hline Uso alcohol & 16 & 19 & 7.59 & 4 & F10-F19 \\
\hline Total & 220 & 19.67 & 8.24 & & \\
\hline
\end{tabular}

P 0.2023

La situación de la Salud Bucal de los adultos sin diagnóstico de alteraciones mentales, considerados grupo control (GC) se observa en la tabla IV:

Tabla IV

SALUD BUCAL (CPOD) EXPRESADA COMO VALOR PROMEDIO (SD) POR SEXO EN ADULTOS AMBULATORIOS (GRUPO CONTROL). 2010.

\begin{tabular}{|l|l|l|l|l|l|ll|}
\hline SEXO & $\mathbf{n}$ & $\mathbf{C}$ & $\mathrm{Ei}^{*}$ & $\mathrm{E}$ & $\mathrm{O}$ & \multicolumn{2}{|c|}{ CPOD } \\
\hline FEM. & 59 & 5.03 & 0.88 & 7.88 & 1.66 & 15.46 & 6.30 \\
\hline MASC. & 50 & 5.06 & 1.14 & 6.08 & 1.02 & 13.32 & 5.37 \\
\hline TOTAL & 109 & 5.04 & 2.92 & 7.05 & 1.37 & 14.48 & 5.96 \\
\hline
\end{tabular}

* Extracción indicada

P 0.0309

La situación de Salud Bucal, medida como media aritmética CPOD, fue significativamente mayor que la de los varones P0.039.

El análisis de regresión para los valores de las variables edad e indicador CPOD mostró una correlación positiva significativa r 0.3514 (Pearson); mientras que el coeficiente de 
determinación fue 0.1416; por lo tanto, quedan 0.86 de piezas dentarias CPO determinadas por otras variables diferentes de la edad y sexo estudiadas.

Se encontró diferencias significativas entre los valores CPOD (diferencia de varianzas) entre los grupos de adultos Institucionalizados (GI), en proceso de Desinstitucionalización (GD) y el grupo de adultos ambulatorios sin diagnóstico de alteraciones mentales (GC), asistidos en el mismo servicio de odontología que los anteriores (ANOVA) P 0.0000, Bartlett's Chi2 0.0000. También fueron significativas las diferencias determinadas por la prueba no paramétrica de Mann- Whitney P 0.0358.

El gráfico IV muestra los valores porcentuales CPOD, estableciendo éstos que la mayor carga de la enfermedad bucal con su consecuencia residual es la pérdida de la pieza dentaria (componente $\mathrm{P}$ del indicador).

\section{Gráfico IV}

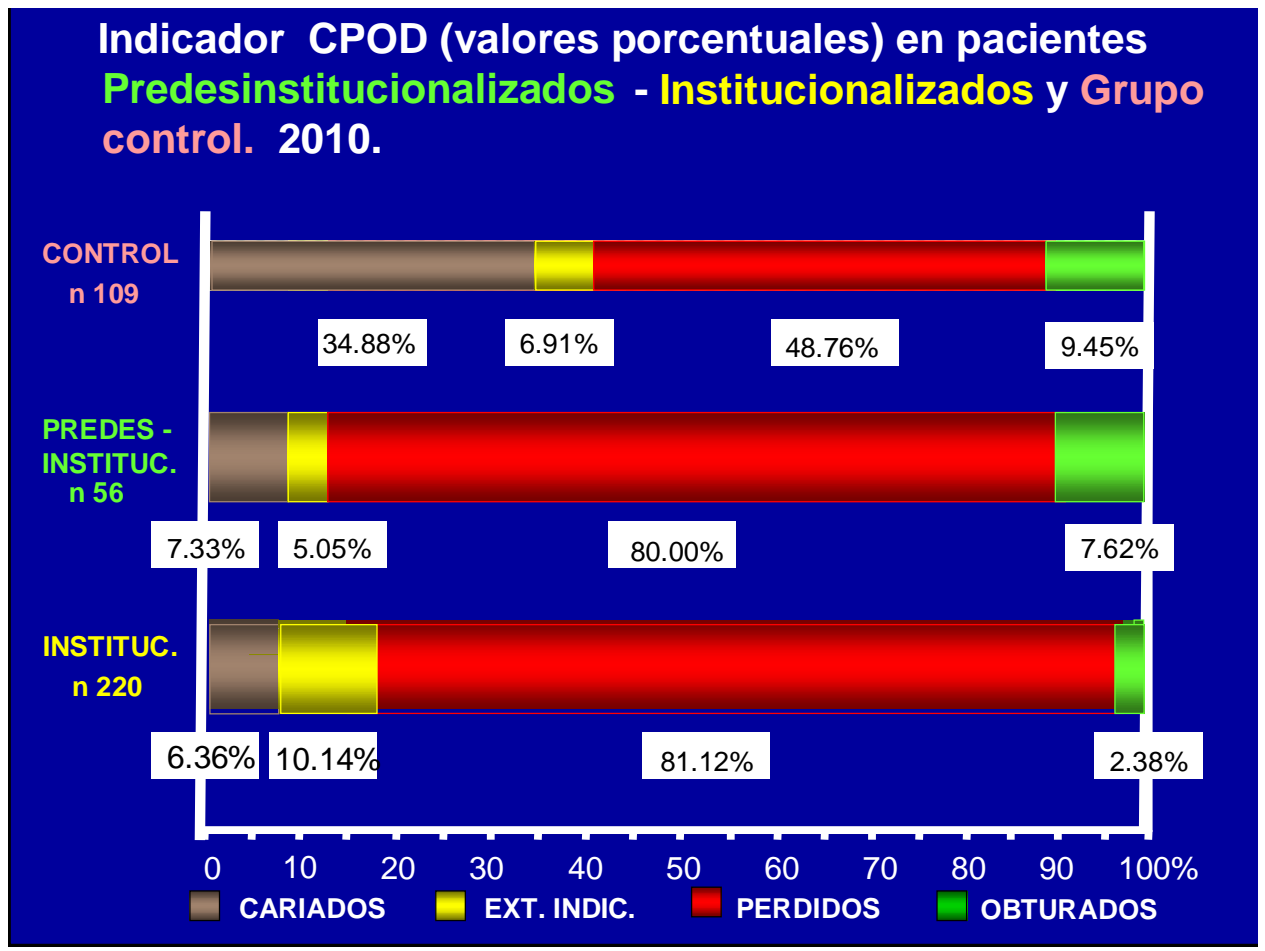

El análisis gráfico para la funcionalidad masticatoria describe una distribución de los datos con asimetría positiva, no normal, con un valor mediana de 82 , rango $8-100$. Los resultados de los análisis numéricos Shapiro Wilk, Asimetría y Kurtosis que se observan en el gráfico 3 mostraron ser significativos $(P<0.05)$ mientras que los de Shapiro Francia resultan significativos al nivel de 10\%: 


\section{Función masticatoria}

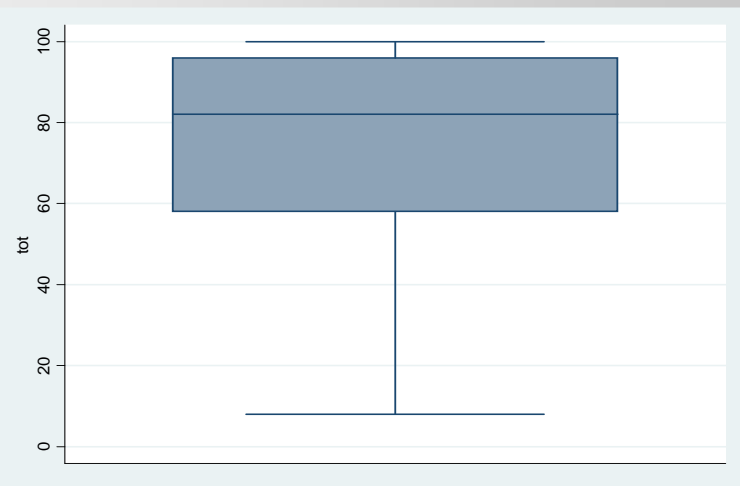

Shapiro Wilk P 0.00009

Skewness/Kurtosis P 0.0164

Shapiro Francia P 0.0956

El gráfico 4 muestra la distribución de datos para las funciones estética y fonética con un valor para la mediana de 34.25, rango 0 - 100. Esta distribución resulta gaussiana según los tests numéricos Shapiro Francia y Asimetría y Kurtosis; es decir no se rechaza la hipótesis nula de normalidad a un nivel de significatividad del 5\%. Sin embargo, el resultado del test Shapiro Wilk, resulta significativo $\mathrm{P}<0.05$ :

\section{Función estético / fonética}

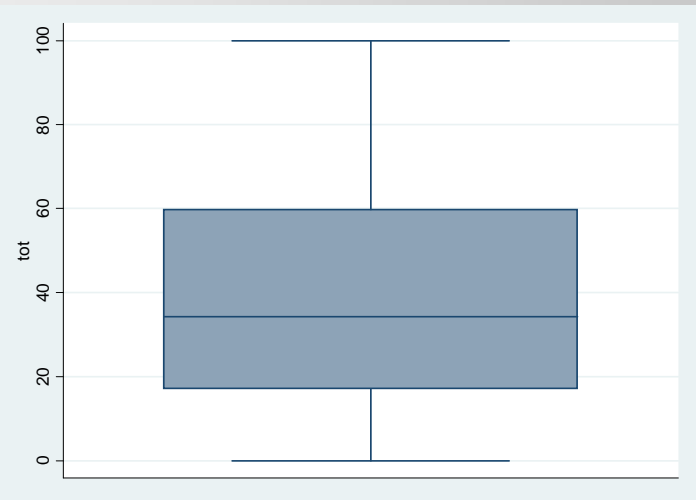

Shapiro Wilk P 0.04689

Skewness/Kurtosis P 0.1404

Shapiro Francia P 0.05109 
Se encontró una pérdida mayor de la función masticatoria en mujeres que en varones. Sin embargo, las diferencias de las medias aritméticas resultaron no significativas $P>0.05$, según lo indica la tabla VI:

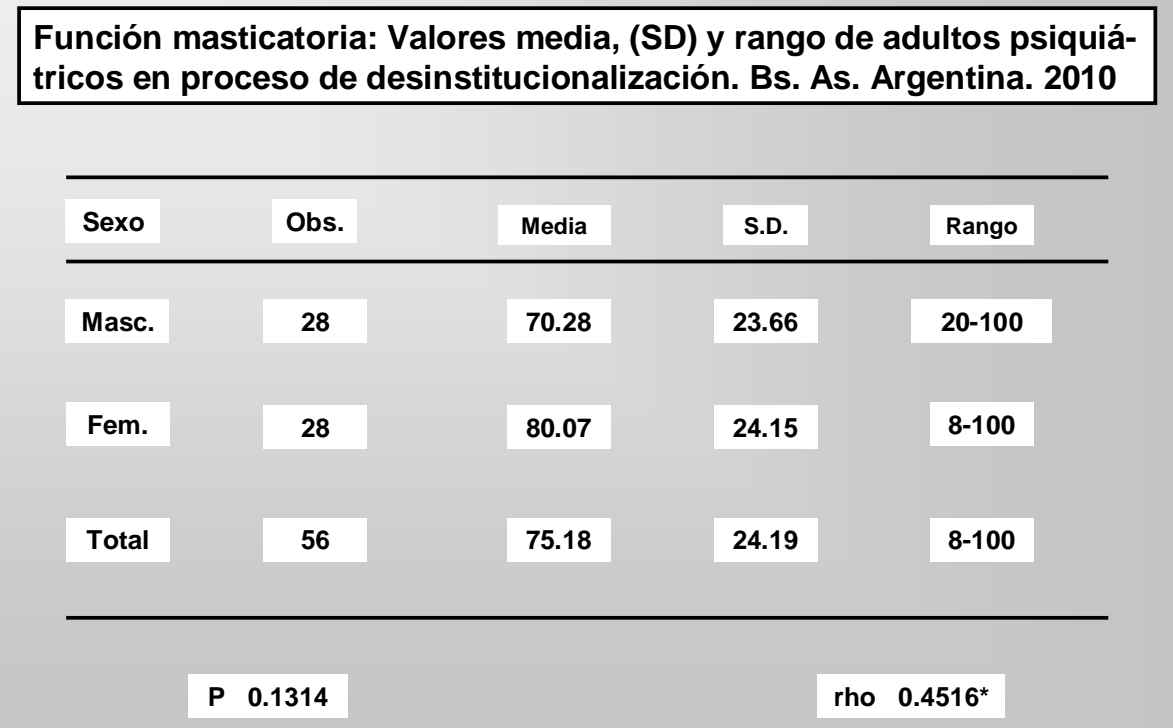

La pérdida de la funcionalidad estética y fonética también fue mayor para las mujeres, aunque la diferencia con los valores registrados para la media aritmética de los varones no fue significativa $P>0.05$, como lo muestra la tabla VII:

Función estética/fonética: Valores media, (SD) y rango de adultos psiquiátricos en proceso de desinstitucionalización.

Buenos Aires. Argentina. 2010

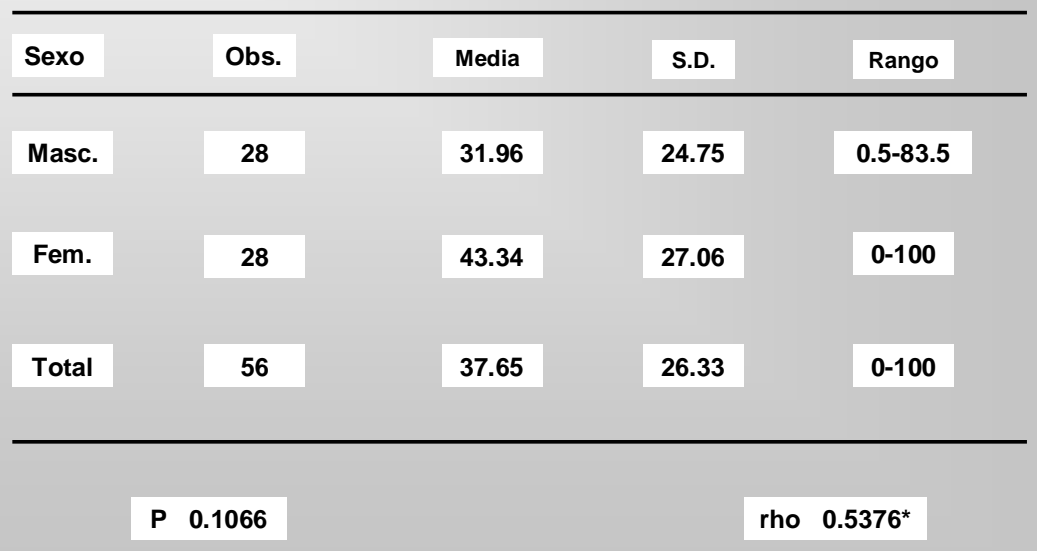


Tampoco determinaron diferencias significativas en los valores los resultados de las pruebas no paramétricas Man Withney para la función masticatoria $P 0.0599$ y para la estética/ fonética $\mathrm{P}$ 0.1234, Kruskall Wallis $\mathrm{P} 0.1235$ para las tres funciones.

Se encontró una correlación positiva significativa al 5\% entre la edad y la pérdida de las funciones con los coeficientes de correlación de Pearson y no paramétrico de Spearman: función masticatoria r 0.4508 y rho 0.4516 y estética/fonética r 0.4994 y rho 0.5376 .

Las tablas VIII y IX muestran la distribución según patología psiquiátrica de los valores para la funcionalidad masticatoria y estética/fonética respectivamente. Se encontró la mayor afección en los pacientes con diagnóstico médico previo de retraso mental, aunque las diferencias de las varianzas con los demás grupos no fueron significativas $P>0.05$ :
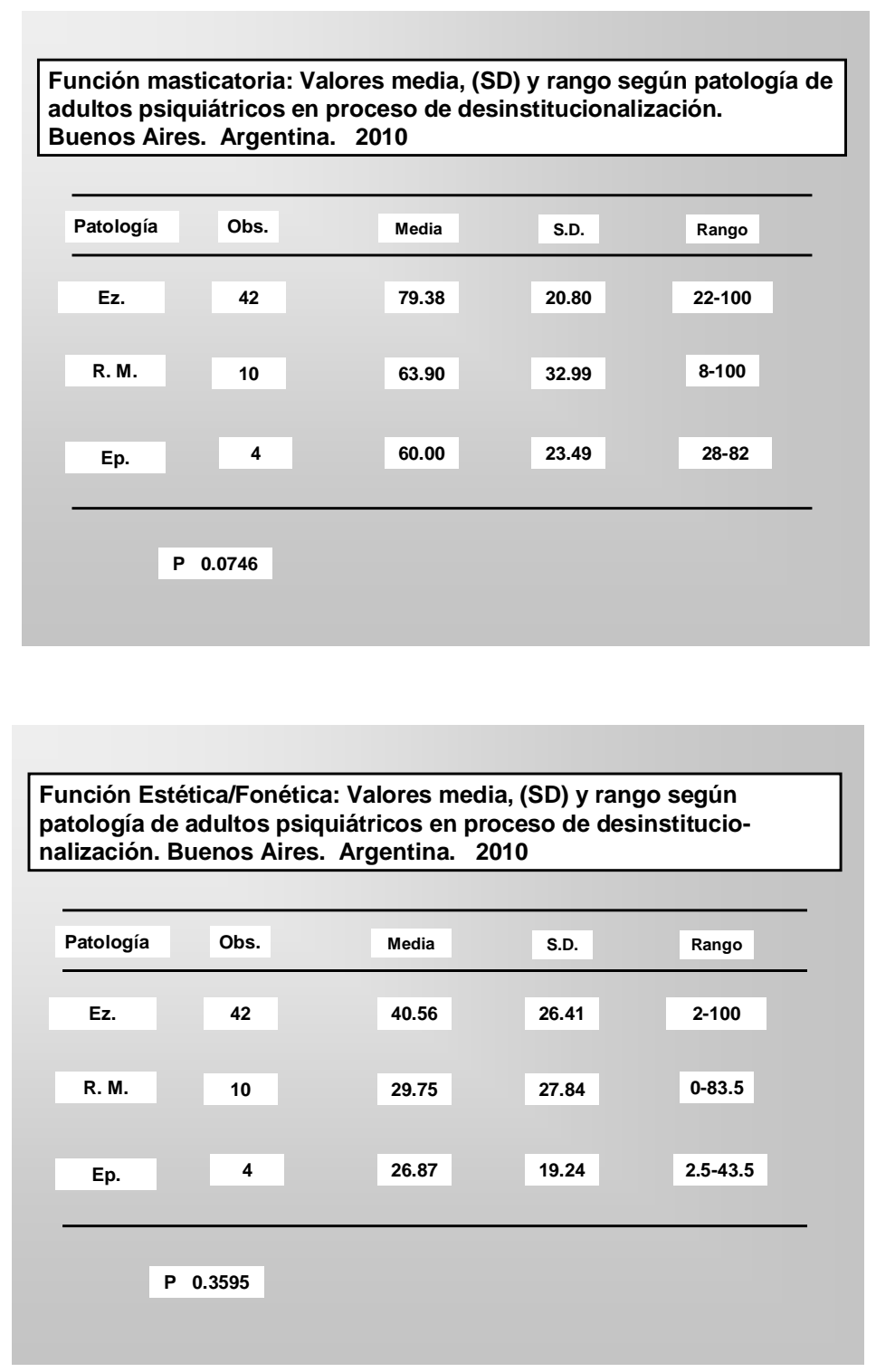
El coeficiente de determinación para las variables edad, sexo y patologías, incluidas en el análisis de regresión, es para la función masticatoria 0.2949 y para la estética/fonética 0.2935 . Estos coeficientes indican, según los resultados de la muestra, que el $29.45 \%$ y el $29.35 \%$ del total de los dientes perdidos y, por lo tanto, de su funcionalidad está determinado por las variables estudiadas, queda un $70.55 \%$ y $70.65 \%$ de la pérdida determinada por otras variables que no son objeto de análisis en este estudio, pero que integran el proceso de la pérdida como la condición socioeconómica, la educación, la alimentación, los autocuidados de higiene bucal, la medicación, la atención de salud bucal recibida, entre otros.

El grupo de adultos en proceso de desinstitucionalización GD estudiado $(n=56)$ determinó que nueve personas (3 mujeres, 6 varones), 16.07\%, no necesitan rehabilitación protética. Once personas (3 mujeres, 8 varones), 19.64\%, necesitan rehabilitación en un solo maxilar y 36 (22 mujeres, 14 varones), 64.29\% la necesitan en ambos maxilares; siendo el maxilar superior el más afectado:

\begin{tabular}{|l|c|c|c|c|c|c|}
\hline \multirow{2}{*}{ Cód. } & \multicolumn{3}{|c|}{ Maxilar Superior } & \multicolumn{3}{c|}{ Maxilar Inferior } \\
\cline { 2 - 7 } & R. h/4 & R. 5/+ & P. C. & R. h/4 & R. 5/+ & P. C. \\
\hline Fem. & - & 16 & 9 & 4 & 16 & 2 \\
\hline Masc. & 2 & 18 & - & 3 & 12 & 1 \\
\hline Total & 2 & 34 & 9 & 7 & 28 & 3 \\
\hline
\end{tabular}

* CÓDIGOS DEL NOMENCLADOR NACIONAL:

04.02.01 Prótesis parcial de acrílico hasta 4 dientes.

04.02.02 Prótesis parcial de acrílico de 5 o más dientes.

04.03.01 Prótesis completa superior.

04.03.02 Prótesis completa inferior.

Los códigos del Nomenclador Nacional 04.02.01 y 04.02 .02 corresponden al código 040201 del Programa Nacional de Garantía de Calidad de la CORA. Los códigos 04.03.01 y 04.03.02 con el 040214 del mismo:

Prótesis Parcial (código 04.02.01)

Prótesis Completa (código 04.02.14)

\section{Mujeres}

36

11

\section{Varones}

35

1
Total

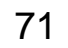

12 
Situación de la necesidad de rehabilitación protética de la muestra estudiada.

\begin{tabular}{lccccc} 
& Mujeres & Varones & Total & $\%$ \\
\cline { 2 - 2 } & 3 & 6 & 9 & 16.07 \\
Desdentados parc. 1 maxilar & 3 & 8 & 11 & 19.64 \\
Desdentados parc. 2 maxilares & 13 & 13 & 26 & 46.43 \\
Desdentados mixtos (parcial, total) & 7 & 1 & 8 & 14.29 \\
Desdentados totales & 2 & 0 & 2 & 3.57 \\
$\mathrm{n}$ & 28 & 28 & 56 & 100
\end{tabular}

b) fase documental.

\section{Marco jurídico.}

La siguiente enumeración registra un ordenamiento temporal, sin categorizar su valor jurídico: algunos tienen rango constitucional, otros constituyen una base de interpretación de naturaleza normativa no obligatoria (reconocidos por su carácter soft law) y otros como de derecho guía o modelo (model law).

Documentos Internacionales. Protección de la discapacidad.

1948.- Declaración universal de Derechos Humanos ${ }^{105}$ (DUDH)

1950.-Convención Europea para la Protección de los Derechos Humanos y Libertades Fundamentales $^{21}$ (CEDH), Roma. Art. 7.

1953.-Convención Europea para la Protección de los Derechos Humanos y Libertades Fundamentales $^{22}$ (CEDH),entrada en vigencia el 3/9/53, adoptada el 4/4/97 por la convención de Derechos Humanos y Biomedicina. Reconoce el Derecho al Consentimiento informado y tiene mayor fuerza que los Principios para la Protección de los Enfermos Mentales para el Mejoramiento de la Atención de la Salud Mental ${ }^{110}$ (PPEN) adoptados por la ONU. 
1961.- Corte Interamericana de Derechos Humanos ${ }^{85}$. Órgano judicial para aplicar e interpretar la Convención Americana de Derechos Humanos de los Estados partes por declaración o convención especial.

Propósito: recibir e investigar peticiones individuales que alegan violaciones de Derechos Humanos y hacer recomendaciones y requerir a los Estados partes que tomen medidas cautelares para evitar daños.

1966.- Pacto Internacional de Derechos Civiles y Políticos ${ }^{110}$ (PIDCP). Res.2200 A (XXI) Asamblea Gral. Naciones Unidas. Supl.No.16 52, doc.A/6316, 999 U.N.T.S.171, entrada en vigor 23/3/1976.

Pacto Internacional de Derechos Económicos, Sociales y Culturales ${ }^{109}$ (PIDESC) Res.2200 A (XXI) Asamblea Gral. Naciones Unidas. Supl.No.16, 49, doc..A/6316, 993 U.N.T.S. 3, entrada en vigor 3/1/1976.

Propósito de estos pactos: vigilar el cumplimiento de la DUDH., integrando la Carta Internacional de Derechos Humanos.

1971.- Declaración del Deficiente Mental. ${ }^{102}$

1975.- Declaración de los Derechos de los Impedidos ${ }^{\vee}$. Asamblea Gral. Naciones Unidas. ${ }^{103}$

Propósito: proteger derechos fundamentales de los discapacitados mentales (salud, empleo, participación política y social, educación, etc.), "prevenir la incapacidad física y mental y ayudar a los impedidos a desarrollar sus aptitudes en las más diversas esferas de actividad, así como fomentar en la medida de lo posible su incorporación a la vida social normal".

1981.- Año Internacional de los Impedidos. Asamblea Gral. Naciones Unidas.

Propósito: lema "plena participación e igualdad"

1982.- Programa de acción mundial para los Impedidos. ${ }^{111}$ Res. $37 / 52$ Asamblea Gral. Naciones Unidas.

Propósito: promover medidas de prevención de la incapacidad, rehabilitación, participación plena en la vida social e igualdad de oportunidades. Es obligación de los Estados miembros, entre otras, planificar, organizar y financiar actividades en cada nivel, ofrecer servicios de rehabilitación a través de prestaciones de asistencia social, nutricional,

\footnotetext{
v "designa a toda persona incapacitada de subvenir por sí misma, en su totalidad o en parte, a las necesidades de una vida individual o social normal, a consecuencia de una deficiencia, congénita o no, de sus facultades físicas o mentales" (res.3447 art.1 Asamblea ONU)
} 
médica, docente, y de orientación y formación profesional, así como ayudas técnicas a los impedidos.

Los Estados miembros quedaron así obligados a:" ofrecer servicios de rehabilitación a través de la prestación de asistencia social, nutricional, médica, docente y de orientación y formación profesional, así como ayudas técnicas a los impedidos"

Carta Africana de Derechos Humanos y de los pueblos. ${ }^{93}$ OAU, adoptada el 27/6/1981, entrada en vigor el 21/10/1986 establece explícitamente "protecciones específicas para las personas con Discapacidad". El ART.16 INc. 4 dice que "el Discapacitado también tiene derecho a medidas especiales de protección de acuerdo con sus necesidades físicas y morales".

1987.- Principios de Limburg. ${ }^{131}$ UN Doc.E/CN 4/1987/17.

Propósito: asegurar el progreso de grupos que requieren protección específica, necesaria para asegurarles el disfrute equitativo de derechos económicos, sociales y culturales (operatividad de PIDESC).

1988.- Protocolo Adicional a la convención sobre Derechos Humanos en Materia de Derechos Económicos, Sociales y Culturales. Protocolo de San Salvador. ${ }^{88}$ Asamblea Gral. Organización de Estados Americanos. Aprobado por ley del Congreso Nacional argentino No. 24658 art.1:

Propósito: ejecutar programas laborales, formar a familiares de personas con discapacidad y eliminar barreras arquitectónicas.

1991.- Principios para la Protección de las Enfermedades Mentales y el Mejoramiento de la Atención de la Salud Mental. ${ }^{110}$

1993.- Normas Uniformes sobre la Equiparación de Oportunidades para las Personas con Discapacidad. ${ }^{106}$ Asamblea Gral. Naciones Unidas. Res.48/96, DC2- 1302.

Propósito: Obligar a los gobiernos a crear bases jurídicas que habiliten la aplicación del contenido del documento. Se equiparan los términos "derechos" y "necesidades' y se establece que éstas deberían ser las bases de la planificación de las sociedades. Internacionalizar los estándares que garantizan a las personas con discapacidad idénticos derechos y obligaciones que los que gozan las restantes personas, ya que comparten con ellas su condición de miembros de la misma sociedad" (art.15) El marco normativo debe ser lo "suficientemente preciso como para dar origen a derechos y obligaciones identificables y practicables" y proveer formas efectivas y realistas de implementación. 
1994.-Observación Gral. No.5 Personas con Discapacidad. ${ }^{106}$ Comité de Derechos Económicos, Sociales y Culturales (anexo res. 48/96 de la Asamblea Gral. Naciones Unidas).

Propósito: disfrute de la salud física y mental.

2001.- Aplicación del Programa de acción mundial para los Impedidos: Hacia una sociedad para todos en el siglo XXI. ${ }^{111}$ ONU A/RES/56/115.

Propósito: plantear problemas socioeconómicos relacionados con la igualdad de oportunidades, la posibilidad de acceder a informaciones sobre el desarrollo social, los servicios y las redes de protección social, el empleo y los medios de vida.

Informe 63/99. Comisión Interamericana de Derechos Humanos ${ }^{82}(\mathrm{CIDH})$

Propósito: consideración del paciente mental como grupo especialmente vulnerable, protección judicial de Principios de la Salud Mental. Interpretación de las normas de la Convención Americana que consagran el derecho a la integridad personal, a la vida y a la protección judicial a la luz de los Principios de Salud mental. La CIDH, en el mismo informe, coincidió con la Corte Europea de Derechos Humanos que, el encarcelamiento de una persona con incapacidad mental en condiciones deplorables y sin tratamiento médico puede llegar a constituir un tratamiento inhumano o degradante prohibido por el artículo 5.2 de la Convención Americana sobre Derechos Humanos".

Recomendación sobre la Promoción y Protección de los Derechos de las Personas con Discapacidad Mental. ${ }^{89}$ Comisión Interamericana de Derechos Humanos

Propósito: ratificación de los principios de la $\mathrm{CIDH}$, para la eliminación de toda forma de discriminación.

2006/2007- "Decenio de la Américas: por los Derechos y la Dignidad de las personas con discapacidad"87 período 2006/2016, con el lema "Igualdad, Dignidad y Participación" .

Propósito: lograr el reconocimiento y ejercicio pleno de los derechos y la dignidad de las personas con discapacidad y su derecho a la participación en la vida económica, social, cultural y política, en pie de igualdad con los demás, [ AG/ DEC.50 (XXXVIO/06)].También declaró la necesidad que durante el decenio se emprendan programas, planes y acciones para lograr la inclusión y la participación plena de las personas con discapacidad y se promuevan medidas efectivas para la prevención de nuevas discapacidades y el acceso a los servicios y programas de rehabilitación.

2007.- "Programa de Acción para el Decenio de las Américas por los Derechos y la Dignidad de las Personas con Discapacidad"87 2006/2016 Asamblea General OEA., XXXVII período ordinario. Implementación del programa. 


\section{Propósito:}

a. Promoción y protección de la salud y prevención de discapacidades:

I. Garantizar el acceso de las personas con discapacidad a los servicios de salud física y mental en condiciones de igualdad con los demás y la debida atención de sus requerimientos, en razón de su discapacidad, en el entorno más inclusivo posible.

IV. Proporcionar a las personas con discapacidad programas y atención de salud gratuitas o a precios asequibles de la misma variedad y calidad que a las demás personas... y programas de salud pública dirigidos a la población.

VII. Garantizar la debida y oportuna atención médica, física y mental de calidad a las personas con discapacidad y proporcionar, de forma gratuita o a precios asequibles, los tratamientos y o medicamentos necesarios para superar la patología y/o controlar las condiciones de salud y prevenir el deterioro de la persona o el agravamiento de la discapacidad.

VIII. Diseñar e implementar estrategias educativas de prevención referidas a los factores condicionantes de la discapacidad y que promuevan estilos de vida saludables para las personas con discapacidad a todos los niveles.

2008.- Convención sobre los Derechos de la Persona con Discapacidad. ${ }^{98}$

Propósito: establecer las medidas mínimas que deben adoptar los Estados Partes para garantizar a toda persona con discapacidad su derecho a vivir en la comunidad: "Los Estados Partes reconocen el Derecho en igualdad de condiciones de todas las personas con discapacidad a vivir en la comunidad, con opciones a las demás, y adoptarán medidas efectivas y pertinentes para facilitar el pleno goce de este derecho por las personas con discapacidad y su plena inclusión y participación en la comunidad".

\section{Documentos Internacionales. Protección de la Discapacidad Mental. ${ }^{v i}$}

1971.- Declaración de las Personas con Retraso Mental. ${ }^{102} 2027^{a}$ Sesión Plenaria ONU. 20/12/1971.

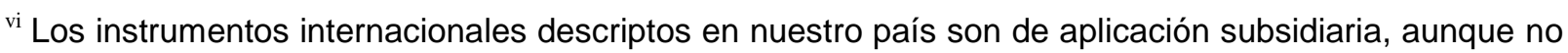
sean convenciones y carezcan de rango constitucional. Si bien éstos no abordan los problemas particulares de las personas con discapacidad mental, la resolución 56/119 de la Asamblea Gral. De Naciones Unidas del 28 de noviembre de 2001 establece propuestas para la promoción y protección de los derechos y la dignidad de las personas con discapacidad.
} 
1975.- Declaración de los Derechos de las Personas Discapacitadas o impedidas. ${ }^{103} 2433^{a}$ Sesión Plenaria ONU. 9/12/1975, designa con el término "impedido" a "toda persona incapacitada para subvenir por sí misma, en su totalidad o en parte, a las necesidades de una vida individual o social normal, a consecuencia de una deficiencia, congénita o no, de sus facultades físicas o mentales.

1977.-Recomendación 818 del Consejo de Europa Sobre la Situación de los Enfermos Mentales.

Declaración sobre Implicancias Éticas Específicas en Psiquiatría (Asamblea Gral. Asociación Mundial de Psiquiatría. Hawai I ${ }^{7}$

1982.-Derechos de los Ancianos. ${ }^{101}$

1983.-Declaración de Hawai II. ${ }^{8}$ Viena.

1989.-Declaración de Atenas. ${ }^{9}$ Proposición y puntos de vista de la Asociación Mundial de Psiquiatría sobre los derechos y la Protección Legal de los Enfermos Mentales.

Declaración de Luxor. ${ }^{31}$ Derechos Humanos de los Enfermos Mentales. Congreso de Nilo, Luxor. Egipto. Federación Mundial para la Salud Mental.

1990.- Declaración de Caracas. ${ }^{115}$ Reestructuración de la atención psiquiátrica: bases conceptuales y guías para su implementación. El hospital psiquiátrico como única modalidad "aísla a los pacientes de su medio, generando de esa forma mayor incapacidad social, crea condiciones desfavorables que ponen en peligro los derechos humanos y civiles del paciente".

1991.- Principios para la Protección de los Enfermos Mentales para el Mejoramiento de la Atención de la Salud Mental ${ }^{110}$ (PPEM).Ares.46/119. Asamblea Gral. Naciones Unidas. Estándar internacional más completo o guía para la protección de derechos a través de decisiones administrativas o judiciales, a través de reformas legislativas y de lineamiento de políticas públicas sobre salud mental.

1993.- Declaración de Viena. ${ }^{104}$ "Los derechos Humanos son universales, indivisibles, interdependientes y están interrelacionados". Las personas con Discapacidad Mental están protegidas por la misma legislación sobre Derechos Humanos que protege a los demás individuos, incluidas las disposiciones de los instrumentos jurídicos vinculantes en la materia. 
Normas Uniformes sobre la Equiparación de Oportunidades para las Personas con Discapacidad. ${ }^{106}$ Asamblea Gral. Naciones Unidas. Res.48/96, DC2- 1302.

1996.-OMS Directivas para la Promoción de Derechos Humanos para las personas con Desórdenes Mentales.

Convención Americana de Derechos Humanos art. 7.

Convención Europea de Derechos Humanos art. 5.

1999.- Convención Interamericana Para la Eliminación de todas las Formas de Discriminación contra las Personas con Discapacidad, ${ }^{84}$ entiende por discapacidad "una deficiencia física, mental o sensorial, ya sea de naturaleza permanente o temporal, que limita la capacidad de una o más actividades de la vida diaria que puede ser causada o agravada por el entorno económico y social" Sus objetivos principales son la prevención y eliminación de todas formas de discriminación contra las personas con discapacidad física o mental y propiciar "su plena integración en la sociedad ".

2001.- Recomendación de la CIDH sobre la Promoción y Protección de los Derechos y la Dignidad de las Personas con Discapacidad Mental ${ }^{96}$, "promover e implementar a través de legislaciones y planes nacionales de Salud Mental la organización de servicios comunitarios de Salud Mental cuyos objetivos sean la plena integración de las personas con discapacidad mental en la sociedad y la participación de organizaciones profesionales, asociaciones de usuarios y familiares, sus amistades, organizaciones de asistencia social y otros miembros de la comunidad en la rehabilitación del paciente".

Asamblea General Naciones Unidas Res. 56/119 doc. A/C.3/56/L.67/Rev. No1 párrafo 1. Análisis de propuestas para promover y proteger los derechos y la dignidad de las personas con Discapacidad.

2005.- Declaración de Brasilia. ${ }^{114}$ Reitera la validez de los principios de la Declaración de Caracas; la necesidad de establecer una atención integral y multidisciplinaria. Procura la mejora de la Salud mental mediante la concertación con diferentes actores sociales. Advierten la vulnerabilidad social y el aumento de la demanda de atención.

2006.- Convención Internacional sobre la Protección y Promoción de los Derechos y la Dignidad de las personas con Discapacidad, 97 "promover acceso, rehabilitación igualitarios, respeto por la dignidad e inclusión social”. 


\section{Derecho Argentino. Protección de la Discapacidad Mental}

Constitución Nacional ${ }^{24}$ art.16, 17, 19, 33, 41, 43, 75 inc.22 (derecho a la igualdad), art.75 inc.72 (establecimiento de garantías no discriminatorias) y 75 inc. 23 (ampara la diferenciación para la igualdad).

Las normativas internacionales básicas de los derechos humanos tienen jerarquía constitucional a parir de la reforma de 1994; no derogan artículo alguno de la primera parte de esta Constitución y deben entenderse complementarios de los derechos y garantías por ellos reconocidas:

Declaración Americana de los Derechos y Deberes del Hombre. ${ }^{86}$

Declaración Universal de Derechos Humanos ${ }^{105}$ (DUDH) art.2, 3, 7, 9, 12, 13, 16, 21, 23, 25, 26.

Convención Americana de Derechos Humanos ${ }^{\text {vii }}$ (Pacto de San José de Costa Rica) ${ }^{83}$ art. $1,7,10,11,17,19,22,24$. El art. 26 establece que los Estados parte se comprometen a lograr progresivamente la plena efectividad de los derechos de la Carta de la OEA; por lo tanto la salud está protegida indirectamente por la Convención Americana de Derechos humanos.

Carta de la OEA art.34 literales i) y I) establece que los Estados convienen en dedicar sus esfuerzos a la consecución de "defensa del potencial humano mediante la extensión y aplicación de los modernos conocimientos de la ciencia médica". Estas condiciones se hacen exigibles a través del artículo 26 de la Convención Americana de Derechos Humanos.

Ley23054 ${ }^{57}$ Aprobación de la Convención Americana de Derechos Humanos. Pacto de San José de Costa Rica. (sancionada 1/03/84, promulgada 9/03/84).

Pacto Internacional de Derechos Económicos, Sociales y Culturales ${ }^{\text {viii }}$ (PIDESC) ${ }^{109}$ art. 6, $7,9,10,11,12,13$.

Protocolo adicional a la Convención americana sobre Derechos Humanos en materia de Derechos Económicos, Sociales y Culturales "Protocolo de San Salvador":El Art. 10 define el derecho a la salud como "el disfrute del más alto nivel posible del bienestar físico, mental y social" y 18 "... toda persona afectada por una disminución de sus capacidades físicas o mentales tiene derecho a recibir una atención especial con el fin de alcanzar el máximo desarrollo de su personalidad".

Pacto Internacional de Derechos Civiles y Políticosix (PIDCP) art. 2, 3, 9, 12, 13, 17, 23, 25,26 .

Protocolo facultativo del PIDCP ${ }^{108}$.

\footnotetext{
vii Aprobada por ley 23054 y ratificada el 5 de septiembre de 1984

viii Aprobados por ley 23313 y ratificada el 8 de agosto de 1986

${ }^{\text {ix }}$ El bien protegido por la norma es supremo, porque de él dependen los otros bienes ${ }^{12}$
} 
Ley $23313{ }^{58}$ Aprueba los Pactos PIDESC y PIDSC y sus Protocolos Facultativos (sancionada 17/4/86, promulgada 6/05/86 Decreto 673)

Convención sobre la Prevención y Sanción del Delito del Genocidio ${ }^{100}$

Convención Internacional sobre la eliminación de todas formas de Discriminación Racial. ${ }^{95}$

Convención sobre la eliminación de todas las formas de Discriminación contra la Mujer ${ }^{99}$ art. 12.

Convención contra la Tortura y otros Tratos o Penas Crueles, Inhumanos y Degradantes. ${ }^{94}$

El reconocimiento directo de nuevos derechos y garantías constitucionalmente amparados que regulan materias de derecho civil permiten afirmar su transformación a derecho nacional determinando una protección supranacional y una constitucionalización ${ }^{73}$ del derecho civil refiriéndose a distintos aspectos como:

a) la persona

DUDH art.6.

PIDCP art.16

Convención Americana de Derechos Humanos art.3

b) la vida ${ }^{x}$

DUDH.

PIDCP art.6.1, 6.2, 6.3, 6.4.

Convención Americana de Derechos Humanos art. 4.1, 4.2.

c) la integridad personal

Convención Americana sobre Derechos Humanos art. 1, 2, 5.

d) la salud

DUDH

PIDESC art.12

Constitución Nacional art.43, 75 inc.22.

Constitución de la Ciudad Autónoma de Buenos Aires ${ }^{23}$ (sancionada 1/10/1996) art. 20, 46.

e) la igualdad y a la no discriminación

DUDH art.7

Constitución Nacional art. 14, 20.

Ley 23592/ $88^{59}$ Antidiscriminatoria (sancionada 3/08/88, promulgada 23/08/88) "quien arbitrariamente impida, obstruya, restrinja o de algún modo menoscabe el pleno ejercicio sobre bases igualitarias de los derechos y garantías fundamentales reconocidos en la Constitución Nacional, será obligado a pedido del damnificado a dejar sin efecto el acto discriminatorio o cesar en su realización y a reparar el daño moral y material ocasionados".

\footnotetext{
${ }^{x}$ Idem supra
} 
Ley 25280/ 9965 (sancionada 6/7/2000; promulgada31/7/2000) aprobada por la Convención Interamericana para la Eliminación de todas las Formas de Discriminación, define el término "Discapacidad" y la frase discriminación contra las personas con Discapacidad" y compromete a los Estados parte a adoptar "las medidas de carácter legislativo, social, educativo, laboral o de cualquier índole, necesarias para eliminar la discriminación contra las personas con discapacidad y propiciar su plena integración en la sociedad".

Ley $22431 / 81^{55}$ (reglamentada por decreto $762 / 97$ ) ${ }^{x i}$ art.1 protección integral de discapacitados "tendiente a asegurar a éstas su atención médica, educación y seguridad social, así como a concederles las franquicias y estímulos que permitan en lo posible neutralizar las desventajas que la discapacidad les provoca y les den la oportunidad, mediante su esfuerzo, de desempeñar en la comunidad un rol equivalente al que ejercen las personas normales". Art. 2: considera Discapacitada a toda persona que "padezca una alteración funcional permanente o prolongada, física o mental, que en relación a su edad y medio social implique desventajas considerables para su integración familiar, social, educacional o laboral"

Ley $23876 / 90{ }^{61}$ Modificatoria Art.20 de la Ley 22431. (sancionada28 y 29/09/90, promulgada $24 / 10 / 90)$

Ley $24240 / 93^{62}$ (sancionada22/9/93, promulgada 24/10/90) Capítulo II regula información al consumidor y protección de la salud.

Ley $24515 / 95^{63}$ (sancionada 5/7/95, promulgada 28/7/95) Creación del Instituto Nacional contra la Discriminación, Xenofobia y Racismo.

Ley 24901/ $97^{64}$ (sancionada 5/11/97, promulgada 2/12/97; reglamentada por decreto 1193/98) art.1 prestaciones básicas en habilitación y rehabilitación integral de personas Discapacitadas. "Institúyase un sistema de prestaciones básicas de atención integral a favor de las personas con Discapacidad, contemplando acciones de prevención, asistencia, promoción y protección con el objeto de brindar una protección integral a sus necesidades y requerimientos"

Ley $23660 / 89^{60}$ (sancionada 29/12/88, promulgada 5/1/89) art.1 y 2 cobertura de carácter obligatorio por las obras sociales del total de las prestaciones básicas enunciadas en la ley. Art. 4: Las personas con discapacidad que carecieran de cobertura de la obra social tienen igualmente derecho de acceder a la totalidad de estas prestaciones básicas a través de los organismos dependientes del Estado.

Ley 25421/sin reglamentar art.2 Creación del Programa de Asistencia Primaria de Salud Mental (APSM) establece que "todas las personas tienen derecho a recibir asistencia primaria

\footnotetext{
${ }^{\mathrm{xi}}$ modificatorias $23876 / 90$ y 25634
} 
de salud mental, cuando lo demanden personalmente o a través de terceros, o a ser tributarias reacciones colectivas que la comprendan"

Ley $25634 / 2002^{66}$ (sancionada 1/08/2002, promulgada 26/08/2002). Modifica el tercer párrafo del Art. 22 Inc.a de la ley 22431.

Ley 26378/2008 ${ }^{67}$ (sancionada 21/05/2008, promulgada 6/06/2008). Aprueba la Convención sobre los Derechos Humanos de las personas con Discapacidad y su Protocolo Facultativo.

Ley $26480 / 2009^{68}$ (sancionada 4/03/2009, promulgada 30/03/2009). Prestaciones básicas para la atención integral de las personas con Discapacidad. Incorpora el Inc.d del Art. 39 de la ley 24901.

Ley 26657/2010 (sancionada 25/11/2010, promulgada 2/12/2010; Decreto PEN 1885/2010) Nacional de Salud Mental.

Deroga la ley 22914 de Internación y egresos en Establecimientos de Salud Mental (sancionada y promulgada 1/12/82; BO. 6/12/82)

Art.7ㅇ:

Inciso a) Derecho a recibir atención sanitaria y social integral y humanizada a partir del acceso gratuito, igualitario y equitativo a las prestaciones e insumos necesarios, con el objeto de asegurar la recuperación y preservación de la salud.

Inciso c) Derecho a recibir una atención basada en fundamentos científicos ajustados a principios éticos.

Inciso d) Derecho a recibir tratamiento y a ser tratado con la alternativa terapéutica más conveniente, que menos restrinja sus derechos y libertades, promoviendo la integración familiar, laboral y comunitaria.

Art.8‥- Promueve equipos multidisciplinarios para la atención en sus artículos 8, 9, 11, 13 y 16. Se incluyen áreas de psicología, psiquiatría, trabajo social, enfermería terapia ocupacional y otras disciplinas o campos pertinentes.

Art. 11\%.- Promueve la implementación de acciones de inclusión social, laboral y de atención de salud comunitaria.

Art. 28‥- El rechazo a la atención de pacientes, ya sea ambulatorios o en internación, por el solo hecho de tratarse de problemas de Salud Mental, será considerado acto discriminatorio en términos de la ley 23592.

\section{Constitución de la Provincia de Buenos Aires ${ }^{25}$ 13/9/1994:}

Art.11 "Los habitantes de la provincia de Buenos Aires son iguales ante la ley y gozan de los derechos y garantías que establece la Constitución Nacional, los que emanan en su 
consecuencia a través de los tratados celebrados por la Nación y los que se expresan en esta Constitución.

La Provincia no admite distinciones ni privilegios por razones de sexo, raza, religión, nacionalidad, lengua, ideología, opinión, enfermedades de riesgo, características físicas o cualquier otra condición amparada por las normas constitucionales.

Es deber de la Provincia promover el desarrollo integral de las personas garantizando la igualdad de oportunidades y la efectiva participación de todos en la organización política, económica y social".

Art.12 inc.3 "Todas las personas en la Provincia gozan entre otros, de los siguientes derechos: "al respeto, la dignidad, al honor, la integridad física, psíquica y moral".

Art.36 "La Provincia promoverá la eliminación de los obstáculos económicos, sociales o de cualquier naturaleza, que afecten o impídanle ejercicio y garantías constitucionales".

Inc.5: de la Discapacidad: "Toda persona tiene el derecho a la protección integral del Estado. La Provincia garantizará la rehabilitación, educación y capacitación en establecimientos especiales, tendiendo a la equiparación de su reinserción social y la toma de conciencia respecto de los deberes de solidaridad sobre Discapacitados".

Inc.8: a la salud: "La Provincia garantiza a todos sus habitantes el acceso a la salud, en los aspectos preventivos, asistenciales y terapéuticos; sostiene el hospital público y gratuito en general, con funciones de asistencia sanitaria, investigación y formación, promueve la educación para la salud, la rehabilitación y reinserción de las personas toxicodependientes ".

Ley 8388/75 Programa Provincial de Salud Mental (Pcia. Bs. As.):

Titulo VII. De los centros de Salud Mental.

“c) División Rehabilitación: un terapista ocupacional, un fonoaudiólogo, y cuando sea conveniente y posible un kinesiólogo".

Ley 10315/95 Externación de enfermedades mentales. (Pcia. Bs. As.):”... como así que los familiares presten al externado la atención debida respecto a alimentación, vestimenta y tratamiento médico ordenado...".

Jurisprudencia. Sentencias en 2da. Instancia.

La búsqueda no arrojó resultados. 


\section{b) Análisis de la estructura de costos de la rehabilitación bucal}

\section{Tecnología de operación:}

Atención ambulatoria programada. Esta operación fue desagregada en funciones, actividades y tareas con los recursos humanos involucrados.

Función: Resolución estética y funcional con reposición de piezas dentarias perdidas. Producto: Prótesis removible, parcial o total.

\begin{tabular}{|c|c|c|c|}
\hline Actividad & Tipo & Tarea & Recursos Humanos \\
\hline Recepción & Secundaria & $\begin{array}{l}\text { - Recepción } \\
\text { - Identificación } \\
\text { - Registro } \\
\text { - Introducción }\end{array}$ & $\begin{array}{l}\text { - Recepcionista } \\
\text { - Paciente }\end{array}$ \\
\hline Diagnóstico & Primaria & $\begin{array}{l}\text { Examen clínico del estado dentario } \\
\text { y periodontal }{ }^{\mathrm{xii}}\end{array}$ & $\begin{array}{l}\text { - Odontólogo } \\
\text { - Asistente } \\
\text { - Paciente }\end{array}$ \\
\hline $\begin{array}{l}\text { Construcción de } \\
\text { prótesis }\end{array}$ & Primaria & $\begin{array}{l}\text { - Toma de impresión de trabajo } \\
\text { - Registro de relación intermaxilar } \\
\text { - Diseño aparatología } \\
\text { - Construcción } \\
\text { - Prueba aparatología } \\
\text { - Instalación de prótesis } \\
\text { - Asesoramiento de higiene y } \\
\text { conservación } \\
\text { - Control post instalación }\end{array}$ & $\begin{array}{l}\text { - Asistente } \\
\text { - Laboratorista } \\
\text { - Paciente }\end{array}$ \\
\hline
\end{tabular}

Tiempo en minutos ${ }^{\text {xiii: }}$

Prótesis parcial removible (parcialmente desdentados) 150 minutos

Prótesis completas (desdentados totales) 300 minutos

\footnotetext{
xii Criterio de inclusión alta básica odontológica del paciente.

xiii Se consideraron los tiempos fijados por el Programa Nacional de Garantía de la Calidad de la Atención Odontológica (CORA)
} 


\section{Matriz Cargas Sociales}

Recurso humano profesional: Se estimó la carga social para un odontólogo de planta considerado principal y un residente de segundo año:

\begin{tabular}{|l|c|c|c|}
\hline Odontólogo 36 hs. semanales & Días & Semanas & Hs. \\
\hline Horas laborales teóricas & 36 & 52 & 1872 \\
\hline Feriados Nacionales y asuetos (13 días) & & & 93.6 \\
\hline Horas descanso/almuerzo (1Hora) & & & 260 \\
\hline Licencia ordinaria días hábiles (30) & & & 216 \\
\hline Licencia científica días hábiles (10) & & & 72 \\
\hline Licencia enfermedad días (5) & & & 36 \\
\hline Licencias pagas hs. & & & 677.6 \\
\hline Horas netas trabajadas & & & 1194.4 \\
\hline Costo \% licencias pagas & & & $56.73 \%$ \\
\hline
\end{tabular}

\begin{tabular}{|l|c|c|c|}
\hline Odontólogo Residente 36 horas semanales & Días & Semanas & Hs. \\
\hline Horas laborales teóricas & 36 & 52 & 1872 \\
\hline Feriados Nacionales y asuetos (13 días) & & & 93.6 \\
\hline Horas descanso/almuerzo (1Hora) & & & 260 \\
\hline Licencia ordinaria días hábiles (14) & & & 100.8 \\
\hline Licencia científica días hábiles (10) & & & 72 \\
\hline Licencia enfermedad días (5) & & & 36 \\
\hline Licencias pagas hs. & & & 562.4 \\
\hline Horas netas trabajadas & & & 1309.6 \\
\hline Costo \% licencias pagas & & & $42.94 \%$ \\
\hline
\end{tabular}


Personal de apoyo: se estimaron los valores para una asistente dental y una recepcionista:

\begin{tabular}{|l|c|c|c|}
\hline Asistente dental 36 horas & Días & Semanas & Hs. \\
\hline Horas laborales teóricas & 36 & 52 & 1872 \\
\hline Feriados Nacionales y asuetos (13 días) & & & 93.6 \\
\hline Horas descanso/almuerzo (1Hora) & & & 260 \\
\hline Licencia ordinaria días hábiles (30) & & & 216 \\
\hline Licencia científica días hábiles (10) & & & - \\
\hline Licencia enfermedad días (5) & & & 36 \\
\hline Licencias pagas hs. & & & 605.6 \\
\hline Horas netas trabajadas & & & 1266.4 \\
\hline Costo \% licencias pagas & & & $47.82 \%$ \\
\hline
\end{tabular}

\begin{tabular}{|l|c|c|c|}
\hline Recepcionista 36 horas & Días & Semanas & Hs. \\
\hline Horas laborales teóricas & 36 & 52 & 1872 \\
\hline Feriados Nacionales y asuetos (13 días) & & & 93.6 \\
\hline Horas descanso/almuerzo (1Hora) & & & 260 \\
\hline Licencia ordinaria días hábiles (30) & & & 216 \\
\hline Licencia científica días hábiles (10) & & & - \\
\hline Licencia enfermedad días (5) & & & 36 \\
\hline Licencias pagas hs. & & & 605.6 \\
\hline Horas netas trabajadas & & & 1266.4 \\
\hline Costo \% licencias pagas & & & $47.82 \%$ \\
\hline
\end{tabular}




\section{Mano de obra}

\section{Recurso humano: Calculo del valor hora}

\begin{tabular}{|l|c|c|c|c|}
\hline & $\begin{array}{l}\text { Odontólogo } \\
\text { Principal }\end{array}$ & $\begin{array}{l}\text { Odontólogo } \\
\text { Residente }\end{array}$ & $\begin{array}{l}\text { Asistente } \\
\text { Dental }\end{array}$ & Recepcionista \\
\hline Régimen Hs. & 36 & 48 & 36 & 36 \\
\hline Coeficiente Hs. & 156 & 208 & 156 & 156 \\
\hline Salario Bruto \$ & 2653.52 & 4549.03 & 2872.59 & 2872.59 \\
\hline S.A.C. \$ & 221.04 & 378.93 & 239.29 & 239.29 \\
\hline Subtotal \$ & 2874.59 & 4927.96 & 3111.88 & 3111.88 \\
\hline Cargas Sociales 24.5\% & 650.06 & 1114.51 & 703.78 & 703.78 \\
\hline ART 0.06+1.55\% & 45.16 & 79.98 & 48.83 & 48.73 \\
\hline Licencias pagas \% & 56.73 & 35.06 & 47.82 & 47.82 \\
\hline Total licencias pagas \$ & 1505.35 & 1594.98 & 1373.67 & 1373.67 \\
\hline Total \$ & 5072.12 & 7714.34 & 5238.16 & 5238.16 \\
\hline Valor hora \$ & 32.53 & 37.09 & 33.58 & 33.58 \\
\hline
\end{tabular}

\section{Costos Directos Variables y Semivariables}

Se valoró la rehabilitación en base a prótesis dentales removibles para desdentados parciales y totales, tipificados en los códigos 040201 y 040214 respectivamente del Programa Nacional de garantía de Calidad de la CORA:

Prótesis parcial removible código 040201:

Costos Directos Variables:

\begin{tabular}{|l|l|c|c|c|}
\hline Insumos & Coeficiente & Cantidad & Costo Unitario & Costo Total \\
\hline $\begin{array}{l}\text { Guantes descartables x } \\
100\end{array}$ & & 12 & 0.23 & 2.76 \\
\hline
\end{tabular}




\begin{tabular}{|l|c|c|c|c|}
\hline Suctores para saliva & & 6 & 0.15 & 0.90 \\
\hline Vasos descartables x 100 & & 6 & 0.1134 & 0.68 \\
\hline Baberos Crosstex x 100 & & 6 & 0.20 & 1.20 \\
\hline Compresas desc. x 100 & & 6 & 0.30 & 1.80 \\
\hline $\begin{array}{l}\text { Barbijos descartables x } \\
50\end{array}$ & & 6 & 0.44 & 2.64 \\
\hline Piedra para turbina corta & 0.100 & 3 & 6 & 1.80 \\
\hline $\begin{array}{l}\text { Gomas para pulir } \\
\text { c/mango }\end{array}$ & 0.100 & 1 & 8 & 0.80 \\
\hline Cubetas completas & 0.100 & 2 & 2.50 & 0.50 \\
\hline Alginato & 0.033 & 3 & 35 & 3.47 \\
\hline Yeso piedra x 5kg. & 0.040 & 3 & 19 & 2.28 \\
\hline Cubeta en acrílico auto* & & 1 & 50 & 50 \\
\hline Placa de mordida* & & 2 & 25 & 50 \\
\hline Piedra para acrílico & 0.050 & 1 & 6 & 0.30 \\
\hline Prótesis hasta 7 dientes & & 1 & 114 & 114 \\
\hline Retenedor simple* & & 2 & 18 & 36 \\
\hline Retenedor triple* & & 2 & 24 & 48 \\
\hline Papel de articular & 0.100 & 2 & 2.30 & 0.46 \\
\hline Total Insumos & & 311.23 & 317.59 \\
\hline
\end{tabular}

* costo de insumos tercerizados a laboratorista

\section{Costos Semivariables:}

\begin{tabular}{|l|c|c|c|c|c|}
\hline Mano de Obra & Cant. RRHH & Unidades & Cant. de hs & Costo Unitario & Costo Total \\
\hline $\begin{array}{l}\text { Odontólogo } \\
\text { principal 36hs }\end{array}$ & 1 & Hs. & 2.5 & 32.53 & 81.33 \\
\hline Residente $2^{0}$ año & 1 & Hs. & 2.5 & 37.09 & 92.73 \\
\hline Asistente dental & 1 & Hs. & 2.5 & 33.58 & 83.95 \\
\hline Recepcionista & 1 & Hs. & 2.5 & 33.58 & 83.95 \\
\hline \multicolumn{7}{|l|}{ Total mano de obra } & & & $\mathbf{3 4 1 . 9 6}$ \\
\hline
\end{tabular}


Prótesis Completa código 040214:

\section{Costos Directos Variables:}

\begin{tabular}{|c|c|c|c|c|}
\hline Insumos & Coeficiente & Cantidad & Costo Unitario & Costo Total \\
\hline Guantes descartables x 100 & & 12 & 0.23 & 2.76 \\
\hline Suctores para saliva & & 6 & 0.15 & 0.90 \\
\hline Vasos descartables $\times 100$ & & 6 & 0.1134 & 0.68 \\
\hline Baberos Crosstex x 100 & & 6 & 0.20 & 1.20 \\
\hline Compresas desc. $\times 100$ & & 6 & 0.30 & 1.80 \\
\hline Barbijos descartables $\times 50$ & & 6 & 0.44 & 2.64 \\
\hline Papel de articular & 0.100 & 2 & 2.30 & 0.46 \\
\hline Gomas para pulir c/mango & 0.100 & 1 & 8 & 0.80 \\
\hline Cubetas completas & 0.100 & 2 & 2.50 & 0.50 \\
\hline Alginato & 0.033 & 2 & 35 & 2.31 \\
\hline Yeso piedra x 5kg. & 0.040 & 2 & 19 & 1.52 \\
\hline Cubeta en acrílico auto* & & 1 & 50 & 50 \\
\hline Placa de mordida* & & 1 & 25 & 25 \\
\hline Piedra para acrílico & 0.050 & 1 & 6 & 0.30 \\
\hline Prótesis hasta 14 dientes* & & 1 & 190 & 190 \\
\hline Pasta zinquenólica & 0.050 & 1 & 88.70 & 4.44 \\
\hline
\end{tabular}

* costo de insumos tercerizados a laboratorista

\section{Costos Semivariables}

\begin{tabular}{|l|c|c|c|c|c|}
\hline Mano de Obra & Cant. RRHH & Unidades & Cant. de hs & Costo Unitario & Costo Total \\
\hline $\begin{array}{l}\text { Odontólogo } \\
\text { principal 36hs }\end{array}$ & 1 & Hs. & 5 & 32.53 & 162.65 \\
\hline $\begin{array}{l}\text { Residente } \\
2^{0} \text { año }\end{array}$ & 1 & Hs. & 5 & 37.09 & 185.45 \\
\hline $\begin{array}{l}\text { Asistente } \\
\text { dental }\end{array}$ & 1 & Hs. & 5 & 33.58 & 167.9 \\
\hline Recepcionista & 1 & Hs. & 5 & 33.58 & 167.9 \\
\hline \multicolumn{2}{|l}{ Total mano de obra } & & & 683.90 \\
\hline
\end{tabular}




\section{Costos Directos Fijos}

\begin{tabular}{|l|c|c|c|c|c|}
\hline Amortizaciones & Cant. & $\begin{array}{l}\text { Precio } \\
\text { Unitario }\end{array}$ & Total & $\begin{array}{l}\text { Amortización } \\
\text { anual }\end{array}$ & $\begin{array}{l}\text { Amortización } \\
\text { mensual }\end{array}$ \\
\hline Unidad dental (10 años) & 1 & 16000 & 16000 & 1600 & 133.33 \\
\hline Compresor (5 años) & 1 & 6740 & 6740 & 1348 & 112.33 \\
\hline Turbina (3 años) & 2 & 600 & 1200 & 400 & 33.33 \\
\hline Total amortización/mes & & & & & 278.99 \\
\hline
\end{tabular}

La amortización mensual del compresor se prorrateó entre ocho Unidades Dentales existentes en el Servicio de odontología.

Valor total de amortización/ mes: $\mathbf{1 8 0 . 7}$

Estructura de costos de la Rehabilitación Bucal para adultos con alteraciones de la Salud Mental

Producto:

- $\quad$ Prótesis parcial removible, código 040201

- $\quad$ Prótesis completa (código 040214)

\begin{tabular}{|l|c|c|}
\hline Costo & Código 040201 & Código $\mathbf{0 4 0 2 1 4}$ \\
\hline Costos directos variables & 317.59 & 285.31 \\
\hline Costos indirectos (carga fabril) & 341.96 & 683.90 \\
\hline Total costos directos variables e indirectos & 659.55 & 969.21 \\
\hline Costos directos fijos (amortizaciones) & 180.7 & 180.7 \\
\hline Costo total (Unitario) & $\mathbf{8 4 0 . 2 5}$ & $\mathbf{1 1 4 9 . 9 1}$ \\
\hline
\end{tabular}




\section{Producción}

Se tomó como base de cálculo los resultados muestrales (necesidades prevalentes) y se estimó una producción de 71 prótesis parciales (Código 040201) y 12 prótesis totales (código 040214).

La estimación de los costos se realizó en la unidad monetaria Pesos (nominales o corrientes) al $30 / 11 / 2010$.

Costos totales código 040201 : $\$ 59657.75$

Costos totales código 040214 $\$ 13798.92$

Costos totales producción estimada:

Para analizar la evolución de precios de la Economía, se deberá mediante una media ponderada de precios, realizar la deflación que ajuste las variables nominales para tener en cuenta las variaciones del nivel general de precios. 


\section{CONCLUSIONES EMERGENTES Y DESAFIOOS PENDIENTES}


Las conclusiones emergentes de este trabajo se inician mostrando la situación de los trastornos de la Salud Mental desde la terminología universalmente aceptada hoy, así como las proyecciones para América Latina y el Caribe para los próximos 10 años. Posteriormente siguen el ordenamiento propuesto en la metodología para su realización: en primer lugar describe la problemática de Salud Bucal de adultos que transitan el proceso de desinstitucionalización; en segundo lugar se aborda el marco jurídico que sostiene el proyecto de intervención propuesto y por último la perspectiva económica desde el análisis de la estructura de costos del mismo.

Las concepciones de Salud Mental han tenido avances y transformaciones a lo largo de la historia. Las más complejas y desarrolladas tuvieron variados niveles de adhesión, progreso, permanencia y transferencia a la práctica. ${ }^{76}$ Es muy complejo concluir hoy, en la postmodernidad con una definición universalmente válida, pero encuentran coincidencia diferentes autores ${ }^{92,135,140}$ acerca de la importancia de los determinantes del medio y desarrollo social, de la percepción de la autonomía de las personas, de un interjuego dialéctico con el medio y la capacidad de enfrentar las decisiones con el mismo.

Este trabajo considera, entonces, que las categorías salud-enfermedad mental están históricamente determinadas por factores macroeconómicos y macrosociales, con un cargo valorativo de lo que se considera normal y patológico de acuerdo al contexto, a los enfoques teóricos y criterios diagnósticos utilizados y a las concepciones filosóficas, morales, psicológicas vigentes y los modelos médicos predominantes. ${ }^{27,50}$

La ley Nacional de Salud Mental $26657^{69}$ así lo ratifica en el Art. 3o: "se reconoce a la salud mental, como un proceso determinado por componentes históricos, socioeconómicos, culturales, biológicos y psicológicos, cuya preservación y mejoramiento implica una dinámica de construcción social...".

En Argentina, así como en el resto de América Latina y el Caribe la Salud Mental no se ha considerado por lo general prioritaria en las agendas gubernamentales. En el nivel de la decisión política se ha pensado que estos problemas no son importantes o que hay muchos otros para priorizar. Por lo tanto el desarrollo de la atención y mucho más la rehabilitación debió enfrentar limitaciones y dificultades, quedando prácticamente fuera de la agenda la de la Salud bucal, como lo indicaron los valores registrados.

Sin embargo, es cierto que los trastornos mentales, si bien pueden tener un impacto menor en la mortalidad, constituyen un problema sanitario en crecimiento y 
muestran un alto porcentaje en la Discapacidad. Se estima que la depresión va ha ocupar el primer lugar en los próximos veinticinco años como causa principal de Discapacidad, constituyendo un problema sanitario y social con un elevado impacto en la economía de un país.

La situación muestra hoy que los trastornos neurológicos y mentales representan en el mundo el $13 \%$ de la carga global de la enfermedad, alcanzando en la región $22.2 \%$, y experimentan un acelerado crecimiento si se compara con el $8.8 \%$ de años de vida ajustados por discapacidad (AVAD) alcanzado en 1990. Si se toma en cuenta la depresión que en el año 2000 ocupaba el cuarto lugar como causa de morbilidad, las estimaciones para el 2020 la ubican en el segundo y, junto con el alcoholismo constituirán los problemas más importantes a resolver en el campo de la Salud Mental. ${ }^{19,126}$

Esta carga que es cada vez mayor podría obedecer a la transición epidemiológica, es decir al desplazamiento de las enfermedades trasmisibles por las enfermedades crónicas, a la priorización de ciertas enfermedades emergentes como la violencia o el SIDA y a un cambio en la estructura poblacional, que alcanza una expectativa de vida más alta y colocan a las personas en riesgo de sufrir los trastornos mentales propios de la adultez. ${ }^{50}$ En Argentina la expectativa es 73.77 años, siendo para varones 70.04 y para mujeres 77.54 ; en la provincia de Buenos Aires alcanzan valores de 73.99 (varones 70.02, mujeres 78.03) ${ }^{46}$.

Un informe del Banco Mundial proyecta para el 2015 un aumento del 28\% de la población total para América Latina y el Caribe, alcanzando cifras de 622 millones de personas ${ }^{119,136}$. El aumento poblacional más rápido se observará en las personas de edad más avanzada. La población de 60 años y más aumentará en más de un $60 \%$ y la comprendida entre 15 y 49 años de edad, que corre el mayor riesgo de sufrir problemas mentales en la edad adulta, aumentará en $22 \%$.

En la provincia de Buenos Aires, la muestra estudiada no excede esta estimación, ya que las edades de ambos grupos GI y GD están comprendidas dentro de esos rangos (Gl 49.65 (10.90) años y GD 48.02 (9,02) años); por lo tanto, el conocimiento de la prevalencia del componente bucal de la salud permite estudiar la brecha existente en la posición de la atención, es decir, el porcentaje de personas que padecen problemas bucales sumados a las alteraciones mentales y que reciben escasa o nula atención.

Diferentes estudios de investigación conducidos en países desarrollados describieron condiciones de precariedad y estados relativamente pobres de la Salud Bucal de pacientes con alteraciones mentales, comparados con la población general del área donde los estudios fueron desarrollados. (Anexos 1 y 7 ) 
Los resultados encontrados por Morasso y col. $^{80}$ (2005) revelaron valores expresados como media aritmética y desvío estándar de 89.84 (41.91) superficies cariadas $\mathrm{C}$, perdidas $\mathrm{P}$ y obturadas $\mathrm{O}$ en adultos institucionalizados con un rango etáreo entre 20 y 65 años, similares a los hallados por Angelillo ${ }^{5}$, 88.6 en Italia (2005). Se encontró diferencia significativa con el estado bucal de la población general asistida en el área de influencia de la institución estudiada, con valores 52.32 (32.46) superficies CPO.

Estos resultados fueron comparativamente mayores a los encontrados en Dinamarca por Hede $\mathrm{B}^{42}$ que estudió 278 adultos institucionalizados con un rango de edad más extendido (18 - 78), alcanzando valores de 70.5 (41.1).

La situación diferencial con el resultado de la muestra estudiada probablemente resida en que los pacientes de la institución neuropsiquiátrica en Dinamarca, recibían un programa de cuidados dentales sistematizado, aunque los criterios para la participación de los pacientes fueron negligentes.

En Argentina se encontró en 2005 la mayor consecuencia residual de la enfermedad dental en las superficies perdidas $(P)$, que en el grupo Institucionalizado alcanzó valores de $85.49 \%$. Los resultados del análisis multivariado mostraron que las superficies afectadas estuvieron influenciadas por la duración de la enfermedad mental en una escala de aproximadamente 1 superficie por año; mientras que en Dinamarca la mayor carga de enfermedad se encontró en las superficies cariadas con valores de $55 \%$, cuando los de la población general fueron $23 \%$.

Los resultados de la presente investigación son coincidentes con los realizados en Catanzaro, por Angelillo y col. ${ }^{5}$ en un grupo de 297 sujetos internados con una edad media de 55.1 y 12 años de institucionalización. La muestra de adultos Institucionalizados del Hospital Alejandro Korn y la de los que se encuentran en proceso de desinstitucionalización estudiadas registra edades menores, 49.65 y 48.02 respectivamente por estar éstos últimos comprendidos en la población económicamente activa (14-64). Sin embargo, los valores CPOD alcanzados son mayores (GI 19.67, GD 15.95). Ambos estudios registran la mayor carga de la enfermedad en la pérdida dentaria $(P)$, con valores 19.95 vs. 13.6 encontrado en Italia.

Pregliasco F. ${ }^{123}$ estudió 219 adultos con retraso mental internados en el Instituto Sacra Famiglia en la cercanía de Milán y Vigil M. ${ }^{133}$ en Dinamarca 407, y Velazco $0 .{ }^{132}$ en España encontraron valores CPOD mayores: 23.1, 26.1 y 24.9 respectivamente; también estos autores reportaron los valores más altos en la pérdida dentaria.

Los fundamentos de la rehabilitación y externación asistida (Programa PREA) consideran que las acciones de rehabilitación logran revertir la exclusión social. 
El programa PREA hace referencia a la escasez de prácticas de rehabilitación en la atención psiquiátrica convencional y a la existencia de antecedentes de acciones de rehabilitación como avances en los logros para revertir la exclusión social; que incluye un trabajo intersectorial. Sin embargo, el sector de los profesionales de la salud bucal queda prácticamente excluido y solamente es mencionada la higiene bucal en la evaluación de la competencia personal o autocuidados como una parte de la higiene personal.

Asimismo se evalúa el afrontamiento personal y social como la capacidad en el manejo de las habilidades sociales y relaciones interpersonales (c.2 anexo 3 del Programa PREA) basadas en las habilidades para la comunicación y trato social, sin tener en cuenta que éstas no podrán realizarse plenamente sin lograr la rehabilitación de la función fonética perdida por la ausencia de piezas dentarias.

Las relaciones afectivas e interpersonales que conforman el entorno social o red de apoyo social también se ven deterioradas por la pérdida o disminución de las funciones fonética y estética, esta última en una sociedad postmoderna donde la imagen tiene un valor predominante.

La jurisprudencia así como algunos doctrinarios (Cifuentes 2008, Bidart Campos 2006) no establecen un criterio único para valorar la intensidad del daño; en cambio consideran que el menoscabo estético es una lesión a las condiciones estéticas, a la belleza o armonía del cuerpo, objetivamente considerada como su integridad personal.

El baremo internacional determina un cuadro ligero de incapacidad permanente parcial con la pérdida de 1, 2, ó 3 dientes y moderado cuando la pérdida alcanza valores hasta 15. Briñón $E \cdot{ }^{15}$ (2006) indica un valor 4 o mayor para determinar una pérdida o debilitación permanente de las tres funciones.

El baremo general para el fuero civil de Altube-Rinaldi ${ }^{2} 2005$, no diferencia los valores para las funciones: que aplicado a nuestro objeto de estudio resultan para la función masticatoria 56.80 (33.75) y para la estética/fonética 8.63 (4.81).

Nuestro resultado mostró mayor incapacidad en mujeres que en varones para las funciones del sistema bucal, pero no se encontró significatividad en las diferencias.

El coeficiente de determinación (variables edad, sexo y patologías) para la función masticatoria es de 0.2949 y para la estética/fonética de 0.2935 . Sólo $29.45 \%$ y $29.35 \%$ del total de dientes perdidos y por lo tanto de la funcionalidad se debe a las variables edad sexo y patologías.

Los valores encontrados para las funciones masticatoria, estética y fonética permitieron determinar, según los baremos aplicados, una debilitación permanente o 
pérdida de la función compatible con incapacidad en los enfermos psiquiátricos que son transferidos al proceso de desinstitucionalización.

La rehabilitación de la pérdida haría suponer una mejoría en la autoimagen y la autoestima; el verse bien y brindar un aspecto agradable a los demás son indicadores de la posibilidad de mejoramiento de las redes de apoyo social.

Los resultados obtenidos por observación en la fase documental propuesta permitieron determinar una extrema complejidad jurídica.

Se enumeró en este trabajo la normativa internacional que protege jurídicamente la Discapacidad y específicamente la Discapacidad Mental, la protección por el Derecho Argentino, la ratificación de derechos y garantías constitucionales de la Constitución de la Provincia de Buenos Aires.

Sin embargo, la displicencia e insensibilidad de algunos operadores jurídicos favoreció la reiterada afectación de los derechos de estos pacientes, de los que tanto se habla en textos constitucionales, legislativos, documentos internacionales y en el discurso doctrinario, pero que en la práctica pasan a ser solo derechos proclamados o simbólicos.

Por eso la visibilidad es el primer gran problema a enfrentar y llamar a estos individuos como son:¿son personas?. Y si son personas ¿son entes morales autónomos?. Si son autónomos, ¿ tienen derechos? En este trabajo derecho a la Salud Bucal, que debe hacerse valer.

Esta condición genera una situación de conflictividad: ¿conoce el legislador o sus asesores las necesidades, los problemas, la disposición de la tecnología para su solución?

La respuesta está implícita en el Art. 35 de la ley marco $26657^{69}$, que normaliza la realización de un Censo Nacional que deberá reiterarse con una periodicidad máxima de dos años para relevar la situación de las personas institucionalizadas.

No hay ninguna disminución a priori, no hay capitis diminutio ${ }^{75}$ condición que permite erradicar la exclusión y descalificación que todavía se escucha en la calle, en oficinas administrativas aun de las instituciones o en aquellos lugares donde se forma este lenguaje de exclusión, que separa y transfiere a aquel que está con problemas mentales a otro mundo que prácticamente no existe.

Esta enunciación es el enfoque de los estrados judiciales en las sentencias y que consideran que la disfuncionalidad mental de ninguna manera altera sus derechos como persona.

Muchas diferencias que aún todavía persisten son invisibles porque se niegan, se declaran inexistentes, aun a través del lenguaje. La visibilidad del problema 
permitiría ponerlo en un escenario de discusión para las políticas públicas pertinentes a las necesidades individuales.

La ley Nacional de Salud mental, sancionada y promulgada en la etapa de finalización de este trabajo de tesis, abre nuevos interrogantes y desafíos:

- Promueve la desinstitucionalización, fomenta la internación en hospitales generales y prohibe la creación de nuevos manicomios, neuropsiquiátricos o instituciones de internación monovalentes públicos o privados.

Paradójicamente la situación de pauperización que afecta a esta población y que incluye a sus familias de procedencia provocó una revalorización del valor de la cama del hospital psiquiátrico; por lo tanto muchos pacientes rechazan ser externados o no son buscados por su familia a pesar de estar en condiciones de revertir el alta médica.

Por otra parte, los exiguos presupuestos en materia de Salud Mental determinan que muchas financiadoras propicien la no internación o la externación precipitada de estos pacientes que pasan a convertirse en una variable de ajuste.

La situación es compleja ante un cambio de paradigma que deberá enfrentar modelos mentales reactivos, de alta conflictividad y resiliencias, donde la representación de la locura genera muchos prejuicios y una ignominiosa segregación.

¿Están preparados los profesionales de la salud y pacientes sin diagnóstico de alteraciones mentales, las familias de los involucrados y la sociedad toda para asumir los cambios que implica ese proceso de transformación hacia una real inclusión?... El desafío está pendiente.

Desde este marco, el ejercicio del derecho a la libertad, la autodeterminación y demás derechos fundamentales como el de la atención de la salud - explícitamente tutelado como extensión del derecho a la vida y a la integración psicofísica constituiría un marco para el desarrollo e implementación de políticas públicas que consideren la rehabilitación del componente bucal de la salud: incluiría la prevención y como acción exigible al Estado evitaría la judicialización del daño.

La proyección de la demanda de rehabilitación para estos grupos vulnerables muestra que la prospectiva de la necesidad es geométrica, mientras los recursos para la resolución son limitados y de característica aritmética.

Puede cuestionarse si todo lo posible en término de unidades de atención odontológica tiene sentido hacerse: es decir se pone en duda si el rendimiento marginal de la atención no es muy bajo en función de la salud real en relación al costo, debido a los rendimientos decrecientes frente a las limitaciones biológicas.

Las características estructurales del mercado de los cuidados de la salud representan intentos compensadores para superar situaciones de asignaciones 
subóptimas derivadas de la no comerciabilidad de muchos riesgos y de la información imperfecta.

Estos rasgos explican que los intentos no llegan a satisfacer el modelo de funcionamiento ideal (competencia perfecta) y constituyen a su vez una barrera adicional a la optimalidad.

La idea dominante implícita o explícita es que es el Estado, al menos en sus actividades económicas, el encargado de remediar esta disfuncionalidad, sobre todo en aquellas personas que se encuentran en una posición desfavorable como consecuencia de los acontecimientos considerados, en este caso adultos con alteraciones mentales en proceso de reinserción social.

Se analizó la estructura de costos de la reposición de las piezas dentarias perdidas, por ser la consecuencia residual de la enfermedad bucal que alcanzó mayores valores en este grupo de pacientes.

Se cuantificó como producto las prótesis removibles parciales y completas, por considerarlas un método sencillo en el proceso de producción, de bajos costos relativos y de similares características a la cobertura del Programa de Prótesis Sociales para los beneficiarios del Instituto Obra Médico Asistencial (IOMA) en la provincia de Buenos Aires; es un modelo que puede ser replicado en servicios de atención de Salud Bucal del sistema público.

Si se considerara un incremento de $100 \%$ de los tiempos de producción estimados - por tratarse de un adulto con alteraciones del comportamiento y que requiere una atención diferencial; para 71 unidades código 040201 y 12 código 040214 (177.5 y 60 horas respectivamente) - este tiempo incrementado alcanzaría un valor para toda la producción de 475 horas que resultan el $39.77 \%$ del total de horas netas anuales trabajadas para un odontólogo principal y $36.27 \%$ para el Residente.

Aún si se considerara este incremento en el proceso de producción, el odontólogo con carga horaria de 36 horas semanales estará en condiciones de realizar por año 238.88 prótesis removibles parciales (código 040201) y 119.44 prótesis completas (código 040214), valores significativamente mayores a los observados.

Se requiere un cambio radical del modelo asistencial centralizado en la ubicación espacial del proveedor y abordaje biomédico de corto plazo, a uno centrado en la dimensión temporal del paciente, de carácter biopsicosocial de largo plazo. Este último le dará relevancia a la comorbilidad con inclusión de la dimensión social.

Los sistemas de salud son reactivos; están concebidos para responder a casos agudos $y$, cuando se ha resuelto esa fase en la situación de las personas con 
problemas mentales, existe indefinición de la infraestructura, de los recursos humanos, aptitudes y responsabilidades que pudieran facilitar su atención adecuada.

Como resultado de este abordaje, la atención de la salud mental se reduce por un lado al tratamiento biomédico a corto plazo en el ámbito hospitalario y por el otro a una discutible rehabilitación que forma parte de un paquete aislado de intervenciones genéricas de asistencia social.

El desconocimiento de la dimensión social conduce a una asistencia inapropiada al confundir el entretenimiento con la rehabilitación. "La rehabilitación psicosocial no consiste en entretener a los pacientes con actividades organizadas por personal no capacitado plenamente o por especialistas en técnicas más insólitas (pinturas, teatros, juegos, canto, escultura, etc.).

Lo que la rehabilitación persigue es facilitar al paciente la oportunidad de rescatar su condición de ciudadano mediante la recuperación de las aptitudes para la vida diaria. La rehabilitación de los enfermos mentales graves puede constituir una tarea asistencial muy compleja que requiere estrategias y alianzas interdisciplinarias e intersectoriales". ${ }^{119}$

La colaboración intra e intersectorial es esencial para fomentar la existencia de una amplia gama de servicios necesarios para apoyar el tratamiento y la atención de las personas, su recuperación y su integración social en la comunidad. Por consiguiente la colaboración de la salud mental con otros sectores de la salud general - así como con otros sectores relacionados pero externos al ámbito sanitario - es decisiva para el éxito de un modelo que aborde todas las dimensiones de la atención de la salud mental ${ }^{141}$

El apoyo de las profesiones de la salud no especializadas (atención holística) constituye una eficaz intervención para la promoción de la causa a favor de la salud mental. Al tener la oportunidad de interactuar positivamente con las personas, como sujetos afectados por trastornos mentales su participación colabora con el cambio de concepciones erróneas.

La información obtenida a partir de la muestra constituye un insumo técnico para que planificadores, financiadores y equipos asistenciales tomen conciencia sobre la condición de sujetos de derecho de las personas con alteraciones mentales, de la protección jurídica y el fundamento económico para el proceso de toma de decisiones.

Su implementación permitiría el desarrollo de políticas con perfiles de uso racional de los recursos en la intervención de la Salud Bucal que incluya las prácticas odontológicas pertinentes a las necesidades relevadas. 
Por lo tanto, la inclusión de la rehabilitación de la funcionalidad bucal, la reconversión de los procesos generaría valor a una lógica organizacional de un Programa Integral e Intersectorial para la Desinstitucionalización del adulto con alteraciones mentales en busca de la reinserción social.

Este trabajo basado en la evidencia obtenible, en los valores de la población, con análisis estadístico con características de validez y exactitud, pretendió transformar la información en conocimiento para que constituya un instrumento de aplicación general en el marco de interacción de la ciencia epidemiológica, jurídica y económica aplicadas a la salud. 


\section{BIBLIOGRAFÍA}


1.- Al-Hiyasat A.S., Khasawneh S. F., Khader Y.S. 2006. Tooth Wear Among Psychiatric Patients: Prevalence, Distribution, and Associated Factors. Int. Journal Prost. 19: 403-409.

2.- Altube J.L, Rinaldi C.A. 2008. Baremo General para el Fuero Civil. Ed. García Alonso.1ra ed. 2da. Reimpresión. Buenos Aires Argentina Cap. XIII; 143-144.

3.- Álvaro J.L. 1992.Diccionario Crítico de Ciencias Sociales. Universidad Complutense de Madrid. Madrid.

4.- Amico L. 2002. Desmanicomialización: hacia una transformación de los dispositivos hegemónicos en salud mental. Margen 35. Revista de trabajo Social $35 ; 5$.

5.- Angelillo, I. F., Nobile, CGA., Pavia, M. De Fazio, P. Puca, M., Amati, A.1995.Dental Health and treatment needs in institucionalized psychiatric patients in Italy. Community Dent. Oral Epidem. 23: 360-4.

6.- Arrow, Kenneth J., Raynaud, Hervé. 1989. Opciones sociales y toma de decisiones mediante criterios múltiples. Alianza Ed. ISBN 978-84-206-6702-7.

7.- Asociación Mundial de Psiquiatría. Declaración de Hawai I. 1977. Implicancias Éticas Específicas en Psiquiatría.

8.- Asociación Mundial de Psiquiatría. Declaración de Hawai II. 1983. Implicancias Éticas Específicas en Psiquiatría.

9.- Asociación Mundial de Psiquiatría. 1989. Declaración de Atenas. Propósitos y Puntos de Vista sobre los Derechos y Protección Legal de los Enfermos Mentales.

10.- Astorga Gatjens L.F. 2009. Incluyendo a las personas con discapacidad en las políticas de desarrollo. Instituto Interamericano de Desarrollo ID. Documento Básico: 2-4.

11.- Basaglia F. y col.1989. Razón, locura y sociedad. Ed. Siglo XXI. México. 
12.- Berman Bieler R. Desarrollo Inclusivo: un aporte desde la discapacidad. 2006. Equipo de Discapacidad y Desarrollo Inclusivo de la Región de Latinoamérica y El Caribe. Banco Mundial: 1-2.

13.- Bidart Campos G.J. 1994. La interpretación del sistema de Derechos Humanos. Ed. Ediar. Buenos Aires. Argentina.

14.- Bidart Campos G.J. 2006. Teoría general de los Derechos Humanos. Ed. Astrea. Buenos Aires. Argentina.

15.- Briñón E. 2006. Odontología Legal y Práctica Forense. Ed. Purinzon. Buenos Aires. Argentina.

16.- Cabral de Mello M., Borneman T., Levav I.eds. 2001. Mental Health World Health ministers call for action. Geneva; WHO.

17.- Casado González. Por qué Bioética y Derecho?.2002. Acta Bioética. Año VIII. №183.

18.- Cifuentes Santos. 2008. Derechos Personalísimos. Ed Astrea. Buenos Aires. Argentina.

19.- Cohen H. 2010. La Transformación del Hospital Psiquiátrico y la Atención en Comunidad. Jornadas Salud Mental 2010. Hospital Interzonal de Agudos y crónicos "Dr. A. Korn".

20.- Consejo de Europa. 1950. Convención Europea para la Protección de los Derechos Humanos y Libertades Fundamentales (CEDH). Roma.

21.- Consejo de Europa. 1953. Protocolo Adicional para la Protección de los Derechos Humanos y Libertades Fundamentales (CEDH). 213 U. N. T. S. 222. Paris.

22.- Confederación Odontológica de la República Argentina. 1995. Programa Nacional de Garantía y Calidad de la Atención Odontológica; 39-43.

23.- Constitución de la Ciudad Autónoma de Buenos Aires. BO 3/2/1998. 
24.- Constitución de la Nación Argentina. 1994.

25.- Constitución de la Provincia de Buenos Aires. 1994.

26.- De Angel Yagues R. 1999. Responsabilidad civil por actos médicos. Problemas de prueba. Madrid, Civitas: 243-55.

27.- Delgado Bueno S. alternativas al internamiento involuntario. 1994. Psiquiatría Legal y Forense. Madrid: Colex.

28.- Despouy, L. 1993. "Los derechos humanos y las personas con discapacidad". ONU. N.Y.

29.- DSM IV Manual Diagnóstico y estadístico de los trastornos mentales.2003. Ed. Masson S.A. Buenos Aires. Argentina.

30.- Espósito W. Tratado de Contabilidad de Costos. 1996. Ed. Macchi. Buenos Aires. Argentina.

31.- Federación Mundial para la Salud mental. 1989. Declaración de Luxor. Derechos Humanos para los Enfermos Mentales. Luxor. Egipto.

32.- Foucault M. Historia de la locura en la época clásica. 1990. Fondo de cultura económica. México.

33.- Gabre P.,Gahnberg I. 1997. Inter-relationship among degree of mental retardation, living arrangements, and dental health in adults with mental retardation. Special care in dentist 17(1): 7-12.

34.- Gabre, P., Martinsson T, Gahnbreg, L.1999. Incidence of, and reasons for, tooth mortality among mentally retarded adults during a $\mathbf{1 0}$ - year period. Acta Odont. Scand. 57: 56- 61.

35.- Galende E. 1994. Psicoanálisis y salud mental: para una crítica de la razón psiquiátrica. Ed. Paidós Buenos Aires Argentina. 
36.- Galli V. Salud mental, definiciones y problemas. Documento de trabajo de la Dirección Nacional de salud mental. Ministerio de Salud. Buenos Aires. Argentina.

37.- Garay P., Fernández Bruno M.1994. “Casas de medio camino” Vetrex, Rev. Arg. De Psiquiatría, IV: 271.

38.- Giraldo A. 1989. Aplicación de un modelo metodológico al análisis económico de un proyecto de salud. Tesis doctoral.

39.- Goffman E.1994. Internados. Ensayos sobre la situación de los enfermos mentales. Amorrortu Editores. Buenos Aires.

40.- Goffman E.1989. Estigma. La identidad deteriorada. Amorrortu Editores. Buenos Aires. Argentina.

41.- Gómez F. 2000. El mito científico de la enfermedad mental. Asilo de cuerdos. Barranquilla: Antillas.

42. - Hede B. 1995. Oral health in Danish hospitalized psychiatric patients. Community Dent, Oral Epidemiol 23: 44 -8.

43.- Hernández S.,Vivanco C. Bertha. 2002. Caries en pacientes con enfermedad mental en un hospital de atención psiquiátrica. Rev. ADM. L y X. 3: 87-93.

44.- Hyde,S., Satariano, W.A., Weintraub, J.A. 2006. Welfare Dental Intervention Improves Employment and Quality of Life. J.Dent. Res. 85 (1): $79-84$.

45.- Hooft Pedro F. 2002. Bioética y jurisprudencia. Acta Bioética. Año VIII No 2: 214.

46.- INDEC. 2005. Proyecciones Provinciales de población por sexo y grupos de edad 2001- 2015. Serie Análisis Demográfico № 46. Buenos Aires. Argentina.

47.- Jenicek M., Clèroux R. 1993. Epidemiología, Principios, Técnicas, Aplicaciones. Ed. Masson - Salvat. Barcelona.

48.- John M.T., Micheelis W., Steele J. G. 2007. Depression as a Risk Factor for Denture Dissatisfaction. J. Dent. Res. 86 (9): 852 - 856. 
49.- Katz I. 1998. Al gran pueblo argentino salud. Ed. Eudeba. Buenos Aires. .Argentina.

50.- Kohn R., Levav I., Caldas de Almeida JM., Vicente B., Andrade L., CaraveoAnduagaJJ. et al. 2005. Los trastornos mentales en América Latina y el Caribe: asunto prioritario para la Salud Pública. Rev. Panamericana de Salud Pública18(4/5):229-40.

51.- Kraut A. 1997. Los Derechos de los Pacientes. Ed. Abeledo - Perrot Buenos Aires. Argentina.

52.- Kraut A.J. 2006. Salud Mental. Tutela Jurídica. Ed. Rubinzal - Culzoni Santa Fé. Argentina.

53.- Kumar M., Chandú GN., Shafiulla MD. 2006. Oral status and treatment needs in institutionalized psychiatric patients: One year descriptive cross sectional study. J Dental Res. 17: 171-177.

54.- Leavell H.R., Clark E.G. 1965. Preventive Medicine for the Doctor in his Community. Mc Graw -Hill Book Company.

55.- Lemus J D, Aragues y Oroz V, Lucioni M C y col. 2009. Administración hospitalaria y organización de Atención de la Salud. Ed. Corpus 1a․ ed. Rosario: Cap.VIII: 159-160.

56.- Ley 22431. Sistema de Protección Integral de los Discapacitados. BO. 20/03/1981.

57.- Ley 23054. Aprobación Convención Americana de Derechos Humanos Pacto San José de Costa Rica. BO. 03/08/1995.

58.- Ley 23313. Aprobación Pactos PIDESC y PIDSC y sus Protocolos Facultativos. BO. 13/05/1986.

59.- Ley 23592. Penalización de Actos Discriminatorios. BO. 05/09/1988.

60.- Ley 23660. Obras Sociales y Seguro. El Derecho a la Salud y su Protección. BO. 20/01/1989. 
61.- Ley 23876. Sistema de Protección Integral de Personas Discapacitadas. Modificatoria Art. 20 Ley 22431. BO. 01/11/1990.

62.- Ley 24240. Defensa al Consumidor. Autoridad y Aplicación. Procedimientos y Sanciones. Disposiciones Finales. BO. 15/10/1993.

63.- Ley 24515. Creación del Instituto Nacional contra la Discriminación, la Xenofobia y el Racismo (INADI). BO.03/08/1995.

64.- Ley 24901. Sistema de Prestaciones Básicas en Habilitación y Rehabilitación Integral a favor de las Personas con Discapacidad. BO. 05/12/1997.

65.- Ley 25280. Aprobación Convención Interamericana para la Eliminación de Todas las Formas de Discriminación contra las Personas con Discapacidad. BO. 04/08/2000. ADLA 2000- D 4086.

66.- Ley 25634. Sistema de Protección Integral de Personas con Discapacidad. Modificatoria 3er. Párrafo Art. 22 Inciso a Ley 22431. BO.27/08/2002.

67.- Ley 26378. Aprobación Convención sobre los Derechos de las Personas con Discapacidad y su Protocolo Facultativo. BO.09/06/2008.

68.- Ley 26480. Prestaciones Básicas. Atención Integral a favor de las Personas con Discapacidad. Incorporación del Inc.d del Art. 39 de la Ley 24901. BO. 06/04/2009.

69,- Ley 26657. Nacional de Salud Mental. Decreto PEN 1885/2010. BO. 03/1`2/2010.

70.- Lavolpe A., Capasso C., Smolje A. 2004. La gestión presupuestaria. Ed. Macchi. Buenos Aires, Argentina.

71.- Locker D., Jorovic A., Clarke M. 2004. Assesing the respossiveness of measures of oral health related quality of life.Community Dent. Oral Epidemiol.32: 10-18.

72.- López Couceiro Edmundo J. 1998. Costos. Conceptos básicos, terminología, ejercicios prácticos. Ed. Macchi Buenos Aires. Argentina. 
73.- Lorezetti R.L. 1995. Igualdad, antijuridicidad, diferencia: derecho a ser diferente, a no ser discriminado. Interpretación y protección. XV Jornadas Nacionales de Derecho Civil, en J. A. IV- 834.

74.- Lorenzetti R.L. 1998. La Empresa Médica. Ed. Rubinzal- Culzoni Santa Fé. Argentina.

75.- Lorenzetti R.L. 2009. Salud Mental, Legislación y Derechos Humanos. Salud Mental y Derechos Humanos. OPS:18.

76.- Lorez Arnaiz M.R. 1986. Hacia una epistemología en ciencias humanas. Ed. Belgrano. Buenos Aires. Argentina.

77.- Maldonado M. 2005. Lesiones Dentarias: Valoración del Daño Odontológico. Cuadernos de Medicina Forense. Año 4 № 1: 53-65.

78.- Ministerio de Salud de la Provincia de Buenos Aires. 1999. Programa de Rehabilitación y Externación Asistida. Res № 001832.

79.- Montero F. 2006. Righ to health and Reabilitation for Persons whith Disabilities. DAR. WHO. Geneva

80.- Morasso A. M., Cobanera A., Maini E., Della Ceca V. Bordoni N. 2005. Salud Bucal en pacientes institucionalizados con trastornos mentales y del comportamiento. Journal of Dental Res. Divisional Abstract.

81.- Morgado A., Abelha de Lima L. 1994. Desinstitucionalizacão: suas bases e a experiencia internacional. Journal Brasileiro de Psiquiatría 43 (1): 19-28.

82.- OEA. 1948. Declaración Americana de los Derechos y Deberes del Hombre. IX Conferencia Internacional Americana. Bogotá. Colombia.

83.- OEA. 1969. Convención Americana de Derechos Humanos (Pacto San José de Costa Rica). Serie de tratados № 36, 1144 U. N. T. S. 222; reimpresión OEA Ser. L. V./II.82. doc. 6 Rev. № 1.

84.- OEA. 1999. Convención Iberoamericana para la eliminación de todas las formas de Discriminación de las Personas con Discapacidad. A.G. Res 1608 (XXIX- 0/99). 
85.- OEA. 1999. Comisión Interamericana de Derechos Humanos (CIDH). Informe 63/99.

86.- OEA. 1961. Corte Interamericana de Derechos Humanos.

87.- OEA. 2007. Programa de Acción para el Decenio de las Américas por los Derechos y Dignidad de las Personas con Discapacidad. AG/RES. 2230 XXXVI $\mathrm{O} / 06$.

88.- OEA. 1988. Protocolo Adicional Convención Americana sobre Derechos Humanos (CADH). Protocolo de San Salvador. № 69, Ser. L V/II. 82 doc. 6 rev. $1: 189$.

89.- OEA. 2001. Recomendación de la Comisión Interamericana de Derechos Humanos sobre la Promoción y protección de las personas con Discapacidad Mental (CIDH). Informe anual, OEA /Ser. /L/V/II.111,doc 20 Rev.

90.- OMS. 2001.Clasificación Internacional del Funcionamiento, de la Discapacidad y de la Salud. (CIF) Ginebra.

91.- OMS. 1981. Informe del Comité de expertos de la O.M.S. en prevención de incapacidades, Rehabilitación. Serie de informes técnicos nro. 66, Ginebra.

92.- OMS. 2001. Informe sobre la salud en el mundo. Salud Mental: nuevos conocimientos, más esperanzas. Ginebra: OMS.

93.- ONU. 1986. Carta Africana de Derechos Humanos y de los Pueblos. Documento CAB/ LEG/ 67/ 3 Rev. № 5, 21 I. L. M. 58.

94.- ONU. 1984. Convención contra la Tortura y otros Tratos y Penas Crueles, Inhumanos y Degradantes. Asamblea General Res.39/46 Doc.of. Supl. (№.51) 197.

95.- ONU. 1965. Convención Internacional sobre la Eliminación de todas las formas de Discriminación Racial. Asamblea General. Res.2106 A (XX). 
96.- ONU. 2001. Convención Internacional sobre la Promoción y Protección de los Derechos y la Dignidad de las Personas con Discapacidad. Asamblea General Naciones Unidas Res. 56/119 doc. A/C.3/56/L.67/Rev. No1 párrafo 1.

97.- ONU. 2006. Convención Internacional sobre la Protección y Promoción de los Derechos y la Dignidad de las Personas con Discapacidad. Organización de Naciones Unidas A.G. Res A 61/611.

98.- ONU. 2008. Convención sobre los Derechos de la Persona con Discapacidad y su Protocolo Facultativo. A/ RES/ 62/170.

99.- ONU. 1979. Convención sobre la Eliminación de todas las formas de Discriminación contra la Mujer (CEDAW). 1979. Asamblea General Res.34/180 Doc.of. Supl. (№.46) 167.

100.- ONU. 1946. Convención sobre la Prevención y Sanción del Delito del Genocidio. AG. Res. 96 (I).

101.- ONU. 1982. Declaración de los Ancianos. Plan de Acción Integral sobre el Envejecimiento. A.G. Res 37/51.

102.- ONU. 1971. Declaración de los Derechos del Deficiente Mental. A.G. $2027^{a}$ Sesión Plenaria.

103.- ONU. 1975. Declaración de los Derechos de los Impedidos. A.G. $2433^{a}$ Sesión Plenaria.

104.- ONU. 1993. Declaración de Viena. A.G. A/ CONF 157/23.

105.- ONU. 1948. Declaración Universal sobre Derechos Humanos. Asamblea General Organización de Naciones Unidas. Res. 217 A (III) Paris. Francia.

106.- ONU. 1993. Normas Uniformes para la Igualdad de Oportunidades y la no Discriminación. Res 48/96, DC2- 1302. (NORUN).

107.- ONU. 1966. Pacto Internacional de Derechos Civiles y Políticos (PIDCP). A/Res/ 2200 A (XXI) Supl. (№ 16) 42. 
108.- ONU. 1989. Pacto Internacional de Derechos Civiles y Políticos (PIDCP).Protocolo Facultativo (2do). Res 44/128.

109.- ONU. 1966. Pacto Internacional de Derechos Económicos Sociales y Culturales (PIDESC). A/Res/ 2200 A (XXI) Supl. (№ 16) 49.

110.- ONU. 1991. Principios para la Protección de los enfermos y el mejoramiento de la atención de la Salud Mental. A.G. Res 46/119, 46 ONU GAOR (Sup № 49): 189, ONU Doc 46/49 Nueva York.

111.- ONU. 1982. Programa de Acción Mundial para los Impedidos. A.G. Res 37/52.

112.- OPS/OMS. 2005. Atención Primaria de la Salud y Rehabilitación. Programa Regional de Rehabilitación. Doc.de trabajo Managua.

113.- OPS/OMS. 2003. CIE- 10. Actualización de la Clasificación Internacional de Enfermedades, Décima Revisión (CIE- 10). Boletín epidemiológico, Vol. 24 № 2.

114.- OPS/OMS. 2005. Declaración de Brasilia. Conferencia Regional para la Reforma de los Servicios de Salud Mental. Ministerio de la República Federativa de Brasil.

115.- OPS/OMS. 1990. Declaración de Caracas. Conferencia Reestructuración de la Atención Psiquiátrica en América Latina. Caracas, Venezuela.

116.- OPS/OMS. 2006. La Discapacidad: Prevención y rehabilitación en el contexto del derecho al disfrute del más alto nivel posible de salud física y mental y otros derechos relacionados. Washington DC.

117.- OPS. 1991. Reestructuración de la atención psiquiátrica: bases conceptuales y guías para su implementación. Ed. Gonzáles Uzcátegui R., Levav I., Washington.

118.- OPS/OMS. 2007. Salud en las Américas. Publicación científica y técnica № 622 Vol.I:142-3Washington DC.

119.- OPS. 2009. Salud Mental en la Comunidad. 2da.Ed. Washington DC, 
120.- OPS. 2002. Seminario de Políticas Sociales y Rehabilitación Integral en los Países del Cono Sur. Montevideo. Uruguay.

121.- OPS/OMS. 2004. Situación de Discapacidad en las Américas. Programa Regional de Rehabilitación. Doc.de trabajo. Managua.

122.- Pantano L.1987. La discapacidad como problema social, un enfoque sociológico: reflexiones y propuestas. Ed. Eudeba. Buenos Aires. Argentina.

123.- Pregliasco F., Ottolina P., Mensi C., Carmagnola D., Giussani F. 2001.Oral health profile in a institutionalized population of Italian adults UIT mental retardation. Spec Care Dentist. 21 (6): $227-231$.

124.- Rekha, R., Hiremath, SS., Bharath,S. 2002. Oral Health Status and treatment requirements of hospitalized psychiatric patients in Bangalore City: a comparative Study. J.Indian Soc. Pedo. Prev. Dent. 20(2): 63 - 67.

125.- Rodríguez J. 2007. La Salud Mental en América Latina y el Caribe: desafios y perspectivas. Documento técnico de la Unidad de Salud Mental, Abuso de sustancias y rehabilitación. OPS/ OMS. Washington DC.

126.- Rodríguez J. 2009. La Salud Mental en América Latina y el Caribe: Retos y proyecciones. Salud mental y Derechos Humanos:77.

127.- Sagues Néstor P. 1998. Elementos del Derecho Constitucional, T 2 Ed. Astrea Buenos Aires. Argentina.

128.- Samuelson P., Nordhaus W., Pérez Henri D. 2006. Economía. Ed.Mc Graw Hill. Buenos Aires. Argentina. Capítulo 1.

129.- Serrano Escobar L, Tejada Ruiz C. 1994. Responsabilidad civil y del Estado en la prestación de los servicios médicos asistenciales. Ed. Jurídicas Gustavo Ibañez, Santa Fe de Bogotá.

130.- Strassburger C., Heydecke G., Kerschbaum T. 2004. Influence of prosthetic and implant therapy on satisfaction and quality of life: a systematic literature review. Part 1 - Characteristics of the studies. Int. J. Prosthodontic. 17: 83 - 93. 
131.- UN. 1987. Principios de Limburg. Implementation of the Internacional Covenant on Economic, Social and Cultural Rights. Doc.E.CN. 4/1987/17.

132.- Velazco, E., Machuca, G., Martínez S., A., Ríos, V. Lacalle, J., Bullon, P. 1997. Dental Health among institucionalizad psychiatric patients in Spain. Special Care Dent. 17 (6): 203-206.

133.- Vigild, M., Brinck J.J., Chiristensen J. 1993. Oral Health and treatment needs among patients in psychiatric institutions for the elderly. Community Dent. Oral Epidemiol. 21: 169-71.

134.- Zito Lema V. 2001. Conversaciones con Enrique Pichón Rivière sobre el arte y la locura. Ediciones Cinco Buenos Aires. Argentina.

135.- Weingarten, C. 1997. Responsabilidad por prestaciones odontológicas. Ed. Astrea. Buenos Aires. Argentina.

136.- World Bank. 2002. World Development Indicators. New York: World Bank.

137.- World Health Organization. 2005. Depression. http:// www.whoint/mental health/management/depression/definition/en/.

138.- World Health Organization (2003b). Investing in mental health. Geneva; World health organization.

139.- World Health Organization. 2005. Mental Health Atlas. Geneva.

140.- World Health Organization. 2007. http://www.who.Int/features/qa/62/es/print.html.

141.- World Health Organization. 2003. Organization of services for mental health. Ginebra OMS (paquete de orientación sobre políticas y servicios de salud mental). 
ANEXOS 


\section{ANEXO № 1}

Situación de Salud Bucal en Pacientes Psiquiátricos Institucionalizados

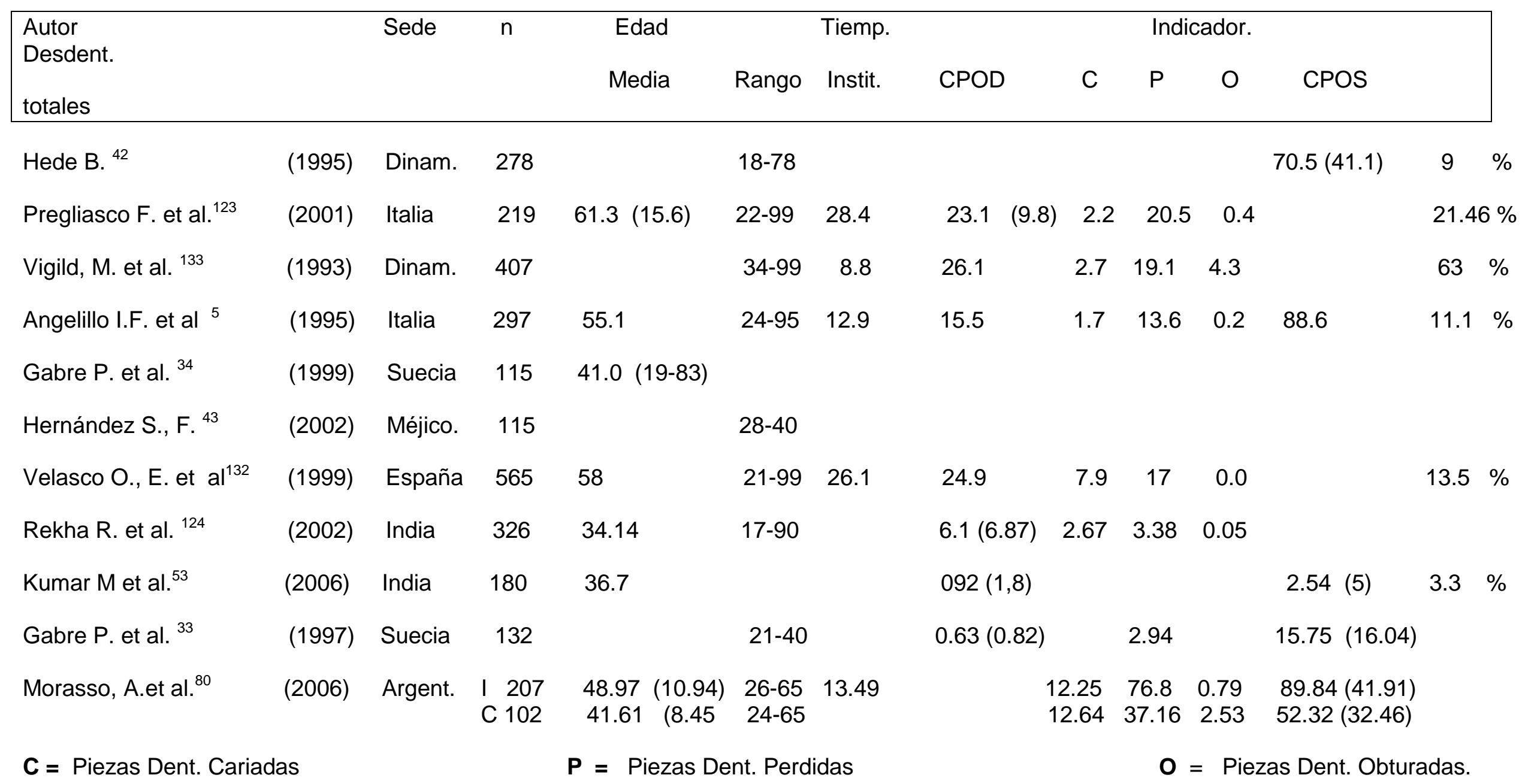

Fuente: Elaboración propia 
ESCALA SALARLAL 10.471 JULIO/10

DECRETO

VALOR BASE\$ 921,36 (CATEG. 830 HS)

\section{$\$ 921,36$}

(Basico cat 8 en 30 horas"coeficiente)"Regimen horario

\begin{tabular}{|c|c|c|c|c|c|c|}
\hline ANOS & GRADO & CLASE & COEFIC. \% & & IRHORARIO & SUELDO \\
\hline $0 A 5$ & MASISTENTE & 01 & 6,75 & 24 & 24 HORAS & $\$ 1.492,60$ \\
\hline OA5 & MASISTENTE. & 02 & 6,75 & 34 & 34 HORAS & $\$ 2.114,52$ \\
\hline OA5 & MASISTENTE. & 03 & 6,75 & 36 & 36 HORAS & $\$ 2,238,90$ \\
\hline OA5 & MASISTENTE. & 04 & 6,75 & 44 & 44 HORAS & $\$ 2.736,44$ \\
\hline \multirow[t]{2}{*}{ OA5 } & M.ASISTENTE. & 05 & 6,75 & 48 & 48 HORAS & $\$ 2.985,21$ \\
\hline & & & & & & \\
\hline $5 A 10$ & M.AGREGADO & 11 & 7,15 & 24 & 24 HORAS & $\$ 1.581,05$ \\
\hline $5 \mathrm{A10}$ & M. AGREGADO & 12 & 7,15 & 34 & 34 HORAS & $\$ 2.239,83$ \\
\hline 5 A10 & M. AGREGADO & 13 & 7,15 & 36 & 36 HORAS & $\$ 2.371,58$ \\
\hline 5 A10 & M. AGREGADO & 14 & 7,15 & 44 & 44 HORAS & $\$ 2.898,60$ \\
\hline \multirow[t]{2}{*}{$5 A 10$} & M. AGREGADO & 15 & 7,15 & 48 & 48 HORAS & $\$ 3.162,11$ \\
\hline & & & & & & \\
\hline $10 \mathrm{~A} 15$ & M.HOSP. "C" & 21 & 7,60 & 24 & 24 HORAS & $\$ 1.680,56$ \\
\hline $10 \mathrm{~A} 15$ & M.HOSP. "C" & 22 & 7,60 & 34 & 34 HORAS & $\$ 2.380,79$ \\
\hline 10A15 & M.HOSP. "C" & 23 & 7,60 & 36 & 36 HORAS & $\$ 2.520,84$ \\
\hline $10 \mathrm{~A} 15$ & M.HOSP. "C" & 24 & 7,60 & 44 & 44 HORAS & $\$ 3.081,03$ \\
\hline \multirow[t]{2}{*}{$10 \mathrm{A15}$} & M.HOSP. "C" & 25 & 7,60 & 48 & 48 HORAS & $\$ 3.361,12$ \\
\hline & & & & & & \\
\hline $15 A 20$ & M.HOSP."B" & 31 & 8,00 & 24 & 24 HORAS & $\$ 1.769,01$ \\
\hline $15 A 20$ & M.HOSP."B" & 32 & 8,00 & 34 & 34 HORAS & $\$ 2.506,10$ \\
\hline $15 \mathrm{~A} 20$ & M.HOSP."B" & 33 & 8,00 & 36 & 36 HORAS & $\$ 2.653,52$ \\
\hline $15 \mathrm{~A} 2 \mathrm{O}$ & M.HOSP."B" & 34 & 8,00 & 44 & 44 HORAS & $\$ 3.243,19$ \\
\hline $15 A 20$ & M.HOSP."B" & 35 & 8,00 & 48 & 48 HORAS & $\$ 3.538,02$ \\
\hline \multirow{5}{*}{$\begin{array}{l}\text { MASDE } 20 \\
\text { MAS DE } 20 \\
\text { MASDE } 20 \\
\text { MAS DE } 20 \\
\text { MAS DE } 20 \\
\end{array}$} & IM HOSP "A" & & & & & \\
\hline & M.HOSP."An & $\frac{41}{42}$ & $\frac{8,49}{8,45}$ & $\frac{24}{34}$ & 34 HORAS & $\frac{\$ 1.868,52}{\$ 5.64707}$ \\
\hline & M.HOSP,"A" & 43 & 8,45 & 36 & 36 HORAS & $\$ 2.802 .78$ \\
\hline & M.HOSP."An" & 44 & 8,45 & 44 & 44 HORAS & $\$ 3.425,62$ \\
\hline & M.HOSP."A" & 45 & 8,45 & 48 & 48 HORAS & $\$ 3.737,04$ \\
\hline \multicolumn{6}{|c|}{ DIRECTOR EJECUTIVO } & $\$ 3.737,04$ \\
\hline
\end{tabular}


ESCALA SALARIAL RESIDENTES JULIO/10

Resolución 426-171292Establece coeficientes y de donde se saca el básico

básico asis!

36 hs. 0 ctto7

$\$ 1.433 .26$

\begin{tabular}{|c|c|c|c|c|c|}
\hline \multirow{2}{*}{ CAT } & \multirow{2}{*}{$\begin{array}{l}\text { MEDICOS } \\
\text { FUNCION }\end{array}$} & \multirow[t]{2}{*}{ COEF. } & \multirow{2}{*}{$\begin{array}{l}\text { (BASSE:MED.ASIST.36 HS.) } \\
\text { DENOMINACIÓN DEL CARGO }\end{array}$} & \multicolumn{2}{|c|}{ JUL-10|CONCEPTO } \\
\hline & & & & JELDO & 104 \\
\hline & \begin{tabular}{l|l|l}
60 11-SOLTERO \\
\end{tabular} & 1,700 & JEFE DE RESIDENTE 1ER.NIVEL & $4.296,31$ & $\$ 95,27$ \\
\hline & $60 \mid 12-C A S A D O$ & 1,850 & JJEFE DE RESIDENTE 1ER.NIVEL & $\$ 4.675,40 \mid$ & $\$ 103,68$ \\
\hline & 60)21-SOLTERO & 1,700 & E RESIDENTE 2ER.NIVEL & $\$ 4.296,31$ & $\$ 95,27$ \\
\hline & $60 \mid 22-C A S A D O$ & 1,850 & J JEFE DE RESIDENTE 2ER.NIVEL & $\$ 4.675,40$ & $\$ 103,68$ \\
\hline & 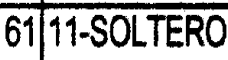 & 1,250 & ER.ANO 1ER.NIVEL & 159,05 & $\$ 70,05$ \\
\hline & 61)12-CASADO & 1,400 & R.AÑO 1ER.NIVEL & $3.538,14$ & $\$ 78,46$ \\
\hline & 61/21-SOLTERO & 1,650 & R.AÑO 2DO.NIVEL & 169,95 & $\$ 92,47$ \\
\hline & 61/22-CASADO & 1,800 & R.AÑO 2DO.NIVEL & $4.549,03$ & $\$ 100,87$ \\
\hline & \begin{tabular}{l|l|l}
62 & $11-$ \\
\end{tabular} & $\overline{1,400}$ & 1ER.NIVEL & $.538,14$ & $\$ 78,46$ \\
\hline & 62|12-CASADO & 1,550 & RES.2DO.AÑO 1ER.NIVEL & $\$ 3.917,22$ & $\$ 86,86$ \\
\hline & 62)21-SOLTERO & 1,650 & RES.2DOAÑO 2DO.NIVEL & $\$ 4.169,95 \mid$ & $\$ 92,47$ \\
\hline & 62) 22-CASADO & 1,800 & RES.2ER.AÑO 2DO.NIVEL & $\$ 4.549,03$ & $\$ 100,87$ \\
\hline & \begin{tabular}{l|l}
63 & $11-S O L T E R O$ \\
\end{tabular} & 1,650 & TES.3ER.ANO 1ER.NIVEL & $\$ 4.169,95$ & $\$ 92,47$ \\
\hline & 63 12-CASADO & 1,800 & RES.3ER.AÑO 1ER.NIVEL & $\$ 4.549,03$ & $\$ 100,87$ \\
\hline & 63 21-SOLTERO & 1,650 & RES.3ER.AÑO 2DO.NIVEL & $\$ 4.169,95$ & $\$ 92,47$ \\
\hline & $6322-C A S A D O$ & 1,800 & RES.3ERAÑO 2DO.NIVEL & $\$ 4.549,03$ & $\$ 100,87$ \\
\hline & 64 11-SOLTERO & 1,650 & IRES.4ER.ANO 1ER.NIVEL & $\$ 4.169,95$ & $\$ 92,47$ \\
\hline & 64 12-CASADO & 1,800 & RES.4ER.AÑO 1ER.NIVEL & $\$ 4.549,03$ & $\$ 100,8$ \\
\hline
\end{tabular}

\section{RESIDENTES BONIFICACIONES}

Ago-05 bonif.s/ap concepto $71-\$ 62,50+\$ 71,50=\$ 134,00$

Mar-08 bonif.clap. concepto $1043,91 \%$ BASICO MED.ASIST.36 HS.ESCALA OCT/07 * COEF.DE RESID.

Mar-10 SE APLICO DIRECTAMENTO EL AUMENTO DEL 10,59\%AL BÁSICO ANTERIOR.

JUI-10 SE APLICO DIRECTAMENTO EL AUMENTO DEL 8,5\% AL BASICO ANTERIOR.

DIFERENCIA SOLTERO A CASADO \$349,39 MARZO/10

DIFERENCIA SOLTERO A CASADO \$387,49 JULIO/10 
SCALA SALARIAL $10.430 \mathrm{JULIO} / 10$ ALOR DEL MODULO $\$ 0,5283$

0,5283 Art. 2 Decreto 1429/09

\begin{tabular}{|c|c|c|c|c|c|c|}
\hline ITEGO & MODULO & HORAS & $\begin{array}{l}\text { SUELDO } \\
36 \text { HORAS } \\
\times 1,20\end{array}$ & $\begin{array}{l}\text { SUELDO } \\
40 \text { HORAS } \\
1,333333\end{array}$ & \begin{tabular}{|l} 
SUELDO \\
42 HORAS \\
$\times 1,40$
\end{tabular} & $\begin{array}{l}\text { SUELDO } \\
\text { 4B HORAS } \\
1,60\end{array}$ \\
\hline 24 & 3818 & $\$ 2,017,05$ & $\$ 2.420,46$ & $\$ 2.689,40$ & $\$ 2.823,87$ & $\$ 3.227,28$ \\
\hline 23 & 3517 & $\$ 1.858,03$ & $\$ 2.229,64$ & $\$ 2,477,37$ & $\$ 2.601,24$ & $\$ 2,972,85$ \\
\hline 22 & 3447 & $\$ 1,821,05$ & $\$ 2.185,26$ & $\$ 2,428,07$ & $\$ 2.549,47$ & $\$ 2.913,68$ \\
\hline 21 & 3380 & $\$ 1.785,65$ & $\$ 2.142,78$ & $\$ 2,380,87$ & $\$ 2,499,92$ & $\$ 2.857,05$ \\
\hline 20 & 2287 & $\$ 1,208,22$ & $\$ 1,449,87$ & $\$ 1.610,96$ & $\$ 1.691,51$ & $\$ 1,933,16$ \\
\hline 19 & 2250 & $\$ 1.188,68$ & $\$ 1,426,41$ & $\$ 1.584,90$ & $\$ 1.664,15$ & $\$ 1.901,88$ \\
\hline 18 & 2219 & $\$ 1.172,30$ & $\$ 1.406,76$ & $\$ 1.563,06$ & $\$ 1.641,22$ & $\$ 1,875,68$ \\
\hline 17 & 2152 & $\$ 1,136,90$ & $\$ 1.364,28$ & $\$ 1.515,87$ & $\$ 1.591,66$ & $\$ 1.819,04$ \\
\hline 16 & 2006 & $\$ 1.059,77$ & $\$ 1.271,72$ & $\$ 1.413,03$ & $\$ 1,483,68$ & $\$ 1,685,63$ \\
\hline 15 & 1915 & $\$ 1.0$ & $\$ 1.214,03$ & $\$ 1.348,93$ & $\$ 1.416,37$ & $\$ 1.618 .71$ \\
\hline 14 & 1834 & 3,90 & $\$ 1.162,68$ & $\$ 1.291,87$ & $\$ 1.356,46$ & $\$ 1.550,24$ \\
\hline 13 & 1815 & 8,86 & $\$ 1.150,64$ & $\$ 1.278,49$ & $\$ 1.342,41$ & $\$ 1.534,18$ \\
\hline 12 & 1798 & 9,88 & $\$ 1.139,86$ & $\$ 1,266,51$ & $\$ 1.329,84$ & $\$ 1.519,81$ \\
\hline 11 & 1784 & $\$ 942,48$ & $\$ 1.130,98$ & $\$ 1.256,65$ & $\$ 1.319,48$ & $\$ 1.507,98$ \\
\hline 10 & 1772 & $\$ 936,15$ & $\$ 1,123,38$ & $\$ 1,248,20$ & $\$ 1.310,61$ & $\$ 1.497,84$ \\
\hline 9 & 1759 & 28 & $\$ 1.115,14$ & $\$ 1.239,04$ & $\$ 1,300,99$ & $\$ 1,486,85$ \\
\hline$\frac{1}{8}$ & 1744 & & $\$ 1.105,63$ & $\$ 1.228,47$ & $\$ 1.289,90$ & $\$ 1,474,17$ \\
\hline 7 & 1730 & 3,96 & $\$ 1.096,75$ & $\$ 1,218,61$ & $\$ 1,279,54$ & $\$ 1,462,33$ \\
\hline 6 & 1710 & 3,39 & $\$ 1.084,07$ & $\$ 1.204,52$ & $\$ 1.264,75$ & $\$ 1,445,43$ \\
\hline 5 & 1698 & $\$ 887,05$ & $\$ 1.076,46$ & $\$ 1,196,07$ & $\$ 1.255,87$ & $\$ 1.435,28$ \\
\hline 4 & 1682 & $\$ 888,60$ & $51.066,32$ & $\$ 1.184,80$ & $\$ 1.244,04$ & $\$ 1,421,76$ \\
\hline 3 & 1672 & $\$ 883,32$ & $\$ 1.059,98$ & $\$ 1,177,76$ & $\$ 1.236,64$ & $\$ 1.413,31$ \\
\hline 2 & 1667 & & $\$ 1.056,81$ & $\$ 1,174,23$ & $\$ 1,232,95$ & $\$ 1.409,08$ \\
\hline & .1520 & & $\$ 963,62$ & $\$ 1.070,69$ & $\$ 1.124,22$ & $\$ 1.284,83$ \\
\hline
\end{tabular}

\section{EY 10.430.BONIFICACIONES}

\section{JNIFICACIONES}

$\$ 60,00$ P.HOSP. DEC.207/04 Y DEC.1823/05.B.NO REMUN

071.

076-

$\$ 35,00$ 21 HS
$\$ 46,0028 \mathrm{HS}$
$\$ 50,0030 \mathrm{HS}$
$\$ 58,0035 \mathrm{HS}$
$\$ 60,0036 \mathrm{HS}$
$\$ 66,0040 \mathrm{HS}$
$\$ 80,0048 \mathrm{HS}$
$\$ 182,0030 \mathrm{HS}$
$\$ 243,0040 \mathrm{HS}$
$\$ 291,0048 \mathrm{HS}$

concepto importes

134- $4 \%$ basico $30 \mathrm{hs}$

151- $\$ 250,00$

10\% BAS. P.HOSP. DEC 637/07 Art 14

Acto

administratlvo

DEC.207/04 B.REMUNERATIVA

DEC.1823/05 B.REMUNERATIVA

079.

081

$\$ 291,0048 \mathrm{HS}$

Art 8 DEC 2953/07
B.REM..DEC. 1429/09.art.6

B.REM..DEC. 1429/09.art.6

B.REM.DEC.1429/09.art.6
B.REMUNERATIVA

\begin{tabular}{|r|r|}
\hline Marz/09 Art 7-ANEXO C-Dec. 1429109 \\
\hline FUERA DE LA GARANTIA \\
\hline $\begin{array}{r}\text { Deede Marz } 108 \text { B.Remunerat.Cat.1 de } \\
\text { REG.30HS.concep.082- }\end{array}$ \\
\hline$\%$ & IMPORTES \\
\hline $12,50 \%$ & $\$ 100,38$ \\
\hline $12,50 \%$ & $\$ 100,38$ \\
\hline $12,50 \%$ & $\$ 100,38$ \\
\hline $12,50 \%$ & $\$ 100,38$ \\
\hline $12,50 \%$ & $\$ 100,38$ \\
\hline $12,50 \%$ & $\$ 100,38$ \\
\hline $12,50 \%$ & $\$ 100,38$ \\
\hline $12,50 \%$ & $\$ 100,38$ \\
\hline $12,50 \%$ & $\$ 100,38$ \\
\hline $10,00 \%$ & $\$ 80,30$ \\
\hline $10,00 \%$ & $\$ 80,30$ \\
\hline $10,00 \%$ & $\$ 80,30$ \\
\hline $10,00 \%$ & $\$ 80,30$ \\
\hline $10,00 \%$ & $\$ 80,30$ \\
\hline $7,50 \%$ & $\$ 60,23$ \\
\hline $7,50 \%$ & $\$ 60,23$ \\
\hline $7,50 \%$ & $\$ 60,23$ \\
\hline $7,50 \%$ & $\$ 60,23$ \\
\hline $7,50 \%$ & $\$ 60,23$ \\
\hline $5,00 \%$ & $\$ 40,15$ \\
\hline $5,00 \%$ & $\$ 40,15$ \\
\hline $5,00 \%$ & $\$ 40,15$ \\
\hline $5,00 \%$ & $\$ 40,15$ \\
\hline $5,00 \%$ & $\$ 40,15$ \\
\hline
\end{tabular}

VIGENTE DESDE SE DEJA DE PAGAR

Feb-04

Aumenta $x$ dec.518/08 Bonif.FUERA

DE LA GARANTÍA

Mar-07

Oct-07

FUERA DE LA GARANTIA SALARIAL,BONIF.NO REMUN

Jul-10

FUERA DE LA GARANTIA 


\section{B\% BASICO PIENFERM B.REMUNERATIVA.FUERA DE LA GARANTIIA \\ 177. 19\% BÁSICO P.HOSP, B.REMUNERATIVA.FUERA DE LA GARANTIIA}

\begin{tabular}{|c|c|c|c|}
\hline IRANTIO030. & $\begin{array}{r}\$ 1,090,00 \\
\$ 1,036,00 \\
\$ 970,00\end{array}$ & $\begin{array}{l}\text { para Regimen de } 48 \mathrm{hs} \text {. } \\
\text { para Regimen de } 40 \mathrm{hs} \text {. } \\
\text { para Regimen de } 30 \mathrm{hs} \text {. }\end{array}$ & $\begin{array}{l}\text { ADEMÁS HAY QUE SUMARLE FUERA DE LA GARANTIA } \\
\text { CONCEPTO 079- } 081=082-095-151-039-034-177-178 \\
\text { DEC.54/05 Y } 637 / 07\end{array}$ \\
\hline 059. & $\$ 170,00$ & Ayuda Escolar & \\
\hline 106- & $\begin{array}{r}\$ 906,17 \text { CAT 5A } 16 \\
\$ 1.071,39 \text { CAT } 17 \text { A } 20 \\
\$ 1,210,23 \text { CAT } 21 \text { A } 24\end{array}$ & $\begin{array}{l}75 \% \text { CAT } 20 \text { REG } 30 \text { HS } \\
60 \% \text { CAT } 21 \text { REG } 30 \text { HS } \\
60 \% \text { CAT } 24 \text { REG } 30 \text { HS }\end{array}$ & BONIF REM EX-URF \\
\hline
\end{tabular}

020. BONIFICACIÓN PELIGROSIDAD 55\% DEL BASICO

ミLA GARANTIA SALARIAL SE EXCLUYE A PARTIR 1/10/07, LA BONIF,EX COMBATIENTES.180\% DE \$ 1.524,78 (CAT.5 JUDICIALES) ¿DECIR BONIFICACIÓN EX COMBABIENTES CONCEPTO $143 \$$

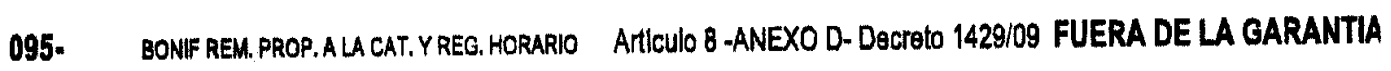

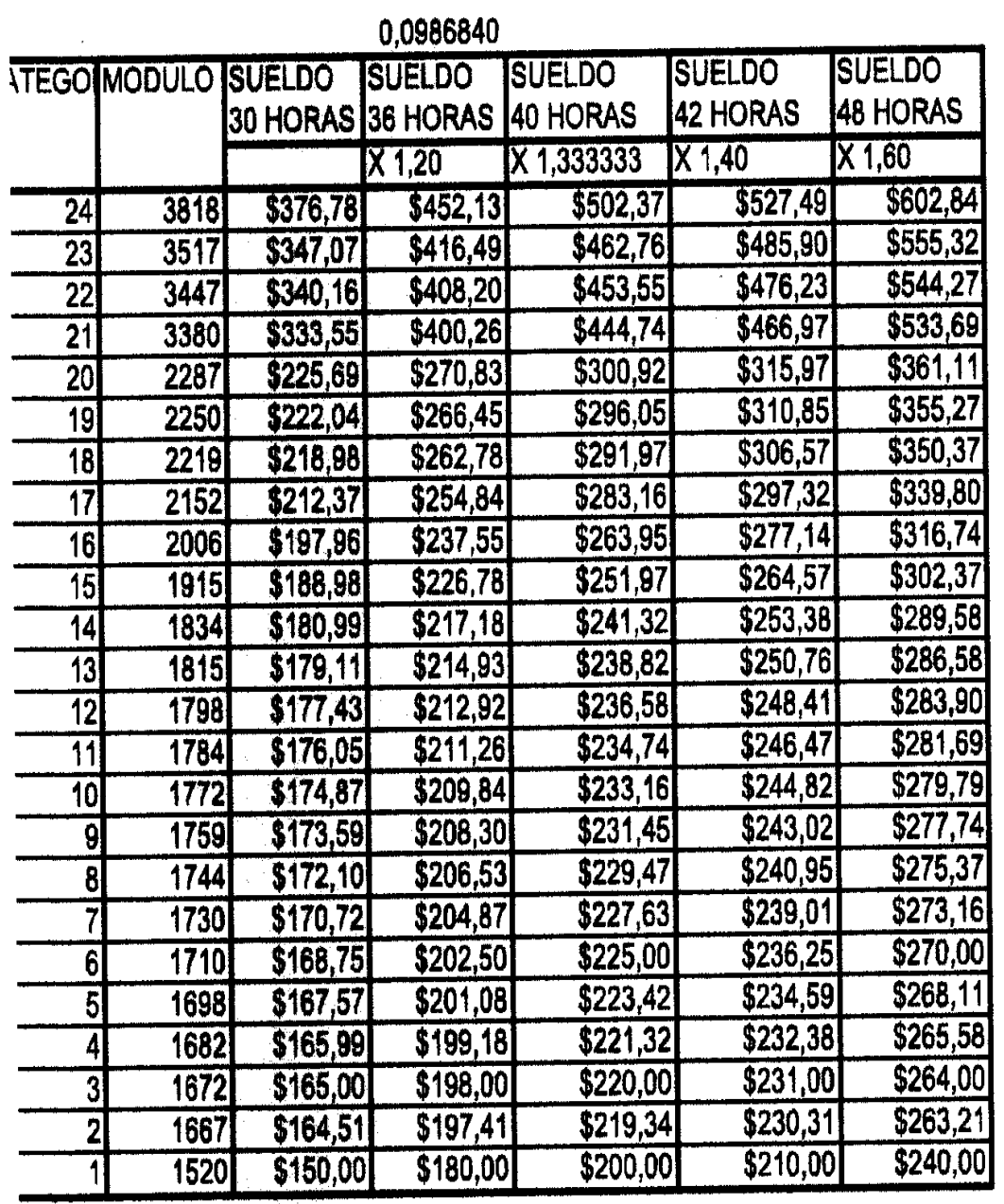




\section{ANEXO № 5}

Encuesta para información secundaria

\section{MINISTERIO DE SALUD PCIA BUENOS AIRES}

Regiones sanitarias $=12$ (esto es así?)

$\underline{\text { Región sanitaria VI }}$

Hospital Interzonal José A Estévez. Lomas de Zamora.

Nro de pacientes:

Región sanitaria VII

Hospital Interz. Especializado Neuropsiquiátrico colonia "Domingo Cabred". Open Door. Luján.

Nro de pacientes:

Región sanitaria XI

Hospital Interzonal Agudos y Crónicos “Dr. Alejandro Korn”. Melchor Romero. La Plata. Nro de Pacientes ( agudos y crónicos):

Son éstos los hospitales o hay más? :

Son polivalentes, momovalentes?:

Cuál tiene servicio de odontología?

\section{HOSPITAL A. KORN:}

Nro. de adultos con alteraciones mentales crónicos

Varones:

Mujeres:

Total:

Costo promedio de cama psiquiátrica:

Cuántos de estos pacientes pasan por año a la etapa de externación? :

\section{PROCESO DE DESINSTITUCIONALIZACIÓN:}

2 modelos de tratamiento en externación de pacientes:

- Curaduría Provincial ( calle 48, 11y 12 La plata )

Nro de pacientes:

- Programa PREA:

Hospital Estevez, nro de pacientes (en programa):

Hospital Korn: Casa de Pre- Alta (calle 569 y 10)

Nro de pacientes:

Franco Basaglia (calle 4917 y 18)

Nro de pacientes:

Pichón Rivière (calle 376 Y 7)

Nro de pacientes:

- Hospital Domingo Cabred, nro de pacientes (en programa):

- Hospital Penna, nro de pacientes (en programa):

Programa PREA:

Nro de pacientes que integran el programa:

Tiempo promedio de permanencia de los pacientes:

Nro de pacientes ingresados al programa en el período 2009/2010:

Costo promedio por paciente: 
№

Apellido.

Nombre.

Fech. Nacim. / /

Sexo.

Fech. Internac,

Diagn. Médico.
Situación.

$\begin{array}{llllllllllllllll}18 & 17 & 16 & 15 & 14 & 13 & 12 & 11 & 21 & 22 & 23 & 24 & 25 & 26 & 27 & 28\end{array}$

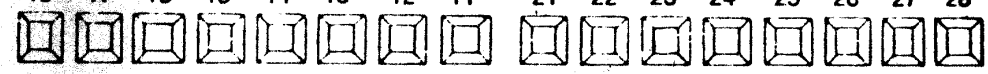

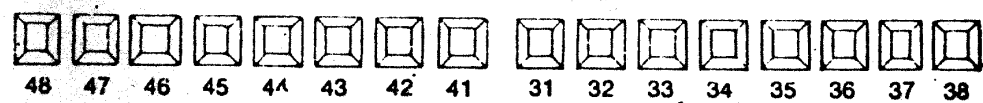
$\begin{array}{llllllllll}55 & 54 & 53 & 52 & 51 & 61 & 62 & 63 & 64 & 65\end{array}$

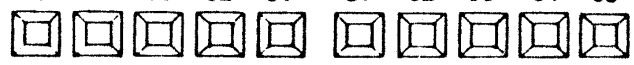
回回回回回

\begin{tabular}{|c|c|c|c|c|c|c|}
\hline C & Ei. & E & O & CPOD & TPP & TPS \\
\hline & & & & & & \\
\hline
\end{tabular}

Observaciones.

$\mathbf{N}^{\circ} 2$

Apellido......

Nombre...ess.

Fech. Nacim. $12,2,63$

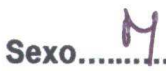

Fech. Internac,

Diagn. Médico. Esquizoftrevia

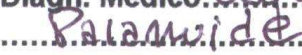

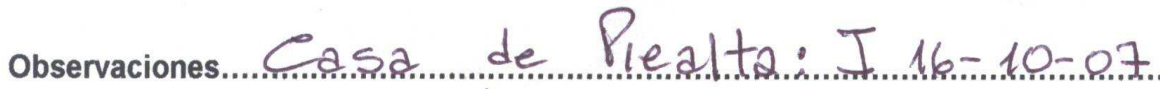

situación...coceso Desimstiluciomsliz. 18 $\begin{array}{lllllllllllllll}15 & 16 & 15 & 14 & 13 & 12 & 11 & 21 & 22 & 23 & 24 & 25 & 26 & 27 & 26\end{array}$

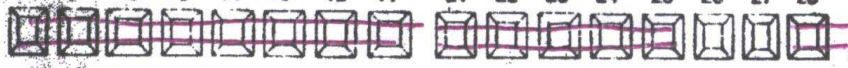

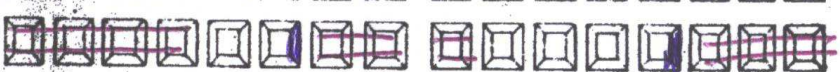

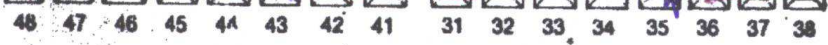

$\begin{array}{llllllllll}55 & 54 & 53 & 52 & 51 & 61 & 62 & 63 & 64 & 65\end{array}$

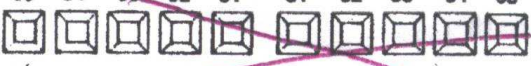

回四四回回回四四回

\begin{tabular}{|c|c|c|c|c|c|c|}
\hline C & Ei. & E & 0 & CPOD & TPP & TPS \\
\hline 2 & - & 25 & - & 27 & 7 & 5 \\
\hline
\end{tabular}

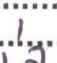

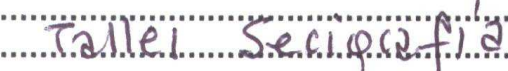




\section{ANEXO № 7}

Estudios epidemiológicos: resultados comparativos.

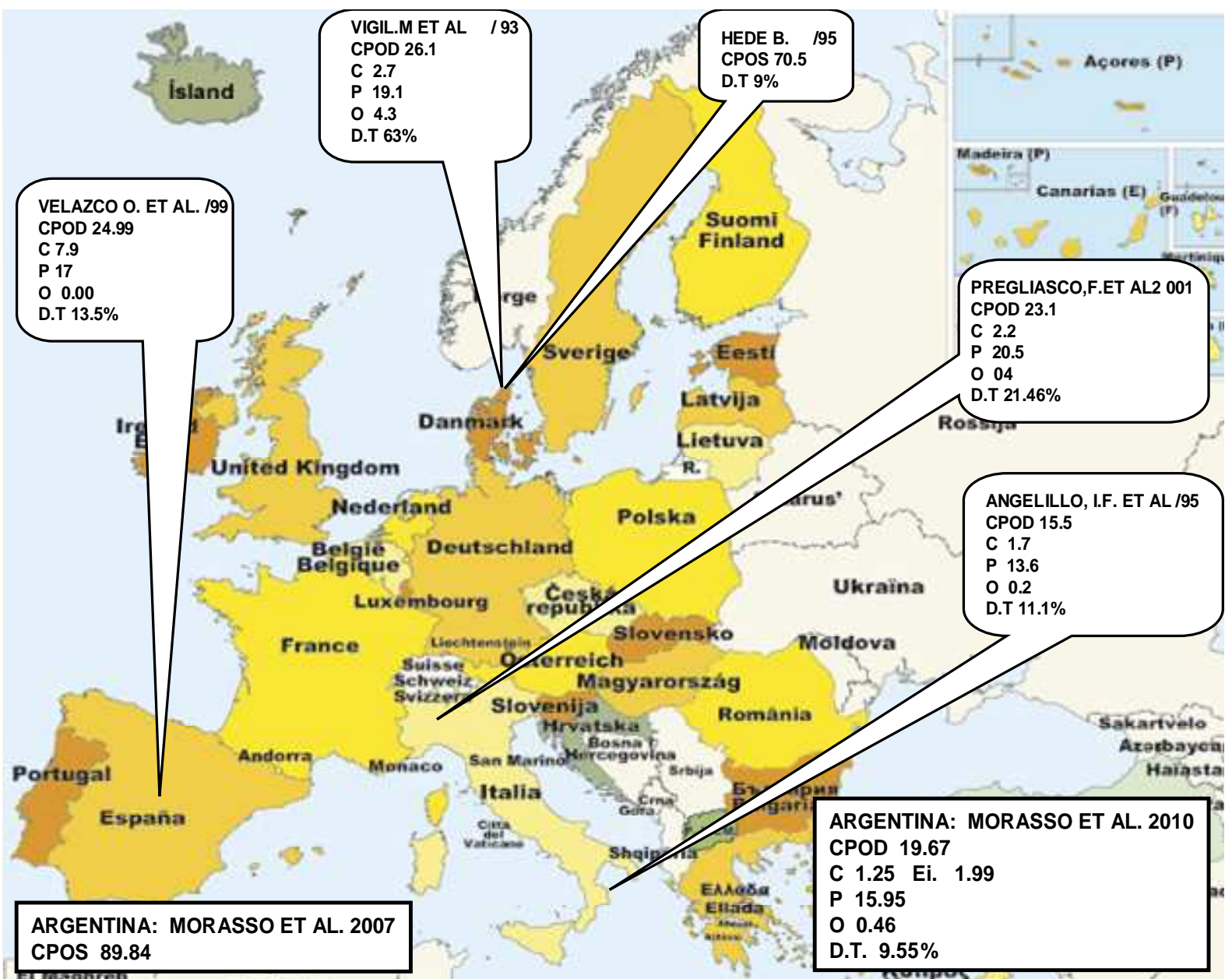

